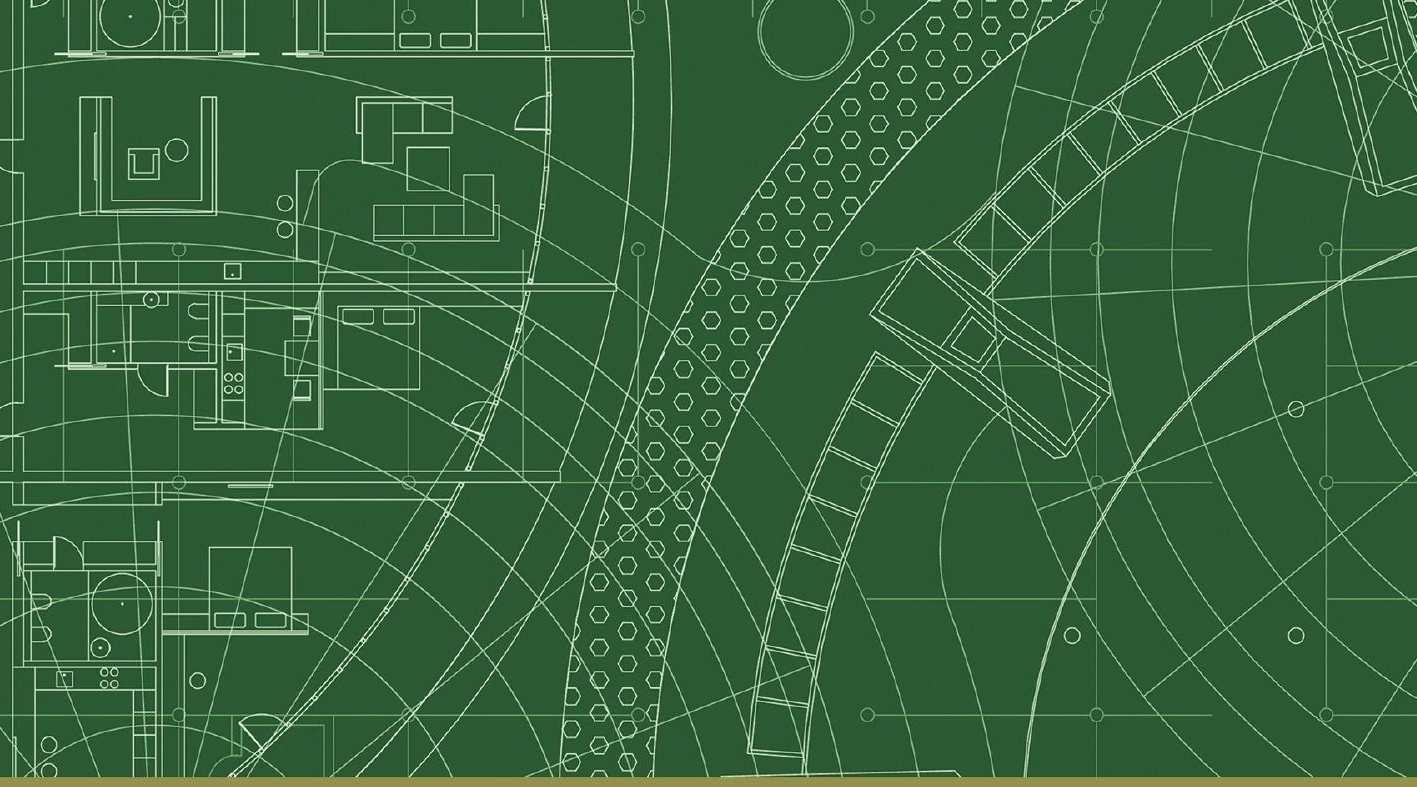

Routledge Studies in Education, Neoliberalism, and Marxism

\title{
ARTIFICIAL INTELLIGENCE IN THE CAPITALIST UNIVERSITY
}

\section{ACADEMIC LABOUR, COMMODIFICATION, AND VALUE}

John Preston

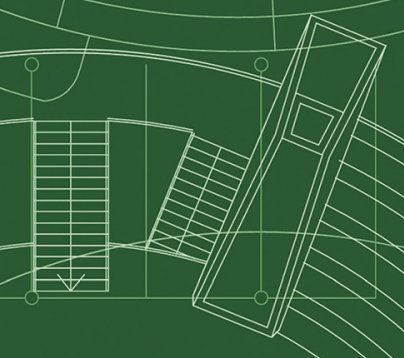




\section{Artificial Intelligence in the Capitalist University}

Using Marxist critique, this book explores manifestations of Artificial Intelligence (AI) in Higher Education and demonstrates how it contributes to the functioning and existence of the capitalist university.

Challenging the idea that $\mathrm{AI}$ is a break from previous capitalist technologies, the book offers nuanced examination of the impacts of AI on the control and regulation of academic work and labour, on digital learning and remote teaching, and on the value of learning and knowledge. Applying a Marxist perspective, Preston argues that commodity fetishism, surveillance, and increasing productivity ushered in by the growth of AI, further alienates and exploits academic labour and commodifies learning and research. The text puts forward a solid theoretical framework and methodology for thinking about AI to inform critical and revolutionary pedagogies.

Offering an impactful and timely analysis, this book provides a critical engagement and application of key Marxist concepts in the study of AI's role in Higher Education. It will be of interest to those working or researching in Higher Education.

John Preston is Professor of Sociology in the Department of Sociology, Faculty of Social Sciences, University of Essex, UK. 


\section{Routledge Studies in Education, Neoliberalism, and Marxism \\ Series editor Dave Hill, Anglia Ruskin University, Chelmsford and Cambridge, England}

19 Crisis, Austerity, and New Frameworks for Teaching and Learning A Pedagogy of Hope for Contemporary Greek Education By Maria Chalari

20 The Impacts of Neoliberalism on US Community Colleges Reclaiming Faculty Voice in Academic Governance By Greg Sethares

21 The Educational Philosophy of Luis Emilio Recabarren: Pioneering Working Class Education in Latin America By María Alicia Rueda

22 Critical Reflections on the Language of Neoliberalism in Education Dangerous Words and Discourses of Possibility Edited by Spyros Themelis

23 The Impacts of Neoliberal Discourse and Language in Education: Critical Perspectives on a Rhetoric of Equality, Well-Being, and Justice Edited by Mitja Sardoč

24 The Emergence of Postfeminist Identities in Higher Education Neoliberal Dynamics and the Performance of Gendered Subjectivities Eleftheria Atta

25 Social Haunting, Education, and the Working Class A Critical Marxist Ethnography in a Former Mining Community Kat Simpson

26 Artificial Intelligence in the Capitalist University Academic Labour, Commodification, and Value John Preston

For more information about this series, please visit: https://www. routledge.com/Routledge-Studies-in-Education-Neoliberalism-andMarxism/book-series/RSEN 


\title{
Artificial Intelligence in the Capitalist University \\ Academic Labour, \\ Commodification, and Value
}

\author{
John Preston
}


First published 2022

by Routledge

605 Third Avenue, New York, NY 10158

and by Routledge

2 Park Square, Milton Park, Abingdon, Oxon, OX14 4RN

Routledge is an imprint of the Taylor \& Francis Group, an informa business

(C) 2022 John Preston

The right of John Preston to be identified as author of this work has been asserted by him in accordance with sections 77 and 78 of the Copyright, Designs and Patents Act 1988.

The Open Access version of this book, available at www.taylorfrancis.com, has been made available under a Creative Commons Attribution-Non Commercial-No Derivatives 4.0 license.

An electronic version of this book is freely available, thanks to the support of libraries working with Knowledge Unlatched (KU). $\mathrm{KU}$ is a collaborative initiative designed to make high quality books Open Access for the public good. The Open Access ISBN for this book is 9781003081654 . More information about the initiative and links to the Open Access version can be found at www.knowledgeunlatched.org.

Trademark notice: Product or corporate names may be trademarks or registered trademarks, and are used only for identification and explanation without intent to infringe.

Library of Congress Cataloging-in-Publication Data

Names: Preston, John, 1967- author.

Title: Artificial intelligence in the capitalist university : academic labour, commodification, and value / John Preston.

Description: New York, NY : Routledge, 2022. I Series: Routledge studies in education, neoliberalism, and marxism I Includes bibliographical references and index.

Identifiers: LCCN 2021022507 (print) I LCCN 2021022508 (ebook) | ISBN 9780367533779 (hardback) I ISBN 9781032123622 (paperback) I ISBN 9781003081654 (ebook)

Subjects: LCSH: Artificial intelligence-Educational applications. I Artificial intelligence-Economic aspects. I Education, HigherEffect of technological innovations on I Education, HigherEconomic aspects. I Capitalism and education. I Marxist criticism.

Classification: LCC LB1028.43 .P74 2022 (print) I LCC LB1028.43 (ebook) I DDC 378.1/7344678-dc23

LC record available at https://lccn.loc.gov/2021022507

LC ebook record available at https://lccn.loc.gov/2021022508

ISBN: 978-0-367-53377-9 (hbk)

ISBN: 978-1-032-12362-2 (pbk)

ISBN: 978-1-003-08165-4 (ebk)

DOI: $10.4324 / 9781003081654$

Typeset in Sabon

by KnowledgeWorks Global Ltd. 


\section{Contents}

Acknowledgements vi

1 Introduction 1

2 Capitalist Universities, AI, and Value 14

3 AI and the Subsumption of Academic Labour 44

4 The Pixarfication of Higher Education 80

5 Disaster Capitalism and Time in the Virtual University 104

6 AI, Existential Threat, and the Capitalist University 125

$7 \mathrm{AI}$ and the End of the Capitalist University 144

$\begin{array}{ll}\text { Index } & 169\end{array}$ 


\section{Acknowledgements}

I would like to acknowledge the support of the Engineering and Physical Sciences Research Council (EPSRC) who funded this work (Grant number: EP/R021031/1). The 'Chatty Factories' project from which this work arose enabled me to create the conceptual framework for the book in terms of its emphasis on 'value critique' (Chapter 2), to consider how concepts from digital manufacturing were applied in the service sector and Higher Education (HE) (Chapter 3), to develop ideas of how sentient commodities arise (Pixarfication, Chapter 4), to analyse how AI is changing production times (Chapter 5), and new ways of theorising the relationship between humans, machines, and capitalism (Chapters 6 and 7). Although the emphasis of the funding was on digital manufacturing, this book considers the implications of digital manufacturing and AI for a particular service sector: HE, but it produces concepts that are useful for thinking about all sorts of capitalist work, commodification, time, and existential threat. I would like to thank all members of the Chatty Factories project. It was a fantastic project to work on with excellent colleagues. The ideas and concepts used in this book, as well as errors, are my own. Rhiannon Firth worked with me at the University of Essex on 'Chatty Factories' and we have other forthcoming publications from the project which enabled us to explore ideas of value, work, and utopias. It was great, as always, to work with Rhiannon.

In terms of the intellectual journey of this project, I would like to thank, in particular, various Marxist colleagues who have influenced my thinking over the years until it has arrived at this point, particularly Dave Hill for having confidence in this book, Mike Cole, Alpesh Maisuria, Glenn Rikowski, Tony Green, Peter McLaren, and James Avis. I would also like to thank fellow colleagues and friends including Kalwant Bhopal, Charlotte Chadderton, and Andrew Ravenscroft for their intellectual support. In the last ten years I have worked at four universities for various reasons from precarity to necessity (Institute of Education, University of East London, Bath Spa University, and now 
the University of Essex). Thanks to my colleagues at the Department of Sociology, University of Essex, who are great people and who continue to produce work in the spirit of the radical tradition from which the University was born.

Final thanks to Liz for her ideas, laughter, love, and support. Love always to my children Isobel and Nina. 


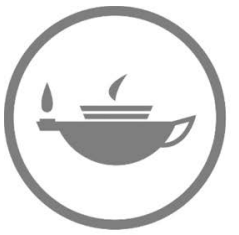

Taylor \& Francis Taylor \& Francis Group http://taylorandfrancis.com 


\section{Introduction}

\section{What Is AI?}

Artificial Intelligence (AI) is one of the most nebulous technologies in contemporary capitalism. It has come to stand for a wide variety of machines, automations, simulations, and speculations. Intelligent assistants such as Alexa and Cortana, Machine Learning (ML), cyborgs, robots, expert systems, downloaded minds, automata, self-driving cars, pattern recognition, transhumanists, post-humanists, semantic nets, neural nets, natural language processing, godlike consciousnesses, and future automated existential threats are all parts of what might be called AI. In many ways there is nothing new about AI. Humans have always imagined enchanted objects and mechanical devices that might approximate some form of consciousness. Cave, Dihal and Dillon (2020) span human history in bringing together fictional and non-fictional accounts, of 'AI Narratives'. Several chapters in their collected volume identify pre-capitalist accounts of AI from Greek philosophy and the Middle Ages. Although these are not AI as we might understand it, these conceptions of intelligent, reasoning, or conscious 'things' are already embedded in a historical mode of production (slavery or feudalism). In contrast, contemporary AI is largely a capitalist technology and (as I argue in Chapter 6) we often look at advanced AI not as a slave or a serf but as an owned machine (as part of capital) and speculatively as a future conscious, or even 'labouring', entity.

The contemporary history of AI (Woolbridge, 2020) makes clear that it is an over-burdened and contested concept. From the work of Turing until the development of semantic AI in what Woolbridge (2020, p.47) refers to the 'Golden Age' (from 1956 to 1974), there was an emphasis on 'General AI' with the prioritisation of general skills across a wide range of domains including perception, problem-solving, planning, and understanding. The perceived failures of this 'Golden Age', as these higher-order problems proved to be extremely challenging, led to a narrowing of the focus of AI ('narrow AI'). AI technologies such as expert systems (which combined AI with human reasoning to address

DOI: $10.4324 / 9781003081654-1$ 


\section{Introduction}

problems in a specific domain), behavioural AI (that focussed on AI and robot behaviour, rather than reasoning), and AI assistants (that worked alongside humans to solve problems) were more successful but still not a step towards more general AI, AGI (Artificial General Intelligence).

Contemporary AI is often associated with ML that is based on statistical techniques, big data, and massively increased computing power to build 'neural nets' that can be taught to solve specific problems. The 'neural nets' involved are not synonymous with neurons in a human, or even a computational brain, but allow practical gains in terms of pattern recognition and strategy (particularly in terms of games such as Chess, Go, or video games). 'Narrow AI' and ML are particularly important in terms of military, business, and government (especially policing) applications. Woolbridge $(2020, \mathrm{p} .210)$ explains that there is now a schism between ML and AI so wide that some researchers in ML do not consider themselves to be AI researchers at all. Although AI was never a 'pure' discipline, the move from AGI to narrow, specific, applications resonate with commercial imperatives in terms of increasing business profitability, imperialist prowess, and state control and repression. This tendency reflects the development and appropriation of science and technology for capitalism.

From the outset, it is important that we understand the multiplicity of AI technologies, and that AI is not synonymous with an electronic 'mind' or 'brain', although conceptions of these are also a part of capitalist expression and understanding of AI. Dyer-Whiteford, Kjøsen and Steinhoff (2019) argue that '...it is only through some familiarity with the science of technology of AI that an effective critique can be mounted' (Dyer-Whiteford et al, 2019, p.9), but it is increasingly difficult to identify a consistent AI scientific project. AI is obviously distinct from forms of mechanisation or computation but might include many different techniques and approaches. Following AI theory more generally, Dyer-Whiteford et al (2019, p.10) distinguish between (narrow) AI, AGI, and Artificial Super Intelligence (ASI). Narrow AI would be able to undertake well-defined, bounded tasks and demonstrate intelligence in a constrained domain, AGI would be able to undertake a broad range of generalisable tasks across broad domains, and ASI would surpass human intelligence across many areas. There have been a number of fictional representations of ASI such as HAL 9000 (2001), Skynet (The Terminator), The Matrix, and San Junipero (Black Mirror). The ASI existential threat has been a persistent one in fiction whether it is from a psychotic ASI in space, one purposively starting a nuclear war, or an AI creating a simulated universe for human pain or pleasure. These threats seem far from our current experience of an automated utopia. We don't look like cyborgs, even though our hands are glued to tiny cellphone screens at work or home. We are not going into cyberspace, even though we will spend most of our day on the internet. At home we do talk to an 
AI to find out the weather tomorrow, but nothing substantively changes. Things are always moving and shifting as technology constantly changes, but the repetition of work and consumption continues.

The impact of AI on our lives, and what AI 'is' are, of course, subjects of AI ethics (Coeckelbergh, 2020). Although AI ethics concerns itself with social impacts, redistribution, transhumanism and post-humanism, environmentalism, racism, gender, and discrimination, it often does so within frameworks where there is no alternative to capitalism. AI can only be understood as capitalist AI. In the workplace, particularly in the factory, AI is just another form of technology which eliminates workers and skills whilst not necessarily creating new jobs or alternative forms of vocation. It is often acting to privatise existing skills into expert systems. As we live in a capitalist society, it is impossible to even think about AI outside of capitalism. We conceive of the ultimate AI (ASI) as a cunning, learning superintelligence. As with human labour before it, the first task of capitalism appears to be primitive accumulation to attempt to contain AI and turn it into a commodity which can be sold. Our views of AI are shaped by this capitalist schema. This schema is not some idealist thought about AI that can be debated through counterargument but a real, material, circumstance of our lives. Again, there is little that is new about this. As labourers, we have always had to adopt prosthetics at work. We wear glasses and hearing aids. Our ability to work is gauged in terms of whether a prosthetic might help us to do so. At work we wear uniforms, suits, welding masks, exoskeletons, and carry phones. Our brains have developed neurochemical pathways that are triggered by the thought of money. We have a symbiotic relationship with knowledge and the cyber-physical. We are not becoming 'cyborgian', capitalism brought us into that tightening relationship with machinery since day one.

There have been recent attempts to consider AI within Marxist theories. Significantly, Dyer-Whiteford et al $(2019$, p.15) refer to the centrality of AI as machinery in Marx's work, in terms of a supplement to human labour and as fixed capital as compared to the variable capital of labour. Whilst it is human labour that creates value, machines are ultimately only a '...supplement or force-amplifier' (p.16) transferring their own value to the product. Their 'social function' is to reduce Socially Necessary Labour Time (SNLT) to produce '... .relative surplus value' (p.16) but this leads to greater competition between capitals and an increase in the 'organic composition' of capital (p.17). Machinery confronts and absorbs the worker, bending the task to its requirements and drawing in labour. Dyer-Whiteford et al (2019, p.17) interpret the impact of machinery on crisis as being both through the imbalance between machine driven production, falling wages, and the falling rate of profit (p.17). Dyer-Whiteford et al $(2019$, p.19) also considers that capital will mobilise the 'general intellect' relegating human labour to the supervisory process but also 'undermining value' and 'abolishing 


\section{Introduction}

work', thereby foreshadowing capitalist collapse. This is part of formal and real subsumption under capitalism in terms of the changing of labour's social form (under formal subsumption) to where the '...content of labour changes' (p.20), moving from the extension of the working day and an increase in absolute surplus value to the production of relative surplus value. The dawning of AI-Capital brings about a further stage of 'hyper-subsumption' (p.21) where 'capital's autonomizing force manifests as AI' (p.21). This is not a process that continues indefinitely. Increases in relative surplus value over time results in a lowering of the total surplus value (and hence profit), unless there is constantly expanding accumulation. AI represents a way out for capitalism as it will try '...with all force to maintain the value of value' (Kurz, 2014, p.54). However, to consider that machines can produce value is part of what Kurz (2014, p.41) calls an 'immortalization of value' a 'failure to escape the value fetish'. AI is best seen, then, as the continuation of capitalism in decline rather than prefigurative of a new and expansive mode, and this perspective sets the tone for this book.

\section{$\mathrm{AI}$ and Bias}

As it is concerned with capitalism, this book takes an unusual angle in not being overly concerned with tracking the impact of specific aspects of AI on equity or social justice. Obviously, within capitalism, AI inevitably reproduces and produces massive inequalities, but it does not particularly matter to the argument presented here whether AI can, or should, be reformed to produce equitable outcomes, if $\mathrm{AI}$ is fair, or whether it is even accurate. By its nature capitalist work (whether it uses AI or not) results in inequalities between capitalists and labourers (and between groups of workers) and exploits and immiserates labour. This book is not primarily based on the moral case for addressing such inequalities as notions of injustice are primary to capitalism and obscured by principles such as 'fair exchange' (of course this does not prevent the use of moral language to describe the brutality, horror, and misery of capitalism). This is distinct from the approach taken in much of the critical work on AI, which considers the impacts of ML algorithms on social justice. In this work, social justice is taken to be a judgement on the equitable functioning of already existing capitalist processes such as the criminal justice system, autonomous technologies (such as driverless cars or autonomous weapons), or the allocation of benefit payments. AI is considered to reinforce existing biases, or to create new biases, but the capitalist system is not called into question. For example, Benjamin (2019a) shows how AI exacerbates existing racial biases in society in the criminal justice system, health, and education. Although this literature on bias is useful in mounting a critique of AI in Higher Education, the response that it elicits is largely affirmative in that it recommends better or different systems of 
AI, or the abolition of AI, inside an existing order (capitalism). The question then becomes how AI can act as a tool in social-democratic societies rather than addressing how AI supports the maintenance of systems (particularly capitalism). It also leads to critiques that sometimes involve simply listing the 'bad things' about AI in a particular area. For example, the argument concerning the decolonisation of Higher Education (HE) is an active debate at present on both sides of the Atlantic. Within this discourse, there is much current work considering the ways in which AI is in some sense racist, white, or colonialist in nature supported by work on 'race' and educational technology (Benjamin, 2019a, 2019b). Although there is a political and moral imperative to consider the social justice impacts of HE, sometimes arguments based on the socially just aspects of technology are prone to commodity fetishism because this work is based on the material features of the commodity form. This could be in terms of the appearance of AI (in terms of, perhaps, whiteness or its gendered nature), the nature of the algorithm, and the principles of AI in terms of logic which are thought somehow to be connected with racism or particular Eurocentric perspectives. Even in its own terms, this literature is sometimes based on Anglo-European and American perceptions and depictions of AI rather than considering Asian, Afrocentric, or Afrofuturist perspectives on AI (Benjamin's 2019b collection is an exception to this as it does consider non-Eurocentric contributions to the bias literature). In contrast, it is possible to take a Marxist view on humanism, in terms of the human species and species being, which is not necessarily based on essentialist conceptions of human nature, instead being grounded in a theorisation of human labour in capitalism. Through primitive accumulation, a labouring subject (collectively, the working class) is brutally separated from the property needed to produce commodities, from nature and from the means to sustain life. Only through capitalist labour (selling labour power as abstract labour) can the worker survive, and this is only through an inhuman system of really existing abstractions that validate abstract labour through commodity exchange (Pitts, 2018). This is not to deny the important work that is being done on race, gender, sexuality, and disability and AI in HE but to signal from the start the approach taken in this book is not particularly concerned with the accuracy (bias) or the equity of AI.

\section{Structure of the Book}

In this book I take a broad perspective on the different manifestations of $\mathrm{AI}$ in the capitalist university. To take a comprehensive view of approaches to $\mathrm{AI}$, I consider $\mathrm{AI}$ in terms of hardware and software, ML, narrow AI, AGI, ASI, and optimisation. I examine the impact of AI on the control and regulation of academic work, its impact on digital learning, holography and remote teaching, the creation of digital commodities, its 


\section{Introduction}

status as an academic field, ethical considerations, digital platforms, and existential threats to the university. The influence of AI on the capitalist university is not just in terms of its impact on replacing and subsuming academic labour but also in terms of commodity production, circulation, exchange, and the 'abstract domination' of capital. This includes the ways in which the social universe of capital acts back on each individual capitalist university through artefacts such as fatigue functions for workers and academic league tables that are the concrete forms of a 'real abstraction' that imposes increasingly pressurised work conditions on academic labourers. AI within the capitalist university is part of the totality of capital and capitalism. Despite this, what seem to be totalising capital relations are paradoxical, incomplete, and contested and in every moment that production and exploitation advance capitalism, it finds itself challenged, and it weakens, exposing alternatives that are prefigurative within itself. The critique presented here is, therefore, a negative critique, one that does not seek to reform the capitalist university, or reimpose a new model of political economy, but considers prefigurative possibilities beyond capitalism, including whether there are possibilities for AI in communism, beyond class and the 'law of value'.

The empirical work on which the book is based emerged not from universities, but from research on the future of 'digital manufacturing' which involved examining the trajectories of AI, robotics, and advanced production through a variety of case studies. In this work, which involved 'manufacturing as a service' and digitisation the ways in which service industries were increasingly adopting the methods of 'digital manufacturing' became apparent. Digitisation, AI and ML, and optimisation are modular technologies that can be inserted into any business operation, and where differentiation between industry sectors is becoming less marked. Similar systems to those used by Uber, Amazon, and Netflix are also employed in manufacturing and universities, and models can be transferred between firms and industries. The university is increasingly concerned with commodity production in which digitisation and AI shape the form of the commodity produced and influence all aspects of activity (production, academic work, and time). Whatever was special about the university when compared to any industry or commercial sector is becoming a trace memory, erased by capitalisation, and dissolved by digitisation.

In Chapter 2, I argue that all global universities are capitalist universities. Whether the economic system is classified as a market, state, or hybrid form, the social relations and social forms in which universities exist are capitalist ones. Even those universities (which are often not formally recognised in national institutional systems) that are explicitly anti-capitalist are subject to the 'vortex' of the law of value (Neary and Winn, 2017). The capitalist nature and status of universities means that their attempts to visualise a more humanising, or even a more technical, vision of education, are consistently subject to the reduction of 
all entities and expressions to economic valuation and profit. Marx's work on value, its expression as 'use value' and 'exchange value', and the social forms of its existence (particularly in the commodity and in its objective form as money), provides the foundation for a consideration of the New Reading of Marx (Pitts, 2018) and value critique in the analysis of AI and HE. The New Reading of Marx (NRM) takes a historical perspective on work, labour (particularly abstract labour), and regards capitalism as (necessarily) a class system that imposes a mode of 'abstract domination', creating capitalist society that is purely concerned with commodity production and the accumulation of money (the objective form of value). Labour, as a specific historical form (our labour power, abstract labour, being a form that only exists in capitalism), is only socially validated (valued in capitalist society) if it is producing value in a purely quantitative determination (which is realised by the capitalist as profit or surplus). Although it may appear that this abstraction is brought into being when the product of labour is validated in exchange (when a commodity is sold for money), it is also posited in the advancement of capital in production, waged labour, and the production of value only under strict conditions (at, or below, the SNLT, for a commodity that is sold in the market at the average level of skill). This is not only the manifestation of a class relation (between capital and labour, involving class struggle and class war) but is also a form of social domination unique to capitalism. Abstract labour, as part of capital, is tragically the basis on which capital itself is accumulated. Through investment in technology and organisational processes (both of which include AI), this process destroys workers' jobs, increases the intensity and subsumption of work (control and domination by capital), and (as the level of technology, capital, and organisation increases) makes it increasingly difficult to produce value itself. This is a key perspective of 'value critique' (Kurz, 2012,2014 ) which considers the existence of value in all capitalist forms, including the 'state form'. We can't see the 'social forms' of capitalism but project these onto real objects, including AI. AI in the capitalist university is the material form then, of what is really a 'social form' in capitalism. Its growth and expansion across all domains of academic life is the material appearance of a process of value production and accumulation. These perspectives - NRM, value critique, negative critique, and class war and struggle - frame the arguments of the whole book. AI can be seen not only in terms of increasing productivity in the university, displacing and subsuming labour, but also within the valorisation process (the 'social validation' of a commodity), extending the 'mind' of the capitalist as AI, validating the idea that commodities should be produced in a bounded time, and presenting itself as an object for future primitive accumulation after human destruction. This theoretical chapter sets the scene for subsequent chapters which examine aspects of AI in the capitalist university in terms of its relationship to abstract labour and labour 


\section{Introduction}

power (Chapter 3), the commodity (Chapter 4), disaster capitalism and capitalist time (Chapter 5), the end of capitalism, existential threat and ethics in the capitalist university (Chapter 6), and prefigurative alternatives, pedagogy, and communism (Chapter 7). These aspects should not be seen to be separate elements of AI and capitalism but part of a unified 'social domination' by capital of humanity and nature in HE. They should also not be seen to be teleological. Each of these relationships is resisted, contested, contingent, and fragile at every point.

The emphasis on value in this book is because Marx's formulation of value, his rejection of it as an objective economic category, and later elaborations of value through value critique are so ontologically distinctive from all other social theories of capitalism as to allow for (along with Marx's associated critiques of class, wage labour, exploitation, subsumption, and immiseration) the pursuit of a negative critique of capitalism, and hence the capitalist university, as distinctive from all other preceding social formations. In terms of AI, it enables us to demystify $\mathrm{AI}$ and the existential threat of AI as part of the continuity and metaphysical reality of capitalism rather than a break or an exception. It is not that 'if we don't' do something capitalism will result in the end of humanity (through AI), that is capitalism. This is not a teleology that ascends to particular social realities or empirical predictions. Skills and jobs might go (and others will be created), but we cannot (even for a moment) suggest which ones. Human labour power as the substance of value (and hence capitalism) may come to an end (desubstantialise itself), but we cannot predict when or how. Indeed, the agony may continue indefinitely and infinitely through mechanisms such as AI that allow production of commodities in virtual realms.

Chapter 3 examines the meaning of 'academic labour' and how this is being affected by AI in the capitalist university. Any discussion of labour must include acknowledgement of its specific form in capitalism, as abstract (and concrete) labour, as well as its location in commodity production in capitalism. With reference to the commodity, HE produces commodities under the same material conditions as any other capital, whether state or privately owned. It is this final commodity (exchanged for money) that represents the ultimate destination of commodity production in the university rather than 'commodity stock' (such as individual lectures or academic papers). An understanding of academic labour is underpinned by class struggle, and I use autonomist perspectives on labour power to make clear the necessity of a class perspective. Processes of quantification and optimisation, accelerated by AI, make academic labour commensurable and measurable. League tables and other means of global comparison, alienate academics from their peers and normalise a global social standard for commodity production. AI tools allow capitalist universities to discover how to maximise their relative position, and these technologies have enabled processes of 
commodification, capitalisation, and marketisation. Automation is an inherent component of capitalist production (Sohn-Rethel, 1978) but despite this, even AI cannot ultimately prevent the stagnation of value and profit as technology and standards of productivity become universal. Capitalist universities constantly need to accelerate technologies and productivity, and further exhaust 'human resources' just to stand still in global league tables. This is the 'treadmill effect' of capitalism and the perceived speeding up of life and activity in capitalist time described by Postone (2003). AI is similar to other forms of tool, machine, technology, or organisational structure in capitalism. It is unexceptional as a machine that has the net effect of returning capitalism back to where it started in terms of the production of value, but at a higher level of production intensity under ever stricter boundaries of a globally set SNLT. Like other machines, $\mathrm{AI}$ is parasitical of labour and labour time, turning living into dead labour (including more machines and AI) and is part of a greater process through the capitalist control and monitoring of work. AI also has some distinctive features in the capitalist university, including the seeming extension of the capitalist 'mind' into the work environment, and its function as a 'social synthesis' in bringing together (alongside league tables and performance indicators) measures of global academic productivity. AI is part of the formal (the establishment of capitalist social relations in universities) and real subsumption (the melding of academic labour into value production and its confrontation by its own products in terms of commodities and science) of academic labour. AI also opens up universities to marketisation and financialisation (hybrid subsumption), and to imagine future possibilities for capitalisation (ideal subsumption) (Szadkowski, 2016). Dyer-Whiteford et al (2019) contend that AI is part of a process of 'hyper-subsumption' where AI becomes part of the 'means of cognition', but I argue this process best depicts a new round of 'primitive accumulation' whereby AI might become a new labouring subject. In these processes of subsumption, capitalist universities are increasingly borrowing techniques from the use of AI in other industries, particularly digital manufacturing, where 'platform manufacturing' and AI techniques that 'scrape skills' from workers are used. In the capitalist university, academic labour increasingly serves mechanic processes, optimised by AI, on various data 'platforms' which make various forms of academic labour commensurable, shaping and socially validating the commodity which is exchanged for its objective form (money) as universities become 'data universities' (UCU, 2020). In relation to collective labour, the chapter also considers Marx's 'transhumanism' in terms of how money, as the objectified form of value in capitalism, comes to stand for all human essences and capabilities, and how capital gains possession of science and the collective powers of labour with particular attention to the role of AI and technology in this process (Hall, 2018). I further discuss conceptions of the 'social brain' 


\section{Introduction}

and the 'general intellect' arguing that ideas of 'immaterial labour', and the formation of a 'general intellect' within capitalism (rather than opposed to it) are utopian and idealistic. AI is an instrument of class war from above, in terms of an attempt to privatise the general and social in production, including academic labour. This is not just a technological, but also a pedagogical, adaptation of capital, whereby workers learn to labour in ways that are 'machine readable' to AI. Despite these pessimistic tendencies, I conclude by stating that capitalism is never totalising and in every moment of production, and in the recognition of the social powers of labour, academic labour invariably and repeatedly fails to act in step with capital.

Chapter 4 considers commodities in Higher Education, and how they are driven by AI and datafication, in terms of what I refer to as 'Pixarfication'. Commodities in HE are part of the general class of commodities in capitalism and, in a particular manifestation of commodity fetishism (enabled by AI), I analyse how commodities are increasingly recognised as having personalities and sentience. I describe this as a process of Pixarfication involving both production and consumption, following paradigms of McDonaldisation and Disneyization. Pixar is a company that produces animations in which consumer products (such as toys, cars, and planes) are ascribed a form of sentience and animism. Using the idea of 'real abstraction' I argue that Pixar's films, in particular the Toy Story franchise, present a literal depiction of the commodity in capitalism. Some commodities in capitalism are becoming 'enlivened' by AI, particularly digital assistants such as Alexa and mobile telephones, but Pixarfication can also be applied to services including those supplied by universities particularly as these are shaped into tangible commodities through processes of datafication. In political economy (both classical and heterodox) there is often confusion and misattribution concerning the nature of the HE commodity. Lectures, students, and degrees are referred to as 'commodified' when in reality these are examples of what might be called 'commodity stock'. The nature of a commodity, and its relation to abstract labour, has to be brutally shaped by capital (primitive accumulation) and in the final stage of exchange is traded for money. The Research Excellence Framework (REF) in the United Kingdom, through which research outputs and other research products are commodified, is used as an example of the process through which the boundaries of commodity stock are formed. In this process academic labour is made commensurable and becomes labour in general (with both abstract and concrete elements). Even the individual products of research are not commodities (they are commodity stock) which are shaped into a collective commodity (the University REF submission, a stream of data representing the products of labour) that is exchanged for money from the UK Government. In this process, Pixarfication involves creating a persona for the commodity through animation (boundary 
formation around the commodity), characterisation (the fetishisation of the commodity and the creation of its 'personality'), and production (the use of the 'Pixified' commodity to drive labour processes). AI and datafication are tools through which the capitalist university enables these processes and literally make the commodity real, and a seeming driver of what (in actuality) is the drive for value production and profit. Pixarfication appears to be 'sentient, super-sensuous, autopoietic commodity production', not an ideological construction, but the reality of production in the capitalist university, to produce commodities (materialised but social in form) that appear to be sentient (through Pixarfication and enabled by AI) that are seemingly autopoietic (masking the reality of capitalist production). This commodity is a 'thing' of labour. As such it is a further perversion of labour, in that the labour power of academic workers is ultimately used to make commodities that (seemingly) have cognition of their own production, and which command more labour of increased intensity to be used in the production process. It is also a point of fragility as value becomes less substantial as production accelerates.

Chapter 5 theorises how time is constructed in capitalism with relation to a recent crisis (the 2020 wave of the COVID-19 pandemic), and how this has led to the use of technological means for distance teaching and learning, mediated and accelerated by AI. Postone's (2003) conceptions of concrete, abstract, and historical time are used to examine different time orders. The specificity of abstract (empty) time in capitalism shapes concrete time (time mediated by external events, such as sunrise) and empties historical time (the time of historical events). The COVID-19 pandemic, mediated using AI and digital platforms, increased the density of events and labour in abstract time, shaping the experience of time by academics and continuing the mundanity of capitalist history (rather than representing any kind of break). Ontologically, dead labour, including the portion of the labourer's life already spent (including academic workers) and the labour of generations of workers before them (including previous academic workers) act, when transformed into capital, as a form of social domination. Given AI and digital tools the recording of lectures can extend the 'life' of the academic labourer (as the commodified, recorded, product of their labour) indefinitely and in new, AI mediated, combinations to produce new forms of subsumption. Through a discussion of disaster capitalism, the idea of ontological breaks and the 'new normal' is critiqued as capitalism continues (in its own sense of historical time, there is no alternative), even as each moment becomes increasingly anguished as the time-density of work increases.

Chapter 6 examines key writers on AI and existential threat as the basis for a commentary on the ethics of AI research in the capitalist university focussing on two 'Nicks' (Bostrom and Land). The first (Nick Bostrom) is known for his work on the existential threat of AI, the difficulties of containing such threats, and the need to work on ingenious 


\section{Introduction}

solutions in the present to prevent an 'intelligence explosion'. Bostrom situates his philosophy in conventional domains of utilitarianism whereas Nick Land, a 'neo-reactionary' philosopher, adopts an accelerationist approach where an AI takeover is an existential treat, rather than a threat. Although both philosophers are bold, edgy, and (it is argued in the case of Land) dangerous thinkers, I discuss the conventional nature of the categories they use in terms of political economy. For Bostrom, AI is treated almost as a metaphorical (and mystified) chaotic form of capital with inevitable profusion and accumulation which must (although he does not use this term) be primitively accumulated to become wage labour. For Land, AI is a monad, as self-reproducing capital, which is an impossibility given the relational and antagonistic nature of capitalism. Land takes a classical political economy understanding of capital as a 'fixed asset' and as a 'source of value'. In relation to the ethics of AI in the capitalist university, I argue that there is, similarly, little comprehension of the specifically capitalist nature of AI, and its development. The ultimate ethic is the enabling of the 'law of value', but the existential threat of capitalism is the most horrific of all.

In the concluding chapter (Chapter 7), I look at planned and prefigurative alternatives to capitalism, and the role of 'revolutionary pedagogy' and co-operative universities, for a future communist society with particular attention to the significance (or not) of AI. One current populist and programmatic strategy, Fully Automated Luxury Communism (FALC) (Bastani, 2019) ascribes a major role to AI in producing a world where, due to advanced technology, work is no longer necessary (and the working class will 'live' in luxury). Although there are tendencies in Marx that suggest that technology and the 'general intellect' are necessary features in the transition to communism, I argue that FALC is utopian and misguided. FALC does not address questions of sufficient levels of technology, the necessity of abolition of capitalist categories (including money), and neglects the centrality of value and accumulation (rather than materiality) being the principle of wealth in capitalism. The FALCu (FALC university) is equally unlikely to enable anti-capitalist outcomes. I also address the idea that post-humanist, pedagogical, variants of Marxism that (perhaps in a post-human university) might provide some kind of hybrid forms (that could involve AI) that could allow us to transcend or abolish capitalism. As with FALC, humanity has been 'post-human' since the origins of capitalism, and there is a distinction between form and social form that is not addressed. Rather than these affirmative alternatives, I argue that a negative critique of capitalism is necessary. This is not just a pedagogical project (and there are good reasons for suggesting that critical pedagogy is far from revolutionary), but a project of building alternatives and experiments that are against capitalism and prefigurative of communism. In these projects, the position of $\mathrm{AI}$ is at best ambiguous (and the Humanist-Marxist tradition 
of Revolutionary Critical Pedagogy would suggest that there are good reasons for suspecting that unmediated praxis, face-to-face, is necessary), but they must involve a concretisation of forms that both reject capitalism (negative critique) and are based on communist social principles (such as co-operative universities). In the capitalist university our (abstract) labour is ironically the phony source of 'artificial intelligence' (abstract domination) and we are, ironically, the existential threat to capitalism (it is certainly the existential threat to us). As capitalism cracks and decays, these alternatives are most likely found in rejection of the capitalist university and embracing concrete possibilities in the present.

\section{References}

Bastani, A. (2019). Fully Automated Luxury Communism: A Manifesto. London: Verso.

Benjamin, R. (2019a). Race after Technology. Bristol: Polity.

Benjamin, R. (2019b) (Ed.). Captivating Technology: Race, Carceral Technoscience and Liberatory Imagination in Everyday Life. Durham, MA: Duke University Press.

Cave, S. Dihal, K. and Dillon, S. (2020). AI Narratives: A History of Imaginative Thinking about Intelligent Machines. Oxford: Oxford University Press.

Coeckelbergh, M. (2020). AI Ethics. Durham, MA: MIT Press.

Dyer-Whiteford, N. Kjøsen, A. and Steinhoff, J. (2019). Inhuman Power: Artificial Intelligence and the Future of Capitalism. London: Pluto Press.

Hall, R. (2018). The Alienated Academic: The Struggle for Autonomy inside the University. London: Palgrave.

Kurz, R. (2012). No Revolution Anywhere: The Life and Death of Capitalism Series No. 1. London: Chronos Publications.

Kurz, R. (2014). The Crisis of Exchange Value: Science as a Productive Force, Productive Labour and Capitalist Reproduction. In: N. Larsen, M. Nilges, J. Robinson and N. Brown. (Eds.). Marxism and the Critique of Value. Chicago: MCM' publishing, pp. 17-76.

Neary, M. and Winn, J. (2017). Beyond Public and Private: A Framework for Co-Operative Higher Education. Open Library of the Humanities, 3 (2), pp. 1-36. DOI: http://doi.org/10.16995/olh.195

Pitts, F. (2018). Critiquing Capitalism Today: New Ways to Read Marx. London: Palgrave.

Postone, M. (2003). Time, Labor and Social Domination. Cambridge: Cambridge University Press.

Sohn-Rethel, A. (1978). Intellectual and Manual Labour: A Critique of Epistemology. London: MacMillan Press.

Szadkowski, K. (2016). Towards an Orthodox Marxian Reading of Subsumption(s) of Academic Labour under Capital. Workplace, 28, pp. 9-29.

UCU (University and College Union) (2020). A Review of Automation and Datafication in Higher Education. London: UCU.

Woolbridge, M. (2020). The Road to Conscious Machines: The Story of AI. London: Penguin Books. 


\section{Capitalist Universities, AI, and Value}

\section{Introduction: The Capitalist University}

The depiction of the university in this book is the capitalist university. The capitalist university is entirely different from pre-capitalist forms of university. The defining feature of the capitalist university is that it produces commodities that are sold (valorised) for money in a capitalist society. As an organisational form, these commodities are frequently educational whether they are direct payments by students (funded by loans or private income), state payments for services provided (for education or research, for example), or the purchase of intellectual property by a private company. When universities are private, public-private, or charitable the production of commodities and the exchange of commodities for money is reasonably transparent. Even when the university is completely owned and run by governments, the activities of these universities take place in a capitalist mode of production. In this broad sense, then, all universities are capitalist in that they conduct their activities where social forms and social relations are capitalist ones. The distinction between universities which are private and have an ideological affinity with profit and the capitalist class and those universities which are charities, or public sector organisations, and have an ideological affinity with social justice, is not a distinctive feature of being a capitalist university. The social forms of capital, labour, and forms of value, even in the state form, are identical. It is only in those universities that are defiantly anti-capitalist that the possibility of breaking with the capital relation and the value form exists. At the same time, within capitalism at every moment, in every action and in every crack and fissure there is the possibility not only of resistance but also of a world other than capitalism. Although any space, time, or body is open to primitive accumulation or commodification by capitalism, and the capitalist university, as the universe of capitalism expands it becomes inevitably weaker and more vulnerable. Hence the capitalist university is part of capitalism but is not eternal. Within every moment of our individual and collective academic labour, in our working and non-working relationships, and in our opposition to

DOI: $10.4324 / 9781003081654-2$ 
capital there is the possibility of negation. Labour, including academic labour, in the capitalist university is precarious, but universities themselves are increasingly precarious as the production and valorisation of educational commodities becomes ever more uncertain. The capitalist university is contingent and uncertain, in constant crisis (as capitalism is crisis, as will be explained) and where resistances are inevitable.

It is telling that notions of escape from capitalism, or from the nation state, are never included, in the purposes of the capitalist university. Occasionally a commitment to anti-capitalism, or even a form of communism, may be included in those universities that are co-operatives or 'free universities' but these are exceptions. University mission statements often include things such as humanistic values, the importance of education for its own sake, service learning, and even educating students to change society. Despite some universities claiming radical origins, and the socialist leanings of many academics, universities produce commodities, invest and borrow, enhance labour power to perpetuate and expand commodity production, progress science, technology, and organisational forms to increase productivity and provide the ideological basis for the capitalist class (including the exercise of bourgeoise critiques of society, environment, and economy). These productive activities are not ideologically determined but are real and material if universities want to survive in the market or to receive state subsidy. The status of academics is seen to be part of the delivery of a public good, or having a wider social purpose but in reality, academics (and other university workers) are selling their labour power to produce commodities (Hall, 2018, p.136) in what is topologically a factory. Any radical notion in the capitalist university can be recuperated in terms of instrumental goals such as increasing student numbers or maximising research income. In this respect, capitalist universities have shown themselves to be masters of recuperation. They are hubs of social innovation in terms of absorbing and transmitting radical ideas of decolonisation, feminism, queer theory socialism, and post-humanism and turning them into educational commodities, research outputs, or reputational assets. It is no paradox that capitalist universities are the predominant cultural institutions responsible for anti-capitalist thought if those ideas can be materialised and commodified. Of course, the history of universities (and the future of some) shows that they can also be comfortable with eugenics and fascist ideas, again if they can be packaged and sold. Should the potential for the valorisation of these commodities change, or if certain ideas become a threat to (real or imagined) university profitability, then they can be divested.

Artificial Intelligence (AI) is a technology, an organisational form, and an ideology that has impacted the mission of many universities. For example, many universities have invested in the growth of certain disciplines in terms of STEM (Science, Technology, Engineering, and Mathematics) and associated fields such as data science. They have adapted degrees, 
learning outcomes, student skills, research, and knowledge exchange to the needs of an AI economy. This is not motivated by any real belief in a technological system, rather AI is providing a signal (often incentivised by the state) as to the type of educational commodity that universities should produce. At the same time, they have adopted AI and data science as methods of controlling and monitoring academic workers (see Chapter 3), and their outputs as well as giving form to the educational commodities that they produce (see Chapter 4). This is not without risk for universities as AI, alongside other technologies such as remote learning and platform capitalist organisational forms, has the potential to challenge the very nature of a university education. It can disrupt its physical and current organisational forms, and as a result there have been some efforts to reclaim humanist and educational values. Aoun (2018) imagines a new disciplinary area, bumanics, to counter the existential threat from AI to jobs, human skills, and education itself. Humanics will allegedly enable students to expand their distinctly creative and cognitive abilities to work alongside AI and retain the purpose of universities as the prime developers of humanic capabilities. Humanics sounds like a discipline that could be pulled from the Science Fiction novels of Isaac Asimov. The reality is more earthy. It is simply about teaching students to embrace the new literacies that they will need to survive in the digital age (called data literacy, technological literacy, and human literacy), alongside changing mindsets and ways of thinking about the world. These are, in an analogy with AI, referred to as cognitive capacities (Aoun, 2018, p.xix). The implications of humanics are that a customised, personalised model of education is necessary with the use of virtual environments and multi-university networks (Aoun, 2018, p.135). Rather than seeing humanics as a retreat into the notion of the human, it is really a further development of labour power and the creation of new micro-education commodities to be sold through platform capitalist networks. The moral purpose of humanics, as a humanist discipline, is paradoxically antihumanist in providing more resource to an alien force (capital).

There is no certain direction of travel in terms of AI. Universities might move towards or against $\mathrm{AI}$ in their missions and incorporate new notions of the 'human' in doing so. This might increase their profits (or surpluses) or add to their losses. They might never know what the impact of their investment decisions is on their bottom line as the creation of new AI mediated processes and commodities is uncertain.

The theme of this chapter is that in the capitalist university we need to focus less on the distinctiveness of missions and the deployment of corporate verbal abstractions (including 'Artificial Intelligence') as of consequence. The unhealthy obsessions both with AI and in saving the humanistic purposes of the university are ultimately meaningless unless they are considered within a negative critique of capitalism itself, its social domination, and what is referred to as its 'social forms'. This is often 
absent in what is deemed to be critical analysis of Higher Education (HE). Of course, comparative HE and studies of HE markets and marketisation produce consequential knowledge, particularly in terms of how capitalism might manifest itself through discrete entities and ideologies, but highlighting the differences in state or market forms ignores capitalism as a form of social domination. As an analogy, if universities were ships being sucked into a monstrous giant whirlpool, we can explore the features of each ship, group of ships, or the distance to travel from a ship to the centre (perhaps calling it 'marketisation'), and that might be useful but to truly understand, and resist, what is happening we need to understand the whirlpool (what Neary and Winn, 2017, refer to as the 'vortex') of capitalism. Universities are swirling eddies in this vortex which is fuelled by labour power (Rikowski, 2000) and 'really existing' abstractions formed from abstract labour but appearing as commodities and fixed capital that act back on, and subsume, us. To some this may appear as economic reductionism, in that there is no room for nuance or agency. In contrast, this approach is economic rejectionism in terms of rejecting the conventional categories of political economy (and against the imposition of a new political economy based on a state or authoritarian re-establishing of value). It reinserts agency, both individual and collective, as although capitalism is crisis in every moment of production, it is uncertain and fragile. In opposition to this position, some theorists reject the very idea that $\mathrm{HE}$ is capitalist. For Marginson (2013) the idea of capitalist markets in HE is impossible, but it should be noted that markets are neither necessary nor sufficient criteria for capitalism. Markets pre-existed capitalism and many capitalist processes involve the transfer of commodities between universities and the state without a market. The capitalist nature of HE includes the commodification of outcomes which are exchanged for money, state support for value production to increase national competitiveness and labour power enhancement, and the scope for financialisation and datafication to open up the public and positional goods of $\mathrm{HE}$ for profit through reification into private assets. Critique of these processes is insufficient. Marx provides a 'negative critique' of capital and capitalism, that is, capitalism has no alternative other than itself in terms of its acceleration and destruction of all entities as part of value production or, alternatively, its destruction into either communism, or morphing into something worse than capitalism. This is not just a matter of morality as to survive daily we (if we are working class) must labour for a wage to survive.

The theoretical framing of this chapter, and the book, is that the relationship between AI and the capitalist university can only be understood through a Marxist negation being the Marxist conception of value, which unlike other forms of political economy definitively means a critique of value (value critique). This means pursuing a negative critique, a rejection of capitalism, the value form, other social forms (including the state), and acknowledging the specificity of labour in capitalism (labour 
power). This involves emphasising the importance of capitalist forms of labour, particularly abstract labour, in an understanding of technology (including AI) and our relationship to it as humans. To understand $\mathrm{AI}$, we need to move and abstract away from it, and enter the domain of abstract labour and other phantoms (particularly the commodity, machinery, and capital) that act as vampires on living labour. This is not to place value above other concepts in Marxist theory. As will be explained in Chapter 3, value is meaningless without a conception of class struggle and, in terms of $\mathrm{HE}$, the relation between class struggle and academic labour where AI now plays its part in the enhancement and disciplining of academic labour towards commodity production. It is also meaningless as a concept outside of capitalism as are the commodity, labour, and capital.

\section{Rethinking Value}

A critique of value and capitalism enables us to move beyond a simplistic material understanding of $\mathrm{AI}$ and its role in the university. $\mathrm{AI}$ is, at one level, a technological amalgam made by human labour that has all sorts of influences on work processes and in ethical determinations of the human, but it is so much less than that. AI is simply just another social form in which value finds its expression, a form of capital and a simple machine. For the capitalist university, it is just as beneficial if it were an empty box that enabled all sorts of organisational processes and data analytics to justify increased productivity or worker redundancies. To borrow a metaphor, it is '.... velvet glove cast in iron' (Clowes, 1993), the supposedly hard science of data analytics masking the capitalist university's appeal to the invisible hand of the market to justify redundancies and efficiencies. Of course, there are all sorts of complexities within this relationship between AI and capitalism, not least in terms of relationships between AI and concrete and abstract labour, the commodity, and the continuity of capitalism. Value critique can unlock the science fiction stylings, hardware, software, organisational forms, and ideology of AI exposing it as a mere form of capital. This involves returning to what is sometimes caricatured as a primeval conception of what is Marxist anti-political economy in terms of the critique of value.

What value is (and isn't) and how it moves, changes, and finds existence and appearance in terms of social forms has become perhaps the most important concept in contemporary Marxist theory. Despite this, it remains the most contentious. Marx's primary and almost complete text on capitalism, the three volumes of Capital (Marx, 1990, 1991, 1992) begins with the concept of value, and its manifestation in forms such as exchange value and use value but the texts consistently return to issues of value. Throughout Capital value appears in many guises, as the seemingly self-valorising 'automatic subject', as surplus value, as 
relative surplus value, as somehow manifested in the commodity and in its objective form of appearance (money). What is most important is that Marx does not seek to replace the conventional categories of political economy with value but rather critiques political economy, including the idea of value itself, as the social substance that (in motion) is capital, and whose motions and appearances are reifications of capitalism. Despite this conceptual power, readings of Marx with value as the primary (what is sometimes called the esoteric Marx) as opposed to a Marxism premised on class struggle (the classic reading of Marx, although the two readings are not as distinct as their advocates might think) are still uncommon. It is only with the New Reading of Marx (NRM) (Heinrich, 2012; Pitts, 2018), the work of Postone (2003) and the associated (but not synonymous) work of the Krisis collective (particularly Kurz, 2012, 2014), that the critique of value has again attained a central place within Marxism and critical theory. Some may find this return to value frivolous as secondary readings of Marx have often attempted to excise Marx of value or to see it secondary to exploitation (Althusser and Balibar, 2009). However, rather than recasting political economy as a separately Marxist or socialist endeavour based somehow on the objective value of labour (a labour theory of value), the first chapters of Capital set the scene for a negative critique of not only that discipline but also of capitalist society. There is nothing instrumental, or economistic, in the concept of value in Marx. Value is not an economic or a moral category but rather '.... a social category that points to a form of life determined by a specific type of exchange relation' (Neary and Winn, 2017, my italics). Marx was never working towards a theory of value, rather he developed a critique of value (Tenkle, 2014, p.13).

This is contrary to the way in which we would usually think of this concept. We are so ingrained in thinking of value as tautologically representing something of worth in modern society, morally or economically (as part of what Marx called bourgeoise political economy), that it seems impossible to form a perspective which would reject this without making use of those conventional categories. In a completely different realm (but one that might be tied to capitalist notions of subjectivity and the centrality of the individual) in universities, we have 'values' that are of importance to the educational mission. Values such as academic freedom and social justice are repeated as truisms that seemingly have an ontologically unquestionable status akin to the subjects of human rights theories. In instrumental discourses of HE, we speak of educational commodities as being 'valuable', 'adding value' to students as they move along the 'value chain'. On the other hand, we criticise values, rather than critique value itself, in terms of making moral judgements concerning what should be the purposes of the university, how university resources should be allocated, or making empirical assessments of how valuable different allocations are. These understandings of value are, 


\section{0}

even in Marx, correct on a surface level as they have an objective, fetishised, reality in capitalist production and for workers. If these bourgeoise concepts are hallucinatory (where the real action takes place in the various motions and appearances of 'value' which moves these concretised puppets around), then it is hard to separate them from economic reality. Workers and capitalists frequently find that their own 'values' are compromised by the periodic inability to 'add value' to products that move along the 'value chain' hence becoming 'valueless' themselves. Hence capitalist universities, and even the critique of those universities, are saturated with 'value talk', and involve both a moralistic and economistic take on what values the university should have, without undertaking a negative critique of value itself.

\section{Value in Marx}

As a prelude to contemporary value critiques, it is worthwhile to introduce Marx's work on value (Marx, 1990, 1991, 1992). This provides not only a grounding for what is to come, but value critique has a firmer relationship with Marx's original theorisations of value than with post-Marxism or with economistic Marxism that attempt to establish Marx as adopting a 'different' form of political economy. According to Sweezy (1970), as the exemplar of an 'economistic' Marxist reading, Marx was writing the beginnings of a Marxian political economy where concepts were better, alternative, conceptualisations of classical and neoclassical political economy. This makes the concept of value transhistorical and means that it can be used uniformly across all historical periods. As a case in point, abstract labour in Sweezy (1970, pp.31-2) is defined as an observation of the way in which labour is employed indifferently across the economy in general (as an economic category) rather than as a social form and expression of a social relation within capitalism. Contrary to this conventional political economy approach, in starting with value, Marx is not intending to establish another form of political economy where his depiction of value would replace the formulations which have arisen prior in classical political economy. Rather, Marx is establishing a negative critique of value (and indeed capitalism) viewing it as a social (rather than an economic) form that only exists in capitalism. Value, as Marx sees it, is not transhistorical and is only established from the dialectically opposing categories (labour and capital) that exist in capitalism. This means that from the outset Marx is trying to avoid an ontology of value where it arises from a transversal physical category whether that is the physics of work (energy expended by a human over a time period) or the direct productivity of labour, soil, or machinery. Marx's formulation of value is a doubly negative critique, to both criticise the object and to argue for its negation. 
Marx (1990) examines the mystifying nature of capitalist categories, and the ways in which he uses those categories (commodity, capital, labour, value) is unique to the capitalist mode of production. In particular, Marx is assuming (in Capital) that the capitalist mode of production prevails, and that this is a fully formed, totalising system. This means that the categories of labour and capital (and class struggle) are already established and in existence. Marx, therefore, starts his discussion of value assuming the totality of capitalist relations, of labour and capital as antagonistic social relationships. It is a '...historical social product' (Harvey, 2010, p.46) of class struggle. An 'entry point' into Marx, whether value, capitalism, or class struggle, is therefore arbitrary as each presupposes the other. Machinery is part of this totalising system and machines such as AI manifest themselves in every aspect of the social relations of capital. This is not just in terms of work, or the relation between labour and capital, but also in terms of the commodity, time, the continuity of capitalism, and the road to communism.

Marx was not particularly concerned with what things are, or what they do - their use values - '...the physical body of the commodity itself... the use-value or useful thing' (Marx, 1990, p.126) in his dual articulation of value. Although it is important that a commodity (which again is a particular category in capitalism) is a 'useful thing' for its sale to occur, this is assumed to be the case. Capitalists will not produce a commodity which cannot be sold, or otherwise utilised to gain a profit (whether rented, accessed through a cloud or platform such as Netflix, or bought), and they are largely unconcerned with the exact nature of the commodity. However, use value is (like other forms of value) a social form that is unique to capitalism. Although all things that people produce have some kind of 'use' in capitalism, only those objects (commodities) socially recognised as having use will have 'use values'. This includes commodities for which the primary purpose is to destroy humans such as nuclear weapons, landmines, poison and guns as long as they have a 'use' for a consumer whether that is an individual or a government. Most important to 'use value' is that the use enables an exchange for money. Marx was no utilitarian and not concerned with the utility, or subjective satisfaction, obtained through the consumption of an object. Commodities are produced only for profit, the conversion of money into increasing stores of money (profit) over time and are the '...material bearers of exchange value' (Marx, 1990, p.126). Value, exchange value, and use value exist (in a social form as there is no material metaphysics of value) simultaneously in the commodity (Aumeeruddy and Tortajada, 2015). Of course, the capitalist university is filled with potential use values, primarily certifications which are exchanged for money by (in the form detested by liberals but increasingly accurate) the student as consumer. Use values are not unimportant, but the emphasis by Marx on value and exchange value points towards the specificity of capitalist production 


\section{2}

and against the relevance of 'thingness' that constitutes it. If we take the form of AI, as a commodity that is sold to universities by corporations, its processing power and abilities that make up its 'sensuous characteristics' (Marx, 1990, p.128, which are constructed with concrete labour for capitalist profit) are less important than its social form (as a product of abstract labour) as it manifests its existence as fixed capital that enables the further exploitation of labour power for profit. Some physical elements of AI are part of its 'material substratum' (Marx, 1990, p.133) such as the chemicals that are used to make the computer chips or the coding for a neural network. However, Marx (1993, p.591) warns of the danger of considering the 'physical attributes' of 'instruments of production' rather than their 'economic form' (Marx, 1993, p.591). The appearance of AI as fixed capital obscures its form as the manifestation of labour which was valorised when that AI was exchanged for money. Of course, if AI is not of 'use' to universities then they will not invest in it, but the 'use' is primarily in terms of reducing the labour time of academics employed to produce educational commodities. Hence AI is used reciprocally with human labour to reduce the time needed to produce reports or generate data, to make predictions and analyse markets, and as a research or teaching tool. It, therefore, has some kind of 'use' value, but use value only exists in capitalism. AI is not used in universities as a form of play, entertainment, or to produce articles written for pleasure unless those things can be directly or indirectly converted into fixed capital (play as an organisational form that enables commodity production in reduced time), or commodities (such as AI-enabled 'edutainment' for students that enables greater satisfaction with lectures). In terms of a future communist society, Marx never argued that this was concerned with the production of alternative 'commodities' or 'use values' as these are forms specific to capitalism.

Exchange value is in appearance a quantitative relation (Marx, 1990 pp.126-7), but this form of value is '...the direct opposite of the coarsely sensuous objectivity of commodities as physical objects' (Marx, 1990, p.138). In terms of exchange value, Marx states that the substance of value is the expenditure of identical human labour power, a commodity that can produce greater value than was expended in its reproduction. Labour power is the '...value forming substance' (Marx, 1990, p.129). This initially sounds like a conventional economic category but as will be discussed below, Marx is not particularly interested in equating human labours in terms of their physiological or mental categorisations (or in determining the rate of exchange of commodities), but rather that they are socially validated in exchange (through the universal equivalent, money) and incipiently in the labour process. There is no attempt to equate human labours in terms of calories expended in each period of time, but rather Marx is considering human labour in the abstract which is that labour that has an equivalent nature only in terms of its 
ability to produce value. As exchange values (commodities that have the possibility of being exchanged), all commodities appear to contain congealed abstract labour time as a social rather than physiological category. The world in which capitalism appears, and the world explained by classical political economy is one in which exchange values are determined directly by hours of congealed (labour) time (price is quite separate from this) or other inputs of factors of production. According to Marx, the determinant unit of time in capitalist production is the Socially Necessary Labour Time (SNLT) (Marx, 1990, p.129) for each commodity which is the time required to produce a given commodity under the current technological and organisational forms of production including skill levels. By classifying labour time in this manner, as SNLT, there is an internalisation of the ways in which technology (including AI) and the average level of skill is specified. Technology is ascribed a role in the labour employed in production (in terms of time) rather than being independently characterised as a separate form, or factor, of production. Skill is also already embedded in this discussion of SNLT. Hence Marx is already demystifying the role of machinery (such as AI) in production, which is a social (being a product of a social totality) rather than an economic category. He is also demystifying the role of skill by making all labourers equivalent in terms of their role as abstract labourers after the process of exchange provides the social validation of that labour, in terms of its relation to the universal equivalent of money (Pitts, 2018).

Although the commodity itself is an external object and a useful thing, value itself cannot be observed. If a commodity is destroyed, or is subject to physical or chemical processes, it is not possible to find forms of value. This point is substantive for those theorists who attempt to ontologically link AI and capital. The idea that capital has become a form of AI (developing consciousness or calculative means), or that there is a hybridisation of AI-capital or capital-AI is ontologically inconsistent as AI is made of 'physical stuff' whereas value (and the seemingly 'self-valorising value' of capitalism as capital) is 'nothing' aside from a social form which appears to be, in a mystified sense, a concrete form. Although AI could be formed of computer code, physical circuitry, or a form of physical and neurological hybrid, value is different from any of these things. Marx states that if we disregard use value (and as I have described, Marx does not afford particular attention to use value) then all commodities are products of labour, but they are already transformed. This means that all commodities are abstract from use value, but all products of labour are of the same kind, which is human labour in the abstract. It may seem trite to say that AI is formed of human labour of some kind, but the point is that AI is formed from abstract labour so is constructed with the aim of profit when sold as a commodity. It is no coincidence that the construction of AI is largely through the efforts of private corporations (and occasionally the state) where profitability is 
the primary criteria. With a few minor exceptions, all planetary intelligence is hence commodified either being sold as a component of human labour power, in owned animals or (non-withstanding the hyperbole of AI) as 'artificial' intelligences which are constructed as commodities.

In capitalism wealth appears as a material form, as commodities which represent stores of value, and as money which is the objectified form of value. Although we do not see value objectively, it has a residue in commodities which (metaphorically) is where crystals of a 'social substance' (which is abstract labour) are held. Although commodities might appear to be very different, they have value (exchange value) independently of their 'form of appearance'. It does not matter what commodities look like (or don't look like in terms of services), they can be realised as exchange values. It must also be noted that value is not a simple Hegelian reversal, a material spirit (value), that moves through history, but one which is formed from abstract labour power which is meaningless without a notion of class struggle, of two forces labour and capital - which require each other for meaning and essence. Value (and value critique) is not designed to be another form of political economy which was to supersede the work of former political economies, rather Marx was concerned with the dissolution of capitalism and establishing a communist society not on a rhetorical or moral basis (as was the case with the utopian socialists) but on a scientific basis. That is not to say that morality was not important to Marx. Particularly in the first volume of Capital (Marx, 1990), he is concerned with the treatment of the working class and consistent calls for better treatment of workers, but this was not the only argument for establishing communism.

The movement of the social category value into different social forms and through time in circuits of money, production, and finance capital gives it not only the appearance of autonomy in terms of being 'self-valorising value' (Marx, 1992, p.185) but is a real abstraction (Sohn-Rethel, 1978, p.20) in that '...the movement of industrial capital is an abstraction in action. Here value passes through different forms, different movements in which it is both preserved and increases, is valorised' (Marx, 1992, p.185). Value is dependent on class relations and the existence of wage labour, and is a unique thing, being an actually existing abstraction. The phantom of abstract labour and the ghost-like realm of exchange value are social forms that are in every commodity and currency. Marx foreshadowed the desubstantiation of value (Kurz, 2012 , 2014), that increased labour productivity reduced the portion of value which was contained in each commodity (Marx, 1991, p.880) which is a key contention of value critique:

The same labour produces the same value for the product created in a given time; but the size of amount of this product, and thus the 
portion of value which falls to a particular aliquot part, depends for a given quantity of labour solely on the amount of the product, and this in turn on the productivity of the given amount of labour, not on its absolute amount.

(Marx, 1991, p.880)

To summarise, Marx does consider that a critique of value was central to a critique of capitalism and political economy (he made it the first chapter of Capital and there are many references to value in his other works). He certainly did not wish to ossify value or to make it the basis for an alternative political programme or economic philosophy, and did definitely not wish to consider value as some kind of material world spirit independent of class struggle. However, he did want to show how value, insubstantial and mysterious as it is, was objectified by classical economists as the theoretical basis for a system of political economy (capitalism) but also how the 'common sense' categories in capitalism (labour, capital, commodities, machinery) were in fact not transhistorical, and had a particular social meaning and appearance within capitalism itself. This is only one aspect of Marx's critique of capitalism and there are particular advantages, and pitfalls, in following this path as will be seen in the discussion that follows. However, by emphasising a critique of value we demystify the role of technology (including AI) within capitalism for a focus on abstract labour, the transformation of labour in capitalism, and the inhuman universe of social forms and what these do to humanity.

\section{Value in the New Reading of Marx and Value Critique}

As explained above, Marx was not attempting to institute an alternative theoretical framework for political economy. There have been attempts to build political-economic models based on Marx's conception of value (and this has often been the basis of planning in socialist countries), and to 'transform' Marx's conceptions of value into prices and profits. These adaptations are not, though, in line with Marx's negative critique. More productively, the NRM, particularly when allied with more mainstream Marxist conceptions of class struggle, and value critique, expand upon Marx's conceptions of value to develop a totalising understanding of capitalism, crisis, and communism.

Pitts (2018) expands upon both the theoretical insights of the NRM of Heinrich (2012) and Open Marxism to articulate a new construction of Marx's theory of value based on abstract labour which is mediated by commodity exchange, ultimately for money. NRM is both a critique of political economy and of society. Following Marx, value relates to abstract labour and not to concrete activities, but controversially (for traditional Marxism) the latent value of abstract labour 
(not as an empirical category, but as a posited potential) is valorised in exchange:

Money enables a measure of abstract human labour in general, responsible for producing exchangeable things in general. The measure - money - brings this abstract labour into existence, in the exchange of commodities.

(Pitts, 2018, p.4)

Value is not embodied in a commodity in a physical sense and is not entirely located in production or exchange (but Pitts, contrary to some understandings of Marx, argues against even the metaphorical idea that value is somehow crystallised in a commodity to reveal itself in exchange rather that labour power posits, or gives the potential, for this which is revealed momentarily in valorisation) but only 'appears' in various forms to finally manifest in the resolution of a process of social validation in exchange. There are certain conditions with respect to this process as valorisation by exchange is no means assured and abstract labour is only valorisable if the time to produce a commodity is equal to or below the SNLT. This abstract process, which enables a critique of conventional economic categories, is enabled by relations of class struggle, domination, and obscured by the monetary form. Labour only becomes abstract labour in retrospect, as part of the process of social validation in exchange. In many ways, it is already quasi-monetary in nature through the advance of money by capital in order to start production and the payment of a 'money wage' which acts to maintain and socially reproduce labour. In arguing this, Pitts (2018) draws on the work of Arthur (2013) who considers that labour already displays elements of abstraction prior to commodity exchange as it is the sale of labour power (potential to labour) that is sold as a commodity so it already has a 'mentally abstract character' (Pitts, 2018, p.93). It receives a monetary wage in exchange for contracted time and workers move between different jobs and unemployment through their lifetimes so there is a relationship between the wage and the reproduction of the workers' lives in totality. However, as in Marx, abstract labour is not the process by which complex (skilled) labours can be reduced to simple (unskilled) forms of labour (Aumeeruddy and Tortajada, 2015). Although concrete labour is expended prior to the ex-post validation of abstract labour, it is only 'value' that is the determinant form of wealth in capitalism, but the validation of abstract labour ex-post determines the ex-post SNLT which sets the average time in which concrete labour must produce a commodity (Postone, 2003, 2017). Labour time is set not through scientific management or other analytical techniques but by the actions of a real abstraction back onto the real world of work as synthetic timing (Sohn-Rethel, 1978). Money, as a universal (seemingly objective) 
entity, provides the social synthesis through which these abstractions become real abstractions and have a concrete existence. Hence Pitts develops Marx's conceptions of value, particularly the conception that exchange completes the sociality of capitalism through an objective form (money). Money, and its accumulation by capitalists, 'determines back' the potentially abstract nature of the whole process as a real abstraction. Competition and concentration of capitals, and the drive for capital accumulation, which appears as 'profit', is a further expansion of this process.

A parallel perspective on abstraction, and particularly abstract labour, allied to the NRM, Wertkritik, value-critique, or the critique of value (Larsen, Nilges, Robinson and Brown, 2014, p.ix) also takes Marx's formulation of value, with its inherent contradictions and crisis, as the basis of a reconstruction of Marx's work. Usefully, this perspective is not merely focussed on value, or on the role of abstract labour in its production, but allows us to consider issues of technology and AI within capitalist crisis. Unlike NRM, this esoteric take on Marxism in value-critique considers labour power itself to be a real abstraction from its inception (Larsen et al, 2014, x), as an unusual commodity that can produce greater value than is necessary for its own production and reproduction. In this sense, abstraction is immediately real in production, not a process whereby economic factors become dominant as social categories through exchange as in the NRM. They are immediately really existing abstractions that make the world, time, and space of capitalism. Abstract labour, through its movement to capital, becomes the source of social domination (Postone, 2003). This is a dynamic process of social domination as profitability is dependent upon constant reductions in the SNLT through new technologies (including AI) and methods of organisation (such as increases in the length of the working day and the speed of work whilst workers are subject to synthetic timing), expansion into new markets and ranges of commodities, and securing natural resources in a 'treadmill' effect (Postone, 2003). Living labour increasingly becomes dead labour, and life and nature becomes capitalised. AI is an example of a capitalist technology which enables these new methods of organisation, the speeding up of production, and the creation and sale of new commodities.

Within this perspective (and indeed in NRM), labour is not an anthropological constant which has the same ontology and social relationships across all societies. The labour that made the pyramids and medieval castles is not the same labour that produces profit for the capitalist in the money form. In capitalist society, abstract labour, labour as a 'common equivalent' is not simply an idea, but a '...historically established, socially powerful, actually existing abstraction that violently brings people under its thumb' (Tenkle, 2014, p.3). This common equivalence is not in terms of reducing people's labour to unskilled work but rather 
the valorisation of all abstract labour in exchange through a common equivalent, being money. The emphasis on violence here is important as value is dependent upon the notion of class struggle and the separation of labour and capital as we will see in the next chapter. For humans, this is a viscerally real abstraction involving the expenditure of a form of energy which is a social, rather than a physiological, energy. This is also immediately abstract in terms of '.... a highly specific rule of time that is both abstract-linear and homogenous....Each and every minute is valuable as it, in the literal sense, presents potential value' (Tenkle, 2014, p.5). Of course, abstract labour occurs simultaneously with concrete labour, the latter creating a material item or service that may be a use value whereas abstract labour is the '...expenditure of labor as such, regardless of any qualitative determination. As such it creates the value presented in commodities' (Tenkle, 2014, p.5). Tenkle defines abstract labour as:

...the reduction of all the different forms of commodity-producing labor to a common denominator. It makes them comparable and as a result capable of being exchanged for one another, by reducing them to the pure abstract, reified quality of elapsed time. As such, it forms the substance of value.

(Tenkle, 2014, p.6)

This is not a natural fact or an anthropological law. What workers do in capitalism is already a reified, social form which is already a form of social domination (Tenkle, 2014, p.6; Postone, 2003) rather than anything that is physiological or physical. People really do come face-to-face with the products of their abstract (as well as concrete) labour in terms of capital, particularly in its objectified form as money, but also in facing machines, such as AI. Following Sohn-Rethel (1978) these are actually existing abstractions rather than mental constructs (Tenkle, 2014, p.7). It must be noted that these abstractions already exist at the point of production and not in the processes of exchange or distribution as in some versions of the NRM. Hence, Tenkle criticises Sohn-Rethel (1978) as considering that this abstraction is formed in exchange. Rather production and exchange are taken to be a unity where production presupposes exchange (this is not dissimilar to Pitts, 2018, interpretation, although Pitts emphasises exchange). Commodities are produced assuming that they can be exchanged on the market whereas Sohn-Rethel (1978), similarly to Žižek (2019, p.31), confuses the necessity of the temporal distinction between production and exchange with the '...social unity of the processes of valorisation and exchange' (Tenkle, 2014, p.8). Value is an objectivity (albeit an abstract, alien one) at all stages of the process of production, circulation, and exchange. '...production occurs already in the context of a fetishized form...value cannot go without a material bearer' (Tenkle, 2014, p.9). Hence at the point of production, all 
labour (no matter what its skill or type) is abstracted into value producing labour.

Kurz takes forward Tenkle's conception of value and in doing so demonstrates the difference between value and the reality of material objects. This is a very important consideration when it comes to the ontological status of AI and technology in universities which are material objects (fixed capital or a commodity). Value, according to Kurz is an '...intangible social abstraction' (Kurz, 2016, p.17) although it appears in real social relations and things its character '...being an abstraction cannot be immediate and therefore also not tangible' (Kurz, 2016, p.17). Objects are not abstract but are made into real abstractions by what Kurz calls the 'social projection mechanism' (Kurz, 2016, p.17). Projection is the mechanism of forming real categories through which we see social forms as material objects which is similar to Pitts' (2018) 'social validation' or Lotz's (2014) 'capitalist schema'. For example, we see AI as an amalgam of computing power or software or as an alternative to the physical human brain. We do not perceive it as the material substrate (fixed capital) of an objective social form (money) that is our own abstract labour validated through exchange come back to confront us in the server room or on our laptop screen. As a social, not physiological, substance, abstract labour is (ultimately and tragically) the substance of capital. What we do at work, productive labour is a dual concept referring not just to material exchanges but to the '...expenditure of abstract human labor as the fictitious substance of value, which on the surface appears reified as exchange value' (Kurz, 2014, p.21). The only labour that is productive by this definition is '...that which is presented immediately as a social real abstraction or value-forming substance' (Kurz, 2014, p.21). It is only in capitalist society that there is the creation and the deviation between two forms of productive labour. Concrete labour, the physical production of commodities, which occurs simultaneously with abstract labour is also a uniquely capitalist form of labour. In the capitalist university, concrete labour involves the production of physical things (such as academic 'outputs', styles of teaching, and financial reports) that are strangely specific to capitalist commodity production.

In terms of automation and AI, there is a tension between the metaphysics of capitalism and a progressive capitalist teleology. Capitalism may have a tendency towards greater technological progress, but it also (because of this tendency) has a countervailing tendency towards the destruction of technologies, particularly those which do not appear to yield a profit. The same applies to skills and education whereby accelerating levels of skills and education in the name of productivity are mirrored in deskilling and the obsolescence of qualifications and whole areas of human knowledge. This rejection of a teleological and also an anti-empirical view of technology is found throughout the work of Kurz $(2012,2014)$ in terms of both economic categories and the relation 
between value and energy in a physical sense. However, parallel to his analysis of material objects, Kurz $(2012$, p.10) does not consider the relationship between value and surface economic categories to be infinite. Value does not possess the ability to transmute itself into anything. 'The idea of a infinite flexibility in relation to the substance of value has been a vast illusion' (Kurz, 2012, p.11). Kurz would be dismissive of an accelerationist position on AI, for example, that would view acceleration as combining all entities, ideas, and technologies into a cybernetic amalgam. As Marx, there are a 'succession of stages through which the broad lines of possible outcomes can be determined' (Kurz, 2012, p.10) and a limit, a tension between the empirical and theory. Whilst theory reveals valorisation the 'mass of real value...cannot be determined directly in an empirical fashion' (Kurz, 2012, p.10) but:

The mass of real value is linked to the substance of abstract labour, thus to the mass of abstract human energy expended in the functioning space of capital. On the other hand capital can only use as much human labour power as it requires, but only in relation to the level of productivity which is also imposed between competitors.

(Kurz, 2012, p.10)

Here Kurz links value to the 'substance of abstract labour', historically specific labour power. In this formulation the '... mass of abstract human energy' does not have a direct relationship with physical energy. This has similarities with Postone's (2003) account of abstract labour. Kurz and Postone would both concur on the 'critique of the concept of labour' (Kurz, 2012, p.16) and consider labour to be a historically specific form of social mediation in capitalism and part of a negative critique of that form (rather than a positive critique, as is sometimes implied in labour movement Marxism). Capitalism is indifferent on how 'brain, nerve and muscle' are expended (Kurz, 2012, p.27), only that the expenditure of abstract labour (or 'the abstract expenditure of human energy', Kurz, 2012, p.27) might be extended, preferably to infinity by capital. The essence of capitalism is abstract labour. '...Marxists occasionally forget what value really is - namely the socially real fiction of objectified human labor in context of the immediate production process' (Kurz, 2014, p.53, my italics).

Value critique, therefore, presents a unique perspective on the relationship between capital, technology (including AI) and crisis. Based on his critique of value, Kurz does not believe that capitalism can continue forever partly because of its tendency towards an advancing technological level of development. Kurz (2012, p.14) contends that the 'minority theories of collapse' of Luxemburg (insufficient realisation of surplus value) and Grossman (overaccumulation of capital) are theories of an 'internal limit' of capital that are premised on empirical determinations. 
Kurz instead proposes that Marx had two theories of crisis that are not yet unified. One was concerned with capital circulation, disproportionalities between production branches, and the other concerned with the underproduction of surplus value due to the diminution of the workforce which becomes superfluous with technological change such as AI. Kurz considers that it is rather that the real substance of capital, labour power, diminishes which underlies the crisis. This is the 'desubstantialisaton' of capital (Kurz, 2012, p.15). Capital itself undermines its own life force and becomes a '...pseudo-accumulation without substance' (Kurz, 2012, p.15). Capitalism replaces labour through new technology and scientific methods of mechanising the human process of production such as Taylorism and AI (Kurz, 2014, p.39), but it can never fully eliminate '...mediated, indirect labor' (Kurz, 2014, p.40). In this sense, Kurz holds to Marx's concept of a gradual increase in attendant labour (although Kurz also extends this to labour involved in circulation). But neither attendant labour, nor machines, can actually produce value. Science is not an 'immediate productive force' in that science, technology, and machines realised in AI cannot produce value (Kurz, 2012, p.41). The idea that technology, which would include AI (although Kurz does not mention that here) can create value would be another '...moment in the immortalization and consolidation of the process of the abstraction of value' (Kurz, 2014, p.41). Technology, including AI, is not able to produce value in the same way that human labour can. Related to this point, technical and scientific labour whether human or cyborg cannot (according to Kurz, 2014, pp.42-3) produce value in the Marxist sense, at least as an entity separate to labour, but this does not mean that we should fetishise immediately productive labour. Rather, this needs to be understood in terms of relative surplus value as part of the development of capital. As well as increasing the length of the working day and the intensity of labour (increasing absolute surplus value) technology leads to a fall in the SNLT and a temporary increase in '...the proportion of the new value that the living labor has created over and above the costs of its reproduction' (Kurz, 2014, p.44). More material products are produced and there is an increase in the concentration of capital (Kurz, 2014, p.45) whilst each commodity produced loses value. Kurz adds another, rarely discussed consequence, which is that '...capital itself becomes the absolute logical and historical limit in the production of relative surplus value' (Kurz, 2014, p.47). Capital is its own limit. Capital '....increases the extent of exploitation, but in doing so it undermines the foundation and the object of exploitation, the production of value as such' (Kurz, 2014, p.47). If capital can expand and accumulate, seize more social space (including by destroying other capitals, trade wars and national wars), and absorb more living labour, outward crisis can be stalled. This involves the 'speeding up' of life and the disjuncture between abstract and concrete time discussed by Postone 
(2003, pp.186-225) and a destruction of space by time (Harvey, 2010, p.37). Even as space and time are warped, our subjectivity of both past and future is destroyed as '.. the temporalization of the future through credit and the temporalization of the past through accumulation is that these two horizons become one horizon for one world, which allows us to speak of “capitalism" or "capitalist world”'(Lotz, 2014, p.103). This cannot continue indefinitely and eventually capitalism runs out of new areas to expand into and '...concrete material wealth can no longer be engendered within the limits of the value relation...a crisis of value itself, from which there can be no longer be a way out for capital' (Kurz, 2014, p.54). This does not mean that we have attained '...the absolute and complete automation of production as a whole, the ghost factory' (Kurz, 2014, p.57) but rather the point at which more labour is being eliminated than is being absorbed. State capitals and monopolies, even future utopias and dystopias controlled by an AI, do not move beyond a 'value-imminent mode of observation' (Kurz, 2014, p.71). It is the 'qualitative disproportionality in the relation between matter and value' (Kurz, 2014, p.71) not (or not just) the 'quantitative disproportionality' which is the root of capitalist crisis. Both capitalism and state capitalist (or AI controlled) regimes still accept value as an organising principle and there is no '....mechanical automatism of the transition to socialism' (Kurz, 2014, p.71).

Although this is a powerful and internally consistent representation of capitalist crisis, one 'critique of value critique' and of the NRM is in terms of the emphasis on value as an abstraction rather than the approach taken to the pursuit of profits by capitalists at the expense of wages, and class struggle, in what is sometimes called 'traditional Marxism'. Firstly, in terms of what capitalists achieve through their investments, there must be some relation, no matter how indirect, or subject to metamorphosis, between value and the surface economic category of profit (perhaps through relative surplus value) as this surfacing of profit (as a form in which value presents itself) must influence the behaviour of capitalists with regard to their actions in investing in fixed capital and new technology. Notwithstanding the notion of a 'real abstraction', capitalists want to see a return on the monetary investments that they make. In particular, subjectivist theory considers that value critique and value theory is 'metaphysics' (Tenkle, 2014, p.11). Although '...value can in no way be nailed down empirically' (Tenkle, 2014, p.11) and labour is not literally preserved in a product (as in positivist, vulgar strands of Marxism), it is a non-empirical category, yet it does appear in various mutated guises (social forms) as exchange value, use value, price and profit, the commodity, the state, and as AI. However, capital is not interested in the world as an abstraction or even in the absolute level of value or how it moves, but only in surplus value (Ortlieb, 2014, pp.81-2) specifically relative surplus value and the determination of profit. Secondly, 
it can be argued that value critique does not sufficiently consider class struggle. This critique is somewhat misjudged as value critique does consider the relation between labour and capital in a manner which is congruent with Marx's original thought. Where NRM, value critique, and other forms of Marxism are somewhat separate is in terms of the attention paid to the working class as a historical agent. Value critique contends that value, as the social substance created by abstract labour and measured by SNLT, is a (if not the) defining principle of capitalism. Therefore, a society that defines value as the primary social principle in society will be a capitalist society. Societies which have been judged by some commentators to be 'state capitalist' (such as the later, dictatorial, forms of the Soviet Union) are criticised as adhering to value as a primary principle of society and as creating a metric based on SNLT. Such societies are seen to be little different from capitalist societies as the state plays a role as a monopoly capitalist. The tendency for such societies to be anti-democratic is also noted by Kurz and others. Similarly, and somewhat bizarrely, workers' struggles which consider that labourers should not only control society but place labour above other principles are regarded as counter-productive in terms of producing a communist society. Labour (at least capitalist forms of labour which is all labour according to value critique, aside from the 'dark side' of value being the forms of labour, such as housework, that indirectly support value production) is tragic in that it creates capital and the conditions of its current and future exploitation. 'Workerism' is rejected by value critique in favour of the dissolution of value. The problem with this perspective, as I will argue in the next chapter, is that it neglects the role of class struggle in developing consciousness and critique in the wider working class seeing it as a logical and intellectual discipline for the intelligentsia. It also ignores the experimental and formative nature of earlier communist societies and struggles. At worst, 'social form analysis' allows for the restatement of a new-bourgeois form of political economy. Lange (2019) argues that recent value-form analysis has ignored the social form of labour in capitalism, that is, Marx assumes the totality of the capital and labour relation from the beginning. The forms of value are not self-explanatory without an appreciation of the specificity of labour in capitalism. Pitts (2018) is more explicit concerning the necessity for work on value to concern itself with the establishment and maintenance of capitalism through violent and continuing dispossession, exploitation, and immiseration. Usefully, Open Marxism, particularly the work of Bonefeld (2014) combines an understanding of the 'real abstractions' and value form with the violence that underpins them through an understanding of Marx's Capital which focusses on its historical rather than its logical (as in NRM) exposition (Pitts, 2018, pp.105-37) as '...the real abstraction of value...cannot be separated from its constitution in the actual relations of life' (Pitts, 2018, p.109). Labour, class, surplus value, 
and class struggle, in the entirety of capitalist society (Arthur, 2015) are integral and presuppose the value form. Although Pitts (2018) considers that these are historical manifestations of labour and capital, they are also logical as these dialectical categories are necessary for capitalist production to occur.

To summarise, the NRM and value critique provide a totalising theory to negatively critique $\mathrm{AI}$ in capitalism in terms of the transhistorical nature of labour (and capital), the endogenisation of technology, and emphasising the imminent and internal nature of capitalist crisis. This informs the simultaneous, rather than coincidental interactions, of technology, labour, and time. This, in turn, explains the relationships between AI, labour, commodities, time, the end of capitalism and communist society which are the subjects of subsequent chapters. However, these theories need to be combined with a more traditional understanding of Marxist conceptions of class struggle and antagonism, otherwise they risk what they most wish to resist - the imposition of a new form of political economy - hence in Chapter 3, I emphasise class and class struggle, as manifested in academic labour in HE, as presupposed and fundamental aspects of capitalism.

\section{Against Entanglements}

The NRM and value critique (together with Open Marxism and class struggle) are Marxist perspectives that are at the centre of how AI and the capitalist university can be critiqued negatively. They are at the heart of the theoretical arguments in this book. There are, though, many non-Marxist conceptions of commodities and value which have been prominent in contemporary debates on technologies such as AI. Arguments regarding the agency of material objects, our entanglements with objects (including AI and computers), and the role of various types of desire and embeddedness in our technological relationships have come to play a major role in critical theory. Despite some useful observations on process, these post-structural and New Materialist perspectives are theoretically inadequate in terms of theorisation of abstractions and the ways in which they relate capitalism to concrete practices (particularly as related to entities such as AI), their bourgeois foundations in a taken for granted understanding of categories of economy and society, and their affirmative or neutral critique of society rather than a negative critique. I will return to the alleged liberatory potential of post-humanism and transhumanist perspectives in the concluding chapter, but here I will explain why New Materialist or Deleuzian perspectives are not being used in this book. Broadly, one brand of perspective, New Materialism (Object Orientated Ontology and Actor Network Theory) are about 'things' and sometimes 'commodities' whereas another (Deleuzian perspectives on 'desire') are about vectors and movements. Either of these 
theories are inadequate to explain the specific form of AI in the capitalist university. Although they use alternative ontologies, these ontologies are inconsistent and add little to the arguments concerning AI and capitalism.

As considered above, the commodity is a staging device in Marxist arguments on the nature of capitalism as a system of social domination. Without the concept of the commodity, it is not possible to sustain a Marxist critique of capitalism (unless this was based on some kind of pure financialisation), but the commodity is actually no more important than any other aspect of this 'real abstraction' maintained through class struggle. It should be noted that commodities are not objects (such as a computer), they can be services (such as education), but commodities have the specifically capitalist characteristics discussed above. One perspective on objects (and some objects are commodities, although object is an inadequate depiction of commodity) that is part of 'new materialism' is Object Orientated Ontology (OOO) (Harman, 2016) which sees objects as being literally anything (a stone, a pile of stones, a thought, a set of ideas, or AI) that entangle and interact together, dismissing the idea of imposing theories concerning grouping and taxonomies, as well as theories about composition or purpose. Objects have an 'is-ness' that withdraws from understanding. Although value critique might, wrongly, be thought to be somewhat in accordance with OOO as theorists such as Harman recognise the appearance of objects interacting 'amongst themselves' (Harman, 2016, p.6), it also recognises that this appearance is only one layer of reality. Harman might accuse value critique of 'undermining' the autonomy of objects by seeing them as an appearance of which value is the essence, but value is a non-objective essence (certainly not an object). The claim of immaterialism (OOO) that objects have an '....autonomous essence' does not necessarily exclude a Marxist consideration of commodities, but this is in opposition to the Marxist understanding of commodities. Commodities do not have an autonomous essence beyond understanding but a really-existing abstract essence (value) in exchange. Although commodities '...have relative independence...from their constituent places or histories' (Harman, 2016, p.9), the keyword here is relative and objects do not have full independence from value as an abstract category in the Marxist ontology discussed earlier. Commodities are not objects as they are the products of abstract labour intended for exchange. This is not transhistorical but is part of capitalism and was violently imposed on humanity and nature.

In addition, New Materialist ontologies read everything as equal, for purposes of negation of anthropocentric privilege, or in seeking the epistemological truth of a flatland. For example, Harman (2016, p.2) depicts Actor Network Theory (ANT) as a '...flat ontology in which anything is real insofar as it acts...' and Object Orientated Ontology as more inclusive again as encompassing all objects and entities whether 
they act or not (Harman, 2016, p. 2). This uses object '...to refer to any entity that cannot be paraphrased in terms of either its components or its effects' (Harman, 2016, p.3). Objects have agency and conduct mediation (Harman, 2016, p.5) and OOO brings in the inhuman action of objects in that '...the vast majority of relations in the universe do not involve human beings...objects interact amongst themselves even when humans are not present' (Harman, 2016, p.6). These theories provide an ontological plane where everything is equal but fail to address metaphysical questions about the nature of reality. Stuff just 'is' and just 'acts', with no special status accorded to the specificity of historically produced forms of objects or non-objects which ascribes agency to every possible contemplated actor. These theories naturalise the commodity as an actor possessing agency rather than the carrier of an abstraction, and obscures power relations in terms of the division of labourers from nature and capitalism as a form of social domination, involving social forms (Choat, 2018). OOO and ANT are affirmative ontologies of objects and also forms of 'materialist post-modernism' adopting a transhistorical framing where everything has a linear history relative only to itself. This leads to accusations that OOO is a simple form of commodity fetishism, that things are the real characters of history rather than examining social relations. This is surface statis, not even accelerationism, which takes objects as entities as they are. Although OOO rejects the accusation of commodity fetishism, it makes things the subject of history. Even the realities of OOO that push back and retreat are not even there for any other entity, being a hallucination of their external appearances, which is a seemingly idealist form of materialism.

Aside from critiques from OOO and ANT on the commodity (more properly the object), there have also been recent critiques on how capitalism operates in terms of 'desire' or 'coding' rather than 'value' and 'class struggle'. Deleuze, as a prominent politically post-structural author, has considered issues of capitalism and value, but whilst Deleuze's analysis of desire can said to be positive, or at least productive (in terms of political and social change - Deleuze and Guattari, 2013). Marx's critique of capitalism (value in motion) is negative, and axiomatically resistant to repurposing, rather than indeterminant. It must be noted from the start that Deleuze is political and his work was influenced by Marx, particularly in his work with Guattari, which defines concepts such as mechanic surplus value, surplus value of code, and territorialisation/ deterritorialisation that have become influential in post-Marxist theory. Some contemporary Marxist writers on AI and technology have considered that Deleuze's analysis is extremely important. Dyer-Whiteford (1999, pp.180-1) argues that Deleuze and Guattari's emphasis on desire as the constitution of social reality has similarities with Marx's notion of value being productive and dynamic but not subject to morality. For Dyer-Whiteford, this is similar to Marx's definition of labour before 
appropriation by surplus value extraction (Dyer-Whiteford, 1999, p.180). However, in this conception of desire Dyer-Whiteford adopts a transhistorical notion of labour without considering that in capitalism labour is abstract labour, as discussed in the above analysis, that can only be critiqued as part of a negative critique of capitalism as a whole. The molecular nature of desire and its territorialisation's are not the same as the movement of value either in its basis as abstract labour or in its appearance in social forms. Deleuze and Guattari's (2013) work does give some consideration to Marx's conception of value as the essence of capitalist society as value in motion. Despite this, the idea that Deleuze and Guattari transcend Marxist theory, or open up new areas of theory by not essentialising aspects of Marxism, are over-estimated either because the authors undermine aspects of Marxism by generalising the terms through which capitalism operates (code rather than value without accepting the historically situated nature of value within capitalism), or by misunderstanding and misapplying Marxist concepts (surplus value which is treated as arising from financialisation rather than exploitation).

This is not to critique Deleuze and Guattari's theory in its own post-structural terms (Colebrook, 2002), but rather to consider it in relation to value critique which (in term of its conception of capitalist society and, for our purposes, the critique of $\mathrm{AI}$ ) presents a superior framework for understanding these relations. To expand on this, capitalism's origin is understood by Deleuze and Guattari $(2013$, p.49) as '...born of the encounter of two sorts of flows: the decoded flow of production in terms of money capital and the decoded flows of labor in the form of the "free worker", but these are not 'flows' of the same order (one is circulatory and the other is an abstraction, as abstract labour), and the correspondence of these with value is unclear. Furthermore, the primary elements of Marxism are the (deterritorialised) worker and (decoded) money, according to Deleuze and Guattari. They do consider abstract labour as an ontologically different form of labour than appears in previous economic formations and value as a substance in motion that realises itself (Deleuze and Guattari, 2013, p.262; see also Tynan, 2009, p.33). These relations are called a distinct 'coding' relative to that which occurred before and unnecessarily mystified as a 'surplus value of flux' (Tynan, 2009, p.40). Choat (2009, p.19) claims that this leads Deleuze to consider a relationality in which '...class relations are not characterised by some pre-existing identity but are reciprocally determined... actual relationship and all social relationships are the incarnation of economic relations as different virtuosities that may be actualised in different ways...' Whilst this reciprocal determination is fundamental, and might transcend certain forms of vulgar Marxism, this does not offer anything additional to Marx and certainly not the NRM or value critique. Matters become confused when the authors consider that capitalism represents a movement from a surplus value of code to a surplus 
value of flux, when surplus value only has a meaning under capitalism. This concretises the economic categories as transcending capitalism and would be clearly rejected in the historically specific (to capitalism) theories of value discussed above. They also refer to a 'mechanic surplus value produced by constant capital' (Deleuze and Guattari, 2013, p.267) which is taken to be a counter-acting tendency to the falling rate of profit where innovation ultimately reduces the SNLT, but this is not explained in terms of value as historically and logically associated with abstract labour. Abstract labour and value are, therefore, included in a 'form' in Deleuze and Guattari's adaptation of Marxism, but they become subsumed in a peculiar understanding of code, surplus, and the mechanic which is particular to their theories. This acts to limit the ways in which Deleuze and Guattari understand capitalist fundamentals and crisis which they relate to disproportionalities between sectors of production or countries (as in the discussion of centre and periphery, Deleuze and Guattari, 2013, pp.266-7). This is discussed by Tynan (2009) who sees a relationship between Marx's rejection of Say's law and his emphasis on the conflictual relationship between worker and capitalist, and the disjuncture between production and machine in Deleuze and Guattari. Tynan (2009) sees the contributions of Deleuze and Guattari in terms of enabling us to consider the unequal relations between worker and capitalist, the relationship between money flows as the interior limit of capital', and the ideological flows of repression and permissiveness between the state and the market. If this is the case, then we might ask why is it even necessary to construct an elaborate apparatus of coding and decoding to recreate what is already there in (even vulgar) Marxism whilst losing the interior contradictions of the value relation itself. In addition, this focus on unequal distribution in exchange does not consider how exchange itself performs the function of social validation (Pitts, 2018) focussing instead on inequalities or disproportionalities. In contrast, value as conceptualised by the NRM and value critique offers not a flattening ontology, but a dynamic one, displaying how through the 'cell' of the commodity form capitalism warps space and time, and how capitalism comes to dominate all social (and physical) space. Compared to theories of coding, territorialisation, deterritorialisation, and lines of flight (which often lead to a focus on money and financialisation with no understanding of why this movement has taken place in terms of a negative critique of value) value critique enables an understanding of capitalism that is neither teleological (that certain movements are inevitable) or merely vectoral (that things operate in different directions with no principle). In conclusion, the Deleuzian analysis of capitalism unnecessarily complicates but also mystifies capitalism. Capitalism is no flatland, Cthulhu, or rhizomic tree, although it might appear as all of those things. The essence of capital is value in motion, but this is not an essentialised notion. The concept of 'mechanic surplus value' adds 
nothing to the concept of surplus value as it already exists but rather mystifies the production of machines (including AI).

\section{Conclusion: AI and the Capitalist University in the 'Vortex'}

In contrary to the theories discussed in the previous section, Marxist theorisations of capitalism and value discussed in this chapter provides us with a way of thinking about universities, technology, skills, and AI that demystifies some of our assumptions around these dimensions of capitalist development, and enables us to think about these questions across the life cycle of the commodity, and in relation to labour, struggle, and negation in a superior way to other recent social theories of value and the commodity. The social positing of value (in any industry, including the academic labour expended in the capitalist university) through abstract labour brings us consistently back to labour not in a positive sense (that valuing labour value above all else should be the aim of a future society) but a negative one. That abstract labour, which only exists in capitalism, creates value which in the hands of capital destroys not only living labour but also the planet. It is hard to see at this stage how current forms of technology, such as AI, which drive the creation of relative surplus value can be used as the basis for a future communist society whereby these can be repurposed, but this question will be discussed in the final chapter.

We can also see, as stated above, the difference between technology and capitalism in terms of the self-valorisation of value. That is, material technology and value are coincidental variables. It is the search for increased profits (relative surplus value) that leads capitalists to invest in increased technology which ultimately undermines relative surplus value (and on a material level, profits). Ultimately, all of this occurs in relation to labour (abstract labour) which is the source of value for capitalism. Hence technology (including AI) and human skill is wrapped up with the relation between capitalist and labourer. Within this, AI has a role, not only in the process of production, as fixed capital, but also within the valorisation process as a whole and is one of the ways in which capitalists attempt to increase their profits, valorise commodities, and expand the universe of capitalist values. Of course, this is the subject of the whole book but even this preliminary analysis suggests a variety of ways in which AI is used in the capitalist university.

Firstly, AI is used not only to measure and discipline work, in the creation of a commodity through the analytics of things such as league tables, but data analytics and AI also act as a process by which value can be 'socially validated', in terms of production of a commodity that can be sold on the market (Pitts, 2018). Processes such as data mining and data analytics are used to validate the existence of a commodity 
(whether student experience or research outputs) that are socially validated through their exchange for money. Pitts (2018, p.237) describes this as the 'work of combustion' and the 'form giving fire' of the creative industries (branding, advertising, and design) but this also applies to the algorithmic work in the service industries, including universities, where $\mathrm{AI}$ is used to give form to the commodities whether these are material or services. AI is part of the '...considerable effort to endow a commodity with a social relationship whereby it can stand in relation to other commodities through the mediation of monetary exchange' (Pitts, 2018, p.228). This could be in terms of academic outputs or student experiences. In terms of student experience, for example, although this is a subjective, mental, experience of the student initially this is given 'form' by predictive analytics based on student surveys and analysis of social media so that this 'potential' commodity can be commodified as a result in student surveys that are exchanged for money in terms of student fees. The abstract labour of academics, in terms of teaching students, is abstract labour that is only valorised in terms of student fees.

Secondly, AI acts to impose labour discipline directly in terms of algorithmic calculations to attempt to calculate the productivity of labour with regard to the global imposition of labour time, the SNLT, to produce an educational commodity. AI acts almost as if it were extension of the mind of the capitalist, and this enables the monetarisation of all aspects of activity in a university.

Thirdly, value critique enables us to make various assessments about the nature of $\mathrm{AI}$ in the capitalist university and not just about its relation to it. At the level of the material, there is an understanding of the relation between physical entities, the material form of AI, and real abstractions. Value, as well as the relation between abstract labour and surplus value may be intangible, non-empirical concepts, but they act back on the material world that we experience. They have real consequences for our lives as experienced in capitalism including the way that we see AI. The material (concrete) component of labour and the material qualities of technology are sense impressions or residues. AI is ephemeral. That is not to say that it is a post-modern signifier that has no connection to reality. It is scientifically real by the criteria of physics, chemistry, and biology. There is physical and mental effort involved in the work of building and coding AI, and electrons move through the circuits of computers are as real as the electrical impulses that move through neurons. Having said this, we must assume that science is capitalist science and is often moved in the directions which are required by capitalism. Therefore, we should not concentrate on only the concretisation of $\mathrm{AI}$ in universities, but its relationship to value and capitalism.

Fourthly, despite the fundamentals of capitalism as 'self-valorising value' there are no teleological assumptions in terms of the ways in which this might progress and move. Capitalism can go through different 
stages, crisis, and reinventions and remain capitalism. There is no reason why capitalism will progress through certain discrete stages of technological development, and no reason why technology or AI should move in a particular direction. Certain technological routes may be closed off, or stunted, because they do not meet the particular direction of capitalism for profit. Other forms of technology might be progressed to meet the need for greater profitability but not deliver on these profits. AI might be a particular and peculiar 'moment' in capitalism. What is certain is that capitalism is driven by profit (the search for relative surplus value) to survive. Although capitalism must revolutionise the means of production, this does not mean that AI will accelerate alongside any particular line, and it may join the list of capitalist industrial fads that did not continue, not because they were technologically unsophisticated, but purely as they were not profitable.

Fifthly, despite this non-teleological or empirical view, value will become increasingly unsubstantial. When all labour is drawn into the production processes of capitalism and pushed towards maximum productivity, skill, and labour time, then value becomes stretched between an inexorably growing universe of commodities. It becomes increasingly difficult for capital to live as surplus value is increasingly hard to realise in the sale of commodities. As capitalism grows towards the infinite, it struggles to breathe. Of course, it continues to struggle with no regard to the actual physical or material resources that are needed to sustain life and ecology. Capital is not interested in the world but only in profit.

In conclusion, Neary and Winn (2017) consider that the value-form vortex '...grounds the modern University as a function of material social processes of capitalist value production'. The vortex of value means that everything becomes a 'social form' within capitalism but not as a flat ontology, but rather a flattening one. This is described by Neary and Winn (2017) as the 'value-vortex' in the modern capitalist university which is '...grounded in the material reality of the value form' (Neary and Winn, 2017). AI is part of this process of grinding down reality to become value. However, it is necessary to consider abstract labour in this context if we are to understand that it produces value under the conditions of class struggle which is not incidental, but integral, to abstract labour as a social form. If there is no 'outside' of capitalism from which a perspective can be developed by workers then the direction of revolutionary progress must be decided on by intellectuals and other groups tangential to workers struggle. The problems with this approach are well established in Marxist theory, but even in its own terms value critique and NRM must (and does, particularly in the work of Pitts, 2018) accept that class struggle is central to the establishment and continuation of abstract labour. Therefore, there is no other way to desubstantiate value (and hence capitalism) other than directly engaging with class struggle at various levels. This involves a connection with worker struggles, mental 
and manual, including academic labour and its relation to technologies such as AI, which is the subject of Chapter 3.

\section{References}

Althusser, L. and Balibar, É. (2009). Reading Capital. London: Vero.

Aoun, J. (2018). Robot-Proof, Higher Education in the Age of Artificial Intelligence. Cambridge, MA: MIT Press.

Arthur, C. (2013). The Practical Truth of Abstract Labour. In: R. Bellofiorie, G. Starosta and P. Thomas. (Eds.). Marx's Laboratory, Critical Interpretations of the Grundrisse. Boston: Brill, pp. 101-20.

Arthur, C. (2015). Dialectic of the Value-Form. In: D. Elson. (Ed.). Value: The Representation of Labour in Capital. London: Verso, pp. 67-81.

Aumeeruddy, A. and Tortajada, R. (2015). Reading Marx on Value: A Note on the Basic Texts. In: D. Elson. (Ed.). Value: The Representation of Labour in Capital. London: Verso, pp. 1-13.

Bonefeld, W. (2014). Critical Theory and the Critique of Political Economy: On Subversion and Negative Reason. London: Bloomsbury.

Choat, S. (2009). Deluze, Marx and the Politicisation of Philosophy. In: D. Jain. (Ed.). Deleuze and Marx. Edinburgh: Edinburgh University Press, pp. 8-27.

Choat, S. (2018). Science, Nature and Ontology: A Historical-Materialist Response to New Materialism. Political Studies, 66 (4), pp. 1029-42. DOI: $10.1177 / 0032321717731926$.

Clowes, D. (1993). Like a Velvet Glove Cast in Iron. Seattle, WA: Fantagraphics.

Colebrook, C. (2002). Gilles Deleuze. London: Routledge.

Deleuze, G. and Guattari, F. (2013). Anti-Oedipus: Capitalism and Schizophrenia. London: Bloomsbury.

Dyer-Whiteford, N. (1999). Cyber-Marx: Cycles and Circuits of Struggle in High Technology Capitalism. Chicago: University of Illinois Press.

Hall, R. (2018). The Alienated Academic: The Struggle for Autonomy inside the University. London: Palgrave.

Harman, G. (2016). Immaterialism: Objects and Social Theory. Cambridge: Polity.

Harvey, D. (2010). An Introduction to Marx's Capital. London: Verso.

Heinrich, M. (2012). An Introduction to the Three Volumes of Karl Marx's Capital. New York: Monthly Review Press.

Kurz, R. (2012). No Revolution Anywhere: The Life and Death of Capitalism Series No. 1. London: Chronos Publications.

Kurz, R. (2014). The Crisis of Exchange Value: Science as a Productive Force, Productive Labour and Capitalist Reproduction. In: N. Larsen, M. Nilges, J. Robinson and N. Brown. (Eds.). Marxism and the Critique of Value. Chicago: MCM' publishing, pp. 17-76.

Kurz, R. (2016). The Substance of Capital. London: Chronis Publications.

Lange, E. (2019). Form Analysis and Critique: Marx's Social Labour Theory of Value. In: P. Osborne, É. Alliez and E. J. Russell (Eds.) Capitalism: Concept, Idea, Image. Aspects of Marx's Capital Today. London: CREMP Books.

Larsen, N., Nilges, M., Robinson, J. and Brown, N. (2014). Introduction. In: N. Larsen, M. Nilges, J. Robinson and N. Brown. (Eds.). Marxism and the Critique of Value. Chicago: MCM' publishing, pp. ix-li. 
Lotz, C. (2014). The Capitalist Schema. London: Lexington Books.

Marginson, S. (2013). The Impossibility of Capitalist Markets in Higher Education. Journal of Education Policy, 28 (3), pp. 353-70, DOI: 10.1080/ 02680939.2012.747109.

Marx, K. (1990). Capital: A Critique of Political Economy, Volume 1. London: Penguin.

Marx, K. (1991). Capital: A Critique of Political Economy, Volume 2. London: Penguin.

Marx, K. (1992). Capital: A Critique of Political Economy, Volume 3. London: Penguin.

Marx, K. (1993). Grundrisse. London: Penguin.

Neary, M. and Winn, J. (2017). Beyond Public and Private: A Framework for Co-Operative Higher Education. Open Library of the Humanities, 3 (2), p. 2. DOI: http://doi.org/10.16995/olh.195.

Ortlieb, P. (2014). A Contradiction between Matter and Form: On the Significance of the Production of Relative Surplus Value in the Dynamic of Terminal Crisis. In: N. Larsen, M. Nilges, J. Robinson and N. Brown. (Eds.). Marxism and the Critique of Value. Chicago: MCM' publishing, pp. 77-122.

Pitts, F. (2018). Critiquing Capitalism Today: New Ways to Read Marx. London: Palgrave.

Postone, M. (2003). Time, Labor and Social Domination. Cambridge: Cambridge University Press.

Postone, M. (2017). The Current Crisis and the Anachronism of Value: A Marxian Reading, Continental Thought and Theory. A Journal of Intellectual Freedom, 1 (4), pp. 38-54.

Rikowski, G. (2000). Messing with the Explosive Commodity: School Improvement, Educational Research and Labour-Power in the Era of Global Capitalism. Paper presented at the British Educational Research Association Conference, Cardiff University, 7-10 September 2000.

Sohn-Rethel, A. (1978). Intellectual and Manual Labour: A Critique of Epistemology. London: MacMillan Press.

Sweezy, P. (1970). The Theory of Capitalist Development. New York: Monthly Review Press.

Tenkle, N. (2014). Value and Crisis: Basic Questions. In: N. Larsen, M. Nilges, J. Robinson and N. Brown. (Eds.). Marxism and the Critique of Value. Chicago: MCM' publishing, pp. 1-16.

Tynan, A. (2009). The Marx of Anti-Oedipus. In: D. Jain. (Ed.). Deleuze and Marx. Edinburgh: Edinburgh University Press, pp. 28-52.

Žižek, S. (2019). The Relevance of the Communist Manifesto. London: Polity. 


\section{AI and the Subsumption of Academic Labour}

\section{Introduction}

As explained in the previous chapter, Higher Education (HE) is just another form of capitalist enterprise that is an element of the vortex of value that is capitalism. Despite the privileging of intellectual labour in societies, and the fetishising of universities as centres of ideas and culture, what academics do is still work. Within capitalism, academic labour is no different from other forms of labour, as it is abstract (and concrete) labour with the aim of creating value in a circuit of commodity production. What academics do in concrete terms (concrete labour, which is often the subject of critiques of aspect of 'academic work') must be considered as a unity with the other, inseparable element of their work, abstract labour. This is not just a description but a conception of value which is both a negative critique and regards value as a social form. Capital is a product of abstract labour in capitalism which becomes increasingly insubstantial as its forces develop. Academic work becomes increasingly concrete with measurement and managerialism but paradoxically its products become less substantive as efficiencies and enhancements are made. This is because organisational and technological innovations, such as Artificial Intelligence (AI), do not directly produce value. They can only posit it (or put it into motion) as enhancing the productivity of labour power and through decreasing the Socially Necessary Labour Time (SNLT) to produce a commodity. These investments can temporarily lead to an increase in relative surplus value which, through further technological and organisational accumulation, is eroded away. This process is only with social meaning when valorised by a complete cycle of production, circulation, and exchange. Hence, there is a constant search by capitalist universities for technological and skill advantage which collectively disintegrates as that advantage is competed away. Any residual meaning in academic work, in terms of its intrinsic value, becomes lost in the blur of accelerating demands and competition between universities as capitals. This is an uncertain, fragile, process that accelerates towards its own destruction, and is an

DOI: $10.4324 / 9781003081654-3$ 
inherently antagonistic one, in terms of the existence of academic labour, within conditions of class struggle. Class struggle also situates the relationship between technologies such as AI and academic labour as one in which the continued supply of labour power and its compliance is necessary for production. Academic labour, as abstract labour, is a particular social (rather than physiological or technical) form. As noted in the previous chapter, value critique and the NRM (New Reading of Marx) have been criticised as avoiding discussions of class struggle. Without class struggle an account of value is meaningless.

In this chapter I will consider how academic labour has been constituted in the recent Marxist literature, with relation to class struggle and how the role of machinery and technology has been conceptualised. This leads to a discussion concerning the ways in which both academic labour and AI are part of the valorisation process. HE is being continuously capitalised and intensified in terms of commodity production. As part of this process, capitalism becomes less differentiated between industries as all are purposed towards the maximisation of profit through commodity production. Despite the variety of technologies, forms of labour, varieties of commodities and branding, HE becomes increasingly capitalised. This makes it simpler to borrow technique of labour discipline from other industries, and we currently see that AI-based techniques adopted from digital manufacturing and services are being used in contemporary HE to subsume academic labour as part of capital. This is a process that involves various kinds of subsumption - absolute, real, ideal, and hybrid - and, I will argue, a (version of) Dyer-Whiteford, Kjøsen and Steinhoff's (2019) concept of hyper-subsumption which represents a scalar shift in primitive accumulation towards AI. The ways in which AI enables a synthetic version of the 'mind' of the capitalist into the academic production process and privatises the attempt to construct a general intellect will also be discussed as a way in which capitalists try to curtail the disruptive, collective power, and revolutionary potential of workers in HE. As soon as AI does not increase profits, perhaps by becoming generalised across HE or through a technological or organisational impasse, then it will be abandoned for a 'superior' technology. Hence the discussion of AI and the adoption of digital manufacturing techniques might be a fleeting moment in HE, but one that illustrates the tendency towards new forms of subsumption and control.

Although it is made of failing components, capitalism gives the impression that it is a totalising system. A discussion of academic labour is intimately connected with the nature of the 'commodity' produced in $\mathrm{HE}$ and its valorisation. Academic labour is purely directed towards commodity production (teaching, research, and knowledge exchange) with an administrative apparatus within universities devoted to achieving the social validation of these forms for money (such as completing 
the data returns to exchange those commodities for income from the state or from a sale of tuition, or knowledge, to private actors). In the traditional, human capital focussed, field of neoclassical economics of education, HE establishments are considered to produce a basket of commodities such as research and education. Students are given the role of consumer in many of these economic models but the state and private industries also purchase outputs. For most HEIs (Higher Education Institutions) worldwide, they are funded (to a greater or lesser extent) by private student fees and other income from research and teaching based on a funding formula (this is true of most HEIs worldwide, few are funded by a block grant from government independent of these factors and if they are then this is subject to a certain level of performance). The final commodities produced by HEIs are therefore usually a series of data returns to government as well as some kinds of private fee income and revenue from other sources, such as research. Only when these commodities are valorised for money, and in an instant represent the valorisation of abstract labour, it is that all that academic labour 'makes sense' within capitalism. Hence students and research outputs, including the final version of an academic paper, can best be thought of as the intermediate products of production just prior to valorisation or the 'commodity stock' (Marx, 1992a). This does not mean that they are ephemeral and non-existent, rather they have a really existing material essence as physical objects (through concrete labour, but they might not be quite the things that academics would have produced outside of capitalism), yet they are also products of abstract labour. The 'data return' by which most HEIs gain their income from the state and other sources, as a commodity, already represents a mathematical (computational) formula, even of a simple additive nature, which is easily monetarised ex-ante in anticipation of the valorisation. In this way, it acts back on academic labour which is already abstract labour in anticipation of that moment of exchange for money. The nature of the commodity in HE means that it is already, for the most part, a formula that requires calculation and there is an obvious role for computation, data analytics, and $\mathrm{AI}$ in the maximisation and optimisation of strategies including the treatment of academic labour power. The final commodity produced by most HEIs (as a data return) is akin to a large-scale item, such as a battleship that is sold to the state rather than as a series of small commodities which are similar to consumer goods. Of course, a minority of HEIs specialise in rapid turnover short courses or modular degrees in exchange for regular fee income and the volatile nature of the $\mathrm{HE}$ commodity in the era of AI will be discussed in the next chapter. It should be apparent that the norm of a collaborative form of production towards a single (or series of large) data commodities makes parallels with digital manufacturing (and the implementation of data analytics) clear. 


\section{The Violence of Academic Labour and Labour 'In General'}

As a social material substance, as considered in the previous chapter, value can only be created in conditions of domination, exploitation, and class struggle which presupposes labour and capital as socially antagonistic, but mutually dependent, categories. Labour and capital depend on each other. The dispossession of property from the working class and the hammering of work into its capitalist form as labour power (abstract and concrete labour) are necessary for the existence of capital:

The worker's propertylessness, and the ownership of living labour by objectified labour, or the appropriation of living labour, or the appropriation of alien labour by capital - both merely expression of the same relation from opposite poles - are fundamental conditions of the bourgeois mode of production, in no way accidents irrelevant to it.

(Marx, 1993, p.832)

It is true that, as academics, we might enjoy aspects of our academic work, and even the production of the 'commodity stock' (teaching students and writing articles) that become the commodities that are realised for money, but we do so under conditions not of our making and always in conditions of struggle. Work, as a transhistorical concept, can be something that humans want and enjoy doing, but this is twisted into an alien and unrecognisable form in capitalist production. Now work becomes synonymous with the constant supply of labour power under the conditions defined by the capitalist to produce value under strict time discipline (production which is only socially valuable under the conditions of SNLT, average skill, and with a valorised product). This does not allow for any 'slack' production, 'mistakes' or 'personal projects' as time to do anything other than that involved in the production of commodities is dead, frivolous, time. It does not allow for any organisational or technological slack or any deficiency in skills of the worker (which are increasingly becoming disciplined by the sentient academic commodity as explained in the next chapter). Labour time in excess of the SNLT, or below the average level of socially defined skill, is not recognised as labour in capitalism. The eventual result of excessive labour time to produce an academic commodity would be that profit will fall in a particular university, and this will mean that the university will leave production (as profits have fallen) or will be taken over or merged with another university, or another type of capital entirely. Even state forms of $\mathrm{HE}$ are under the watchful eye of capitalist companies in terms of whether any 'slack' labour time or resource can be replaced by private sector processes. These objective and alienating compulsions are the 
conditions of any worker within capitalist production and they will subjectively and objectively suffer the consequences unless they resist (and in resistance the threat of losing the capacity to labour - unemployment is threatened). Of course, some (perhaps most) workers might succumb to capitalist work easily, perhaps joyfully, for fear of losing their wage or a slight subjective advantage in consumption above other workers. Such fears are completely justified and realistic. In capitalist society, not to be exploited means to earn no wage or any of the other benefits of work (in some societies this includes health care). The power of a class struggle theorisation of value is that it brings into the dynamic of work an appreciation of not only the subjective and objective but also the naturally resistant elements of that relationship. By combining this with value critique, a theoretical framework can be created that protects such critique from some of the arguments that have been made against it by what has sometimes been called 'traditional Marxism'. In essence, this is simply a reminder of the primordial (since primitive accumulation) duality of class relationships in capitalism. Human beings including academics have to labour as they:

...can only survive by selling themselves temporarily, or more precisely, by selling their vital energy, as labour power, for an external purpose...For them labor thus primarily means a fundamental extraction of vital energy and in this respect is thus an extremely real, actually existing abstraction.

(Tenkle, 2014, p.4)

The expenditure of abstract labour in capitalism creates value which is a form of social domination. Academic workers might oppose the extraction of labour power at various levels of organisation from the trivial and subjective (daydreaming), to the organised (union work) and objective (creating co-operative universities). It is not that abstract labour involves a particularly defined labour process or mode of organisation, but rather it is in the a priori nature of labour in capitalism and academic labour is no different in this respect. The increasing precarity of academic labour, redundancies, and performance management are rightly seen as signs of the increasing proletarianisation of academic labour but the nature of academic labour, as abstract labour in the creation of value, is equivalent to all other forms of labour in the process of valorisation as discussed in the previous chapter.

In the moment of valorisation of the commodity for money all labour involved in its composition is validated as abstract labour. Academic labour time is already abstract labour (in value critique) or at least posited as abstract labour (in the NRM) but awaits a final combustion before it is meaningful in capitalism. In HE, this commodity is usually a data return and in the moment that the monetary return hits the 
University bank account every interaction between student and lecturer, every seminar run by a GTA (Graduate Teaching Assistant), and every keynote held by a Professor in the formation of that commodity reveals its nature as abstract labour. It is valuable to the university only in terms of the creation of value. This collective labour, and then the entire social capital of global HE production, returns to face each of these workers in terms of investment in new technological and organisational forms (including AI), a falling SNLT, and an increasingly alienated, stressful, and competitive workplace. Although academic workers might identify with different class strata and class interests (for example, many academics identify as middle class and some have inherited wealth), they all objectively labour to produce value in conditions of class struggle.

Class struggle is fundamental, and not optional, when analysing the nature of labour and value within capitalism, and this includes academic labour. Autonomist Marxists have paid particular attention to the role of labour and class struggle within the creation of value. De Angelis (1995) defines value as the class relation of work (De Angelis, 1995, p.118) with abstract labour as substance, its measure as SNLT and its objective form as money (this is the money form of value which is the only material way in which value appears objectively in capitalist society). According to this view, the labour theory of value is a class relation, being both the capitalist imposition of, and working-class resistance to, work as discussed above. The production of value is synonymous with resistance and class struggle. It is, therefore, conceptually better to invert the phrase 'labour theory of value' to a 'value theory of labour' (Elson, 2015) in that it is the creation of value in capitalism (as self-valorising value) that is intrinsic to the relation between labour and capital. Such a conception of labour opens the possibility of working-class struggle being both within and against capital to consider possibilities 'beyond the law of value' (De Angelis, 1995, p.119). De Angelis, therefore, defines work both in terms of the labourer and capitalist's side of the relation. This emphasis on the 'class relation of work' immediately identifies the creation of value in terms of the production side of the relation rather than the circulation side, which is where value becomes exchange value but as discussed in the previous chapter, the realm of circulation is necessary in terms of valorisation. This abstract relation has visceral consequence for work activity.

These consequences are not only in terms of social domination and the ways in which a 'real abstraction' determines the concrete manifestation of life in capitalism but also in terms of alienation and the continuously expanding 'abstraction away' from lived experience. De Angelis considers that capitalist work (abstract labour) separates the worker from their sensuous experience of working (concrete labour, but even the performance of this in capitalism is alienating), placing them in a 'position of indifference' to such labour (De Angelis, 1995, p.110). 
In every moment of work, the labourer must overcome 'pain, human suffering, human brutalisation, boredom...' (De Angelis, 1995, p.110) as well as the immiseration and inequalities of working. As money is boundless as a social objective, the possible number and variety of commodities are limitless and as capital has to expand and accumulate to survive, there is no limit to the imposition of work. Similarly, Tenkle (2014, p.5) considers labour to be abstract in the temporal separation between work and experience '...time that has been separated from the subjective sensations, feelings and experiences of working individuals'. It should be noted that it is this aspect of labour, its nature as abstract labour in capitalism which makes it unique. Abstraction is thus not just a theoretical process, whereby an abstract entity comes to dominate our work but part of lived experience. We can feel abstraction through our alienation from work and the objective and subjective experiences that result from this, including our use of technologies such as AI.

This approach to abstract labour and class struggle is in opposition to so called 'technological paradigms' which use formal, mathematical, linear programming approaches to the determination of value. There are several problems with the technological approach from those who take a more social approach. Firstly, it neglects the specificity of the form of value (money) which is a specifically social form of mediation. Abstract labour refers to a social process rather than a merely technical congealing of labour. The social nature of this process is seen in all the processes involving value, including its production and circulation. Secondly, abstract labour exists prior to the process of exchange (as it is technologically determined) whereas in the social paradigm, it is only in exchange that the social validation of abstract labour occurs. De Angelis (1995) considers that both perspectives are problematic as they do not recognise the substance of value as identifying 'a social relation of struggle of a particular nature' (De Angelis, 1995, p.121). It is the class struggle approach that adds to the truly social dimension of value above the social-validation (and positing of labour as abstract labour) approach. In opposition to the technological paradigm, De Angelis (1995) therefore opens the possibility (following Cleaver, 1979) of a 'strategic' or 'political' reading of the labour theory of value (De Angelis, 1995, p.128). This view is not without some controversy. Kicillof and Starosta (2007) consider that De Angelis' argument has two heroic contentions. Primarily, that Marx's critique of classical political economy was based on his conception of the specific form of labour in capitalism, rather than simply a critique of the inability of the classical economists to consider capitalism as a historical form. Additionally, that abstract labour is the substance of value and that abstract labour is the capitalist form of work. Kicillof and Starosta consider abstract labour to be instead '..... generic material form' (Kicillof and Starosta, 2007, p.16) being the expenditure of the brains, muscles, nerves, and hands of humans. Here they posit that it is 
acts of private, physical labour, that are simply brought together as a single 'generic material form' in the commodity. This infers that there is a combined physiological form of abstract labour in the commodity (which does not seem to be a particularly Marxist depiction of abstract labour). As workers needs are determined by capital '...there is no way in which they can stand in absolute contradiction with the 'principle' of capital's self-expansion' (Kicillof and Starosta (2007, p.23) '...there is no exteriority to the alienated social relations of capital' (Kicillof and Starosta (2007, p.27). However, there is a key difference between labour power and labour which is not considered by Kicillof and Starosta (2007). It is labour power that capitalists wish to obtain - the consciousness of the worker is of peripheral (although not unimportant) consideration in determining their willingness to provide labour power (in exchange for a wage). Ultimately, physiological theories of labour do not really describe how labour is sold and used in capitalism. Workers don't sell corporeal units (use of their brains, hands etc.), they sell their time and this is bound up with the fact that immiseration means that time is not the labourer's. Although Marx was interested in energy as a metaphor, it was a social metaphor, and this was not to ever state that labour power could be expressed in calorific terms (and, as previously stated, value is only ever relative as it is determined by all other social labours, average levels of skill, and technological development). Besides, workers are conscious subjects who viscerally feel the consequences of work and not just energy transfer machines.

A class struggle reading of abstract labour is applicable to academic labour, and its relationships to technologies and machines such as AI. It enables the identification of despotism in capitalism and identifies value as not just an analytical category but one in which revolution is implicit. In locating class struggle as central to the understanding of abstract labour and value, De Angelis provides an important rebuttal to Kurz (2014) and Postone's (2003) critique of labour movements within capitalism. Class struggle, and labour movement Marxism, is not only (except in its most reformist formulations) about fetishising value and promoting wage labour but also about the brutality and alienation of work and of overturning those relations. This is a fundamental element of working class struggle and critique. Extrapolating from De Angelis' work means that we must consider that all aspects of capitalist existence, including the relationship between humans and AI, can be contested through class struggle. This brings into question the nature of the human under capitalism and the extent to which materials such as prosthetics and other enhancements can be part of labour rather than capital. Indeed, these classification struggles are occurring in terms of how unions consider robot labour, and partnerships between humans and robots. Note that this is not about disputing the existence of these categories, such as 'human' or 'labour' but recognising class struggle around their 
parameters which has existed since the earliest days of capitalism. De Angelis does not see class struggle as being either inside or outside the production of value but rather synonymous with it (De Angelis, 1995, p.119). Autonomist and Open Marxists sometimes emphasise wider definitions of class struggle and 'cycles of struggle' (Dyer-Whiteford, 1999, p.13) which includes wider understanding of class to include the precariat and non-market labour. Class struggle is offered as an alternative to a simplistic domination by capital. 'Labor is for capital always a problematic "other"' (Dyer-Whiteford, 1999, p.65). Labour can never be fully incorporated into capital, and the working class are defined in terms of their struggle against capital, not as simply selling labour power, but this determination has weaknesses in that it does tend towards analysis of 'social principles' or 'immaterial labour' which will be critiqued in the next section, when I discuss AI and the General Intellect. Labour power cannot be performed without resistance. This is not in terms of utility or preference but in terms of the axiological potential of the individual, the collective, and the human species more generally. AI enters this terrain of struggle but does not determine it.

\section{AI and the Nature of Academic Labour}

There is a distinctive literature on academic labour which is separate from that on academic work (which primarily focusses on conditions of work and the impact of this on academic identity and conditions) as it considers labour as a historical, capitalist, category for critique within a negative critique of capitalism (Winn, 2015). Hall (2018), employing a Marxist framework of a negative critique of value, considers that academic labour takes place within what he refers to as a circuit of expanded alienation whereby academics are alienated from their own labour (labour power), production (product of labour), self and humanity (species-being). Through quantification and league tables academics are also alienated from their peers as production of academic commodities becomes 'commensurable and measurable' based on abstract time (Hall, 2018, p.83). Processes of subsumption by capital as a social power in academia impoverishes and proletarianises academic labour and leads to fragmented identities and anxiety (Hall and Bowles, 2016, pp.38-40). At the same time, academic labour is objectified as an alien property of capital. Maisuria and Helmes (2020) employ a historical approach to academic labour, showing how capitalisation, commodification, and marketisation have manifested themselves in contemporary HE through neoliberal policies. The 'neo-liberalisation' of the University has been achieved (despite worker resistance) through competition, privatisation (and quasi-privatisation), new technologies and managerial forms, the rise and promotion of the 'entrepreneurial' academic and curriculum reforms that promote competitiveness and employability. This drive for 
profit and surplus is the reality of academic labour, which increasingly becomes subsumed by capital. Within the totality of capitalist relations, academic labour also produces resistances and forms of communality and collegiality including alternative, co-operative forms of education (Hall, 2018; Maisuria and Helmes, 2020), and spaces (albeit contested and self-contested) of free and resistant labour (Shukaitis, 2019). Academic labour, and its relation to AI, therefore needs to be understood within a negative critique of labour as '...inside-against-beyond the capitalist university' (Szadkowski, 2016, p.10).

In terms of its relation to academic labour, AI is not a peripheral technology as automation is central to capitalist production which appears as if it has an 'automatic character' (Sohn-Rethel, 1978, p.119), mobilised by labour and machinery, but in reality is '...inherent in the production relations of capitalism' (Sohn-Rethel, 1978, p.119) which converts all processes into 'automation' (Sohn-Rethel, 1978, p.121). AI is part of this in replacing human labour power in capitalism whilst simultaneously extending and intensifying the production of labour power. Part of this process is in terms of increasing the quality of labour power through investment by capitalists in the social production of labour power. There is nothing 'magical' about technology and automation mechanisms including AI, in terms of their influence on capitalism. Indeed, the development of AI ultimately (over time) has no net effect on surplus value and profits:

From the moment that the increased productivity becomes widespread, innovative individual capital loses its edge. Nevertheless, it is not a matter of a return to a point zero or to a previous starting point. On the contrary, the higher level of productivity transforms itself into a new general standard. The hour of labour, as the basic unit of abstract labour, is always the same, it cannot have as such 'different' levels. However, the new standard of productivity imposes the condition that fewer of those hours of always identical abstract labour be required for an increased mass of products. When capital is devalued or destroyed in the crisis, the achieved standard of productivity remains the same, because it is inscribed in the aggregate constituted by knowledge and know-how.

(Kurz, 2014, p.17)

We should, therefore, not be under the illusion that AI employed in universities is ultimately transforming capitalism. There is a hallucinatory sweep of capitalism with its ever-expanding skills, velocities, exoskeletons, big data, and machines. AI is a contemporary technology which may seem to revolutionise everything in universities. The appearance may be of a 'Constant revolutionising of production' (Marx and Engels, 2002, p.223). The reality is that technical revolutions are a sign 


\section{AI and the Subsumption of Academic Labour}

that capitalism is a stagnant and weak system. Capital, in movement, is not like a growing layer of technology around the globe that constantly expands. Rather it but is akin to the thinness of a sap moving through the world like it would through a dying tree and leaving nothing but dead labour in its wake. Similarly, accelerationism may consider it original to state that an hour isn't an hour, that time is non-linear, and that the future is hailing the present, that we are being happily invaded and colonised by an inevitably inhuman future (which is why the neo-reactionary philosopher Nick Land, who will be discussed in Chapter 6, turned to Lovecraft, as much as Marx). We never reach a technological singularity as when we think we are approaching the event horizon, the present consistently becomes historically useless, and the production clock consistently starts again as the SNLT falls towards nothing.

$\mathrm{AI}$ is an example of a mere machine, and machines in capitalism can be both entities (usually physical objects) or activities (organisational forms and practices which can include regimes of skill accumulation and use). AI is both of those things in terms of its physical manifestation and coding, but also in terms of the ways in which work activities are orientated around supplying information for the AI or are disciplined by AI monitoring. AI does not produce value but, through enhancing the productivity of labour (which only arises as AI itself is formed of soaked up labour time), might enable the temporary existence of relative surplus value. Capitalists attempt to maximise, using AI alongside other machines, all the forms of labour power which are applied by capital. This means maximising everything physical, mental or otherwise identified in the body, or bodies however defined, or contemporaneous with it, dividing, combining, and multiplying work to maximise labour power applied to a commodity. In HE this involves the analysis and optimisation of individual work patterns, and how work can be best combined with others. Machines like AI also reduce the labour time required to produce a commodity (the SNLT) hence increasing relative surplus value. As stated above, in whichever form AI is employed as soon as the use of a particular AI or arrangement of AI becomes generalised, this relative surplus value disappears along with additional profits. Capitalism resets itself at a higher level of technological development as if the previous wave of AI had never existed. Rather than an accelerating world of AI, our capitalist world is static as AI never really makes a difference in the long run to anything, in terms of the production of value. Furthermore, AI can be antagonistic to the development of class consciousness and class struggle. Dyer-Whiteford (1999) examines various autonomist perspectives on technology which reject the idea of technology as progress. Technology is considered to be a weapon (Dyer-Whiteford, 1999, pp.69-71) with a specific capitalist formulation but one which can be resisted, subverted, and sabotaged by workers. 
In terms of academic labour, we can consider AI for most purposes as a typical machine, no different from a hammer, but it can also be seen as a modern manifestation of the extension of the 'brain' of the capitalist into every domain of academic work. As class struggle is inevitable in capitalism, technologies such as AI are one way in which the capitalist class can insert themselves into work practices by enforcing work discipline (Maisuria and Helmes, 2020, p.25). AI inspired data analytics, or machine learning, even of poor quality, can provide a cloak through which capitalist universities can supposedly justify their decisions to shut courses or sack employees with troublesome research interests or union activities. AI is also a component of the absolute and relative subsumption of academic life through extending the working day beyond the physical presence of the lecturer and researcher, and applying new organisational and technological forms to the workplace. Digital technologies extend the working day by allowing home and mobile working (Hall, 2018, p.147) facilitated by AI-driven technologies that provide nudges to lecturers and allow the division of labelling of lectures and seminars into isolated components that can be restructured into 'new product'. AI, machine learning, platform capitalism (Uberfication according to Hall, 2016) and AI inspired analytics on lecture capture or research outputs subsume academic labour into value production and capital, increasing relative surplus value as a component of real subsumption. As part of this, AI facilitates the 'social synthesis' of global academic labours in league tables and performance indicators. It is also part of the 'social validation' of academic labours which represent an intermediate part of the production process into a final commodity. Hall (2018) considers that as academia becomes increasingly subject to privatisation and commodification, it also becomes obsessed with exchange value as opposed to the use value of academic products. This capitalisation leads to new organisational and technological forms, an increase in the organic composition of capital, and the subsumption of HE by value production as it contributes to the 'social totality' of capital. Alienation and commodity fetishism mean that technologies, including AI, are projections of a 'distorted human essence' (Hall, 2018, p.74) in which technology further divorces academics from the means of production and acts to further proletarianise academics (Maisuria and Helmes, 2020, p.23). This proletarianisation (which is often associated with the Marxist concept of 'primitive accumulation') continues through technological means. These technologies aim only to produce increased absolute, and relative, surplus value. Hall (2018, pp.148-52) argues that for academic labour the promise of educational technology to liberate workers from working time and inefficiency is instead a form of technological alienation (subsumption) that rather makes academics dependent on these technologies. Cybernetic forms of control monitor the performance of individual academics, increase the power of managers and re-engineer HE globally for 
marketisation. This includes the use of metrics and the 'datafication' of HE (Maisuria and Helmes, 2020, p.15).

\section{$\mathrm{AI}$ and the Subsumption of Academic Labour}

AI needs to be understood as part of the process of a wider subsumption of academic labour. Szadkowski (2016) adopts an 'orthodox' Marxist reading of subsumption that enables a reading of how AI might influence aspects of this process. Formal subsumption, the formal establishment of capitalist social relations (in terms of the labour process appearing as a process of capital, the expropriation of the means of production, the dialectical creation of labour and capital, and the immiseration of labourers requiring the sale of labour power) makes it possible for universities to extract absolute surplus value through increasing labour time and the intensity of work (Szadkowski, 2016, p.16). Labour is subordinated to the rule of value whose production is determined by the entirety of social labour and social labour time (SNLT). As discussed above, AI and machine learning are ways in which capitalist universities can specify commodities and optimise inputs of labour. Real subsumption involves the labourer confronting the mystified products of capital in terms of commodities, technology, and science (the general intellect) which transform labour processes. Whilst formal subsumption is primarily quantitative (in term of increasing the working day and the intensity of work), real subsumption changes the quality of work to become specifically capitalist (Szadkowski, 2016, pp.16-7), but the two forms of subsumption are not independent nor does one represent a necessarily more 'advanced' stage of capitalism, and there may be iterations between them. Szadkowski (2016) also makes reference to two forms of subsumption described by Marx which are rarely discussed. Hybrid subsumption is, for capitalists, a prefigurative form of capitalisation of an area of production where financialisation or quasi-market activities are used by capitalists to open up areas of production. Ideal subsumption is used, by Marx, to criticise economists who refer to production relations as capitalist when they are not, but Szadkowski (2016, pp.22-3) sees this as potentially referring to the way in which bourgeois conceptions of capitalism are related to all aspects of life. These four forms of subsumption are analytically powerful as they allow us to consider the dynamics of capital and its accumulation in a variegated HE 'industry' (Szadkowski, 2016) which, although it might not be fully in the private sector, is scaling up to the production of a variety of commodities that can be exchanged for money (Sohn-Rethel, 1978, p.130). Similarly rejecting a periodisation, or teleology, of forms of subsumption, Hall and Bowles (2016) refer to 'architectures of subsumption' that reproduce capitalist social relations. Increasing quantification and measurement of research outputs and student satisfaction and obsessions 
with university 'brand' are elements of the subsumption of academic work to the law of value. AI enables real-time performance data on academics to be managed through '...quantification and the internalization of algorithmic regulation' (Hall, 2020, p.125). AI is, therefore, part of the positing of academic labour as abstract labour, prior to its realisation as exchange value through algorithms that relate labour to objective variables such as number of students, research outputs, or knowledge exchange.

Dyer-Whiteford et al (2019) consider that AI additionally brings about a new form of subsumption which they call hyper-subsumption, whereby it becomes part of the 'means of cognition' (Dyer-Whiteford et al, 2019, pp.63-7) as part of the infrastructure or 'grammar' of capitalism. In some senses hyper-subsumption is like real subsumption where the 'general intellect' is mobilised by capital. For capital, cognition is no different from muscle as a concrete labour, and it is not particularly interested in whether machines replace, or act as a multiplier to, workers' arms or brains in realising profit. Hyper-subsumption is also described as being the end-point of a teleological history of forms of subsumption (Dyer-Whiteford et al, 2019, p.51). It could be described as the realisation of capital as thought, or as a thinking machine (Dyer-Whiteford et al, 2019, p.67), but this is remarkably close to accelerationist theories that equate capital with a mechanical materialism (critiqued in Chapter 6). However, hyper-subsumption could usefully be used to describe the end of the current project of capitalism but not the end of capitalism in general with a conscious AI (or more likely a new human/ AI cyborg organism) taking the place of labourers aside from which the conditions of capitalism would be unchanged (as will be discussed in Chapter 6, this is implicit in theories of existential threat of AI, which are largely concerned with how to make AI into labour). This does not only involve the creation of AI of increasing intelligence, but also the subsumption of human processes of thought and reason to capital, a process that is already in motion. Moore (2018) analyses the ways in which AI is used in workplaces to allow for 'All-of-Life Surveillance' of labour. In these processes all aspects of work including the emotional, affective, moods, reactions, and gestures can be quantified, analysed, and controlled (Moore, 2018, p.140). Frischmann and Selinger (2019) detail the ways in which 'techno-social engineering' is currently being used to make human mental processes more amenable to interaction with robots and AI, including potentially the engineering of humans to be incapable of thought and reason. Preston (2017) has additionally detailed the ways in which pedagogy and learning are disappearing as concepts in 'competency based education' which is becoming increasingly common in HE. These tendencies increase the scope of capital to appropriate and control labour power whilst denying it any prefigurative possibilities of resistance. 
The potential of AI in this respect also introduces a 'Stakhanovite' mental labourer which imposes synthetic timing (Sohn-Rethel, 1978) on the labour of academic workers. Synthetic timing is that imposed by the demands of capital rather than specifically scientific management (although it can be masked by such processes and justified post-hoc). Such things have always been part of computation but with AI the synthetic timing of labour, external to the actual time for labour to be performed, becomes more insidious. There is not only a 'human' comparison for the time in which mental tasks should be performed but also an imminent AI comparison which accelerates the downward spiral of SNLT. AI represents the idealised Stakhanovite imminent labourer, able to work at any time and at any speed. To differentiate hyper-subsumption as separate from relative and absolute subsumption, and to avoid teleological explanations of historical progression, it could be described as the replacement of the entire human species by an exact equivalent whilst maintaining the transhistorical categories of labour and capital. This is possibly closer to barbarism than capitalism. As will be discussed in Chapters 5 and 6, forms of hyper-subsumption are a particularly capitalist solution to both the embodiment of labour power (and its resistance) and $\mathrm{AI}$ and existential threat.

\section{From Digital Manufacturing to Digital Higher Education}

$\mathrm{HE}$, in its entirety, is an industry. Capitalism is concerned only with profit and machines, services, and organisational enhancements that are sold to one industry can be sold to another. Conceptual barriers between industries can be dissolved through technologies that employ similar methods to maximise profits. Marketisation and financialisation dissolve the barriers between industries to open them up for exploitation. In manufacturing industries, a contemporary concept is 'manufacturing as a service' whereby manufacturers offer personalised products to a customer, or their commodities as a service, whether that is a consumer at home or another industry. Similarly, service industries increasingly employ Taylorist principles which previously operated in manufacturing. The early manufacturing system of 'piece work', for example, where workers were paid for each product produced, has been reinvented as 'platform capitalism' whereby service providers, such as taxi drivers, are paid for each journey fulfilled in a period of time as practiced by companies such as Uber. As noted earlier, this 'Uberfication' of services has similarly been applied to the operation of Universities (Hall, 2016). $\mathrm{AI}$, as a form of machine that has universal applications across a range of industries, therefore, allows for the control and comparison of different forms of labour both within and across sectors. All industries, including HE are increasingly subject to what Szadkowski (2016) refers to as hybrid subsumption, the potential for all areas to be opened up 
for capitalisation, as well as its absolute and real forms. The growth and increased profitability of what has been called the 'Edutech' sector (being part of the private sector that specialises in educational technologies) is part of this process. Underlying these processes of subsumption is the repurposing of all aspects of labour power as capital, including workers skills and capacities. This is not just for purposes of profitability but is a necessity for the continuation of capital as workers must be consistently appropriated from the means of production and placed and replaced into positions, where they must continuously resell their labour. This involves repeated rounds of primitive accumulation (Bonefeld, 2002) and the continuous enclosure of knowledge production by capital (Canaan, 2019, pp.70-3). Hence, the accumulation of both individual and collective mental, ideational, and emotional properties (Moore, 2018) that might exist outside of capital are stripped from individuals and collective workers, including academics, and AI is a key tool in this process. HE is, unsurprisingly, colonised by $\mathrm{AI}$ and machine learning techniques that are used in other industries.

In manufacturing, the intoxication of what has been called the 'Fourth Industrial Revolution' (Schwab, 2016), Industry 4.0, digital manufacturing or New Industrial Systems (NIS) has been an actively pursued dream of a seamless and frictionless movement of sensuous commodities (or sentient commodities as in Pixarfication, which will be discussed in Chapter 4) in factories where all aspects of the factory, and all external aspects are monitored, controlled, and predicted using tools such as AI, the Internet of Things (IoT), and wireless and mobile technologies. Such factories operate as hermetically sealed information and skill boxes where anything that can be monetarised and capitalised either now or in the future is made into private property. Machine learning, and more sophisticated forms of AI (including AI embedded in machines, production lines, and commodities) is central to the operation of a digital factory. Although digital manufacturing is the latest innovation in capitalist production, it must be remembered that this is just an iteration of capitalism and no different from capitalist forms of production more generally. According to Cole (2021, pp.46-7) Industry 4.0 is a capitalist, anti-democratic, and inequitable ideology that benefits the ruling class. In common with the 'treadmill effect' (Postone, 2003) of capitalist production, its intention is not only the reduction of concrete production times (through falling SNLT and the application of synthetic timing) and the reduction of circulation times (through smart logistics) but in digital manufacturing, the metric of concrete time is altered further in moving from the analog through the digital to the quantum. The 'speeding up' of time in capitalist production is extended beyond the limits of the standard clock measure of time (the second or millisecond) to further finer divisions. Through digital logistics, digital manufacturing leads to a fall in times for distribution by applying digital methods to factories. 


\section{0}

This reduces space for the storage of items and also speeds up circulation times. In terms of use value it leads to the speciation, intelligence, and inversion of products (their Pixarfication, as will be discussed in the next chapter). Commodities are further engineered to secure their own valorisation, and to act back on the labour process to enable profitability. Capital further inverts the human to become the 'organs' of factory machinery using AI in the hollowing out of human skills through digitisation and routinisation (Avis, 2020, pp.52-3). AI can also specify optimal 'fatigue functions' in Industry 4.0 which are measures of human resilience that attempt to ascertain the limits of how hard humans can work. Humans become the conscious linkages of capitalism. Even consciousness implies a human characteristic, but this increasingly becomes a commodified consciousness, or consciousness as fixed capital where the mind/brain can be used as a machine function. As well as decreasing time, and space compression, this converts the worker into the prey of parasitic capital which attempts to remove any individual or collective form of resistance, particularly manifestations of class struggle. Digital manufacturing's push beyond human and mechanic capabilities is a manifestation of what Pitts (2018) refers to, using the work of SohnRethel (1978), as how labour timing does not come about as a result of the application of scientific management (which can be extended to AI techniques), which is a coercive timing but rather becomes a synthetic timing. As explained earlier, this is not interested in the 'time of the act' but removes the act from all of its contents and causalities to be disciplined by the practical abstractions of capital.

In terms of grounding this theorisation in real practices, as part of an empirical project involving observations and interviews considering how knowledge is being used in manufacturing environments (known as 'Chatty Factories'). I considered how digital manufacturing seeks to subsume the potentialities of labour and repurpose this as capital using AI and machine learning techniques. Digital manufacturing uses AI to optimise both in terms of cost functions (to maximise profits) and fatigue functions (to maximise the use of labour by capital in the production process) which, when combined with other data, can become algorithms for profit maximisation. As well as data, such as fatigue functions being employed within individual factories, there is also a sharing of algorithms and results between companies, nations, and industrial sectors (particularly between manufacturing and services). The fatigue function, for example, is developed through the application of AI in different environments which becomes part of a 'behavioural surplus' (Zuboff, 2019). This is a component of the knowledge of the production process, that becomes part of the datum of various capitals which, in turn, determines the labour time required to produce a commodity. This datum may differ from place to place, but as part of the world market with global science and technologies of manufacturing and human factors, 
it eventually becomes a universal that acts back on labour as a determinant of abstract labour. Technology, particularly AI, enables capitalism to gain deeper knowledge of workers physical, mental and social capabilities to increase exploitation and to understand better their capacity for commodity production (Moore, 2018). As discussed above, the digital also becomes part of the time compression of work. Digitisation of various kinds enables one to divide time into successively smaller units to split processes of production and circulation (the 'moments of capital') into fragments of time. With the constant monitoring of workers through digital value chains, exploitation and the degradation of labour accelerates. Capitalism abhors limits and digital manufacturing aims to transcend biological limits in terms of the worker's body in a human form by constantly aiming to extract the maximum surplus value from workers. Taylorism can be seen to be an initial part of this process where '...the fusion of natural-scientific technology and the science of labour must bring about another, far more hideous capitalist monstrosity, because such a fusion eliminates human labor altogether from the immediate process of production' (Kurz, 2014, p.39).

AI facilitates these processes, but in the most developed forms of NIS human skills, movements, and capabilities are deliberately read by an AI that copies, replicates, reproduces, and improves upon these skills. There are several ways that this appears in the real world of capitalist manufacturing and services. Firstly, humans are being used to train robots to replicate their skills and eventually to replicate their jobs. According to a Forbes article (6th May 2015 'The Job of the Future is Training Robots to Work with Humans' - Knapp, 2015), the training of robots by humans is becoming more common in manufacturing. Knapp (2015) explains how conjoint teaching and learning increases the potential of both workers and robots implying that there is a conjoint pedagogical space that enables 'more' to be created (presumably in terms of profits). Similarly, Rayethon's factory in Tuscon, Texas comprises humans and robots that work together but the robots purposively do not arrive at the factory prepared to meet the requirements of production automatically. Rather Rayethon installs software which makes it simpler to 'retrain and retask' the robot. Work tasks are first simulated by humans and then tested by the robots. Once the task is perfected, then it is pushed to all of the robots in the factory. This learning also occurs in terms of how workers move around a factory. General Motors' factory workers and robots learn to work safely around each other. Their collaborative robot, that stacks tires, has been fitted with heightened force sensors that can detect human movement (as 'manufacturing is a contact sport') and humans are provided with training through an 'awareness week'. 'The robot is now considered to be part of the team'. A. Zahner's welding robot learns by watching engineers through copying their movements to weld along an arc. In all of these ways, robots are learning human 


\section{AI and the Subsumption of Academic Labour}

skills to eventually replicate these in the workplace. This not only removes human labour from production and is a manifestation of real subsumption, but it also creates a consistently reduced time for the production of commodities. Secondly, the collaboration between humans and robots is creating systems whereby human skills can only exist in a form where they can only be used if it is in work with certain robots or machines. For example, Hollinger (2016) examines how collaborative robotics (cobots) are changing manufacturing, which means that human labour needs to be restructured and re-engineered to work with these AI-embedded devices. SEW-Eurodrive also uses collaborative robotics. Workers work in 'cells' restocked by robotic trucks, assisted by 'Carmen' the robotic arm and a robotic workbench. Workers need to learn to work alongside cobots and the ability of cobots to produce alongside humans is consistently improved through machine learning and artificial intelligence. Robotic arms can be programmed without coding by humans moving them and hence they learn to replicate the movements of workers by repeating those movements. This is not restricted to multinationals and SMEs (Small and Medium Enterprises) may also use cobots (cooperative robots). Stenner-Pump uses a cobot (Baxter) in production to feed parts in both the manufacturing and packaging process. However, they are more commonly used by large corporations. Airbus is testing a system where humans can 'pilot' a cobot and testing a system where a robot on wheels will point out where humans need to drill holes. Mercedes-Benz has replaced some robots with humans, as they are less agile and humans are quicker to 'reprogram' themselves when faced with novel problems. Shah (2016) states that we are reaching an 'inflection point' in terms of how humans and robots work together. She claims that:

Roboticists are starting to reverse-engineer the human mind by translating the cognitive models that humans use intuitively into computational models that machines can use. With this approach, robots and humans working in pairs have been able to accomplish complex tasks as well or better than human teams.

Shah's team at MIT are working on software that allows robots to infer tasks from observing human teams and analysing their decisions to arrive at a strategy. In defence and healthcare robots could learn through expert human demonstrations. Again robots are considered to be working with humans, but companies are interested in gaining skills from humans:

Robots will truly be at our service, ready, willing, and able to learn from watching us. They will work shoulder-to-shoulder on assembly lines, in hospitals, and on the front lines of emergency response. The 
awkward robots of the past will be replaced by valued members of the team.

(Shah, 2016, my italics)

Nichols (2015) gives the example of a robot that is learning to crack eggs by watching videos on YouTube. The researchers in this project consider that 'Our ultimate goal is to build a self-learning robot that is able to enrich its knowledge about fine grained manipulation actions by watching demo videos'. Studies such as this are used to argue that self-learning robots could revolutionise manufacturing and meta-data from these robot/human hybrids can be used in wider networks. For example, researchers at Lappeenranta University of Technology (LUT) have developed a self-adjusting welding system that uses a neural net to correct welding mistakes and improve its performance. The FRAME project at the University of Nottingham aimed to construct a 'fully automated, self-learning and self-aware production system'. Despite these attempts to 'strip skills' from humans, it may be difficult to automate all areas of human skill formation. Chui et al (2016) in a report for McKinsey consider that education is the most difficult area of production to automate. Speculatively this could be the reason that robot/human pedagogy and learning is an area that is mainly being developed in manufacturing. There are also forms of pedagogy, where there are no shared human/ AI domains and the robots and humans must learn to work around each other or where the pedagogy of the other is unknown and perhaps unknowable. Researchers are aiming for rudimentary forms of pedagogical presence, in terms of the robot sensing how the human learns, and adaptation in terms of how to work around the human (through force sensors). There are also forms of learning where the human can bank learning inside a cobot through modelling the desired behaviour either visually or by moving the cobots arm or other feature so that it can reproduce a particular movement. Robots and AI do not have to learn through the actions or thoughts of an individual, they can analyse the learning of a team. In this way there is a distillation of learning in terms of a many-into-one process. This is a change of scale in terms of skills, the separate learning processes of a team are synthesised into one process by an AI. This concentration of labour is similar to the concentration of physical labour by a machine. In other pedagogical work, the robot occupies its own pedagogical space, learning to do tasks through the use of a neural net or other types of machine learning. Hence skills are relocated from something that exists within the individual human ('human capital') and into a collective, shared intellect, but an intellect that is owned by a private corporation.

There are many ways in which robots and AI are 'stripping skills' from workers in manufacturing, but there is nothing teleological about the future of robotics and AI. Robots and AI are produced not for 
deterministic reasons (in terms of removing skills from humans) but so they can produce relative surplus value, in terms of soaking up additional labour, and hence profit. In observations from the 'Chatty Factories' project, some specialist areas of production did involve constructing anthropocentric robots, but usually the future of robotics is aimed at producing robot 'bodies' suitable for capital, involving robots that can extend to various spatial dimensions rather than those that can conduct complex forms of learning and engagement with humans. Innovations in this area include drones capable of heavy lifting; drones that can print using construction materials (such as tarmac for roads); robots that can print other robots using 3D printing, with capabilities for the 3D printing of metal; robots that can extend upwards (from a solid wheeled base) for up to 20 metres; animal robots (of the Boston Dynamics type); and small robots for pipework; robots that can fold themselves so that they can post themselves through letterboxes (or through small holes) and reassemble themselves; and drones that carry small-wheeled vehicles. In all cases, profit, pragmatism and cost is the reason for the construction of these robots as specific tools that allow machinery to transcend the current limits of time and space (whilst often requiring human labour as part of the function). The specificity of such robots to the requirements of capitalism in terms of repairing infrastructure or surveillance is also apparent. The requirement for AI, or even machine learning, in these robots is sometimes minimal. It is not necessary to produce forms of consciousness when simple machine learning can lead to increased profit. As already stated, robots, AI, and algorithms do not impart any additional value to a product by being like humans (only that which was embedded in them from their construction and that is transferred to the product, all other things being equal) but may increase relative surplus value. Hence the stripping of worker's skills in current capitalism is a tendency of capitalist production, but one that might be reversed if there was conceived to be the potential for profit elsewhere.

Although HE is often considered to be very different from manufacturing, remarkably similar processes as in 'digital manufacturing' are being employed to repurpose worker's capacities to naturalise them as part of capital. In HE, a similar subsumption takes place - '...capital enforces human-machine interaction as a means to parasitize labour... The reconditioning of this machinery is important for the widening circuit of alienation that reproduces exploitation' (Hall, 2020, p.128, referencing Wendling, 2009, p.100). HE is to an increasing extent a form of manufacturing of educational commodities. As discussed earlier, the commodity produced in HE is often determined by a statistical return to government where Universities are not private or operate using a quasi-market. Therefore, academic labour is often an intermediate part of the production of a 'final commodity' which is akin to a large manufactured item. For example, in terms of obtaining funding for a student, 
this is often the product of the final result of an algorithm (or algorithms) that can include the student's completion of their degree, their employment after their degree, and their satisfaction with their degree (in the UK these are all part of what determines University funding in 2020). Hence in terms of the production of the final commodity, each individual concrete manifestation of academic labour provides a partial and fragmentary portion of what will eventually become the commodity that is valorised. The lecture, or course of lectures provided, the personal tutor session, and the e-mail feedback on an essay in the early hours are all intermediate parts of the production of the final commodity prior to its valorisation (normally through a funding or statistical return for money). This also includes the administrative and professional services labour to 'produce' this final commodity. As stated previously, Marx (1992a, p.215) refers to intermediate components of commodities as 'commodity stock', and academic labour involves adding to this stock by activities that will eventually see this already abstract labour valorised as money. Every word spoken in a lecture or written in an article (as long as it is performed with the average level of skill and at or below the SNLT) becomes commensurable for money even though it exists for a time as 'commodity stock' before becoming a commodity for valorisation. Although the conception of 'student as consumer' is unfortunately correct, the students themselves are just a vector for the passing through of 'commodity stock' which is realised in terms of payment of fees or valorisation of various outcomes (student experience, their employment, continuation or acquiring a degree). The student's co-operation in the process of commodity production for the University is a 'force of nature' (in that they want to acquire a degree or find a job).

A report for the University and College Union (UCU, 2020) considers several ways in which AI is being employed in the contemporary University which are remarkably similar to the types of AI applications that are used in manufacturing. As well as the automation of tasks and the speeding up of work, datafication and AI is part of how the 'many functions, practices and tasks of $\mathrm{HE}$ are being rendered "machine readable" as digital information' (UCU, 2020, p.6) which means that the work of academics becomes subsumed by capital in a form ready for data analytics, machine learning, interrogation and control and where, in some cases, AI can take autonomous actions to intervene in the labour process. AI learns what academics do, not necessarily in terms of learning to write an article or teach a student (although that could be on the horizon) but learning how to maximise the return on the university investment. The abstract nature of commodity production posits the labour of academics as abstract in terms of emphasising activities that are 'readable' in the production of value. This means that the concrete labour of academics (the text in which an article appears or the words spoken in a lecture), unproductive labour (work that is performed below the average level of 
skill, a lecture provided free to the community with no commodifiable benefit, or an article that is written for free in a political newspaper), and work that is of no 'value' (a book that takes decades to produce that is not valorised by the University) is considered to be useless if it does not fit the funding algorithm. Universities increasingly become 'data universities' with 'quantitative control' (UCU, 2020, p.3) of academic outputs and labour. Universities can then be 'unbundled' into different areas of commodity production which can be subject to data analysis, performance indicators, and 'digital dashboards', the provision of which is often farmed out by Universities to private companies (UCU, 2020, p.10). This allows for the production of what was referred to earlier as the 'behavioural surplus' (Zuboff, 2019) as the knowledge obtained is used to improve algorithms, provide training sets for machine learning, and develop increasingly advanced forms of AI. Hence the measurement of academic labour is used to develop fixed capital worldwide, as another form of real subsumption in a networked 'smart campus' (UCU, 2020) which is analogous to 'digital manufacture'. At the national level, in the UK, national level data infrastructures have been developed to measure institutional performance which can be reported on using data dashboards. UCU (2020) and De Angelis and Harvie (2009) analyse the process through which the 'immaterial labour' of academics is made commensurable through measuring academic commodity production (or at least the production of intermediate commodities) and through driving down the SNLT (De Angelis and Harvie, 2009). This process is both synchronic (equating labours) and diachronic (pushing down SNLT) and operates within institutions, in nation states, and across nation states and sectors. AI is a concrete example of the process that De Angelis and Harvie (2009) describe in terms of applying machine learning to workload models, hence accelerating processes of subsumption.

The increasing technological sophistication of AI means that it is possible to gain knowledge of individual and collective labour processes, in a form similar to manufacturing, but we must be careful not to mystify AI as omniscient and omnipotent. For capitalism, synthetic timing (Sohn-Rethel, 1978, p.155) rather than scientific notions of timing, being how long a job should take (to be profitable) rather than how long it could take (given a scientific analysis of its components) is a necessary feature of capitalist production. Like all technologies, AI is part of the compulsion for workers to work harder and faster, and to that extent it does not matter if an AI has any scientific basis, if it can be used as an element of synthetic timing. The notion of unrealistic targets in academia (in terms of producing journal articles, teaching classes, or gaining funding) that might have a material basis as the 'real' measure of production (how fast it is possible to work) is forever subordinated to the 'synthetic' measure of production (how fast it is necessary to work in the capitalist university). In this way, the application of 'Industry 4.0' 
and 'digital manufacturing' techniques to HE are a manifestation of the despotism of capital rather than scientific progress.

\section{The Hyper-Subsumption of Collective Academic Labour by AI: Social Brain and General Intellect}

As previously discussed, Dyer-Whiteford et al (2019) consider hypersubsumption to be a recent form of subsumption involving AI, robotics, and post-human forms of labour. This extension of subsumption is helpful but somewhat teleological and it does not transform real subsumption in any meaningful way other than accelerating the law of value within, and extending it across, existing and new industries. Workers are constantly subsumed by the physical manifestation of capital of different sorts including mechanical looms, production lines, and computer terminals. However, hyper-subsumption could also refer to the complete replacement of human workers with AI entities and this might occur in HE in terms of the hyper-subsumption of collective academic labour or the '...total replacement of the subjectivity of a human labour power' (Sohn-Rethel, 1978, p.173). Note that for this to occur, it would involve the primitive accumulation of AI labour as wage labour (which is implicit in work on the existential threat of AI, as explained in Chapter 6 that can only conceive a viable form of AI existing as a form of wage labour) and its relative and real subsumption by capital to become value production. This could also involve, perhaps in its preliminary phase, the replication of human labour through digital human twins which we can already see, in essence, in terms of the online lecture and seminar which is replicated beyond the normal working day (see Chapter 5). Concepts used by Marx such as the 'social brain' and the 'General Intellect' allow us to interrogate not only the liberatory, but also the subsuming tendencies of collective human, and artificial, intelligences. Hyper-subsumption can be usefully connected with the 'social brain' and 'general intellect' (which are frequently used as liberatory concepts, particularly in recent work on 'Fully Automated Luxury Communism', as discussed in Chapter 7) to show how AI is subsuming present, and future, collective, academic labour.

Marx's critique of capitalism is bleakly transhumanist. Capitalism not only fundamentally transforms the nature of work and the mode of existence of the worker but also the nature of the capitalist and humanity in general. Money, as the objectified form of alienated labour, becomes human capacities. Marx (1992b, p.377) considers how human capabilities, what 'am I', becomes money. What were human capacities such as strength, beauty, mobility, and moral 'goodness' become not just properties of money. Money is human capacity, and human essence in capitalism is and is not just enabled by money or purchased by money. Marx describes mind as money: 
I am mindless, but if money is the true mind of all things, how can its owner be mindless? What is more, he can buy clever people for himself, and is not he who has power over clever people cleverer than them?

$$
\text { (Marx, 1992b, p.377) }
$$

Mind cannot entirely become a commodity now, but money itself is the 'true mind' of things. A Marxist version of transhumanism is that money becomes all of the properties of the human and (within capitalism) the objectification of all human capacities. Of course, in the more mature Marx, money is the objectified form of abstract labour power as entirely alienated labour. Money acts as the universal agent of 'separation' and 'cementing' in capitalist society - 'It is the chemical power of society' (Marx, 1992b, p.377). Money operates as a 'singularity' in terms of the objectification of abstract labour power and the turning of this against humanity as an alien power. In contrast, humble $\mathrm{AI}$ is a mere machine and a fixed asset, but it also represents the capitalist fantasy of the purchase of mind, not just human minds which can only be hired on a temporal basis as labour power for a wage, but an artificial mind as a commodity and asset. Despite AI not meeting the earlier promise of becoming an artificial consciousness, it remains a fantasy within capitalism that consciousness can be sold and purchased. Capitalism does not require 'human brains' as such (although if elements of brain tissue or product from humans or animals can be commodified or sold, capitalism will find a way), but the labour power that is part of personhood which is not necessarily associated with any particular organ. Capitalism needs some element of human consciousness which, in terms of intent and imagination, is a fundamental property of labour power, which allows capital to appropriate the individual and collective powers of labour (Braverman, 1998, pp.34-5). In contrast, AI might be nothing like a human brain or mind but could function as an amalgam of learning entities that seems to simulate a mind. According to Hall (2018, pp.108-9) (after Marx, 1993)'...capital soaks up or takes in the knowledge skills and capabilities' of what Marx called the 'social brain'. In HE this might include '...performance management through learning analytics and data mining' and 'extending the management of networks' as well as methods of cybernetic control (Hall, 2018, p.112). In this way, collective knowledge about academics as workers, and academic work, becomes part of the 'social brain' of capital. Sohn-Rethel (1978) considers that the very idea of 'mind' and 'mental labour' in capitalism is necessary to maintain the real abstraction of the exchange relation which takes place in abstract time and space (Sohn-Rethel, 1978, p.48). Commodities transfer ownership for money in empty, abstract space and in instantaneous, empty time (Sohn-Rethel, 1978, p.53). Although these concepts may exist in human minds, they do not arise from the mind, rather from a real 
abstraction of commodity exchange. Hence the 'social brain' of AI is not just the product of accumulated worker knowledge. It is also one of the sites of abstract thought (in this case symbolic manipulation) that makes possible the social synthesis of capitalism. For example, teaching students can happen in all sorts of different times and places in a university involving many collective hours of teaching. Paying for tuition (by the state or private individuals) is a transfer of funds for a commodity that takes place in an instant. That real time of teaching can be turned into an infinitesimal time of commodity exchange requires abstract thought (as it is, in practice, a real abstraction). Computation, machine learning, and AI allow 'thought about abstract thought' in terms of how best to count, compare, and optimise actual hours of teaching in terms of their profitability.

The concept of a privately owned social brain, or a 'commodified mind' (Artificial General Intelligence, or AGI) in HE, or other industries, is also appealing to capitalists as it appears to resolve two inherent contradictions of capitalism. Firstly, the intractability of consciousness in the labourer. Capitalists would love to map the entire capacity of the human for exploitation, including their mental resilience. They can't fully control consciousness as such because they need the intentionality and creativity of individual and collective labour to constantly increase productivity. An AI that destroyed human consciousness (in the sense useful to capitalists) needs itself to be conscious (in the sense useful to capitalists), so that it could become the source of a new round of primitive accumulation in capitalism (otherwise that would be the end of capitalism). Capitalism has to create its own 'gravediggers' whether that is humans or AI. Secondly, every action that capitalists take desubstantialises labour further and makes the production of value even more ephemeral. Capitalists believe that a mind external to capitalism would enable a cool perspective on its own existential threat (see Chapter 6). A mind external to capitalism might be able to think its way out of the existential threats of capitalism in a way that capitalists are unable to do so. In some ways, capitalism has already produced its own 'mind' seemingly external to itself without AI (the theory and praxis of communism), which it has to consistently reject or it would not remain as capitalism. Capitalists would prefer a godlike AI telling them what to do rather than releasing power to the working class.

In conjunction with the idea of a 'social brain', in the section in the Grundrisse which is sometimes called 'The Fragment on Machines' (which is the latter section of Marx's notes for 'The Chapter on Capital' Notebooks VI and VII, Marx, 1993), Marx considers the concept of the General Intellect. From the outset by its nature the fragment, is only that - notes and fragmentary thinking - and to search for some particularistic hidden meaning without the other works of Marx privileges speculation and 'Marxology'. The earlier sections of the notebook, in particular, are 
cautious on the role of machines in capitalism. Firstly, Marx considers that the development of machinery and technology is part of the more general development of capitalist competition which operates incrementally and tentatively, especially in its initial phases (Marx, 1993, p.560) and where the development of the 'constancy' of fixed capital requires the ready supply of appropriate labour (Marx, 1993, p.563). Secondly, although science in capitalism is the collective power of labour, this is also true of all other manifestations of capitalist society (including the division of labour and the social powers of production) which subsequently appear to be powers of capital (Marx, 1993, p.585). Thirdly, capital usually exists in a form that there are many workers to one capital (although one can imagine a future form of capitalism with a single AI labourer selling its labour to many capitalists). Therefore, in the lead in to the 'Fragment on Machines', Marx does not appear to be deviating from ideas on machinery that would appear in his later work. There is no conceptual break in his theory of machinery (other than it meets the uses of capital), all natural and scientific attributes are assumed to be properties of capital and (although this is not a necessary condition) there are many workers available as a ratio to each capital. Similarly, the 'Fragment on Machines' (Marx, 1993, pp.690-95) begins by restating the point that the materiality of capitalist production is '...only a mean of production for capital, for which value alone is an end in itself' (Marx, 1993, p.690). It is not that human labour becomes superfluous in the automatic system of production that Marx proposes, but rather that it becomes metamorphosised into becoming 'conscious linkages' of machinery which are 'scattered' amongst it as a 'living accessory' with its 'insignificant doings' (Marx, 1993, p.693). This is a transmutation of both humanity and machinery but by no means distinct from the real subsumption of labour. In a later section (Notebook VII), Marx considers that a situation could exist that '...depends less on labour time and on the amount of labour employed than on the power of the agencies set in motion during labour time' (Marx, 1993, p.704) including science and technology. This, too, is little different from real subsumption as the 'amount of labour employed' usually becomes less significant in the generation of value as the productivity of labour and technology increases in any case. Similarly, the 'agencies set in motion during labour time' are still part of the working day. Particularly for academics (as a sub-class of knowledge workers), science produced in the working day becomes a property of the university. A real change only appears when it is the 'appropriation' of the worker's cumulative knowledge (rather than labour power as such) that becomes the foundation of wealth (Marx, 1993, p.705). This 'general intellect' might prefigure a different society but not due purely to 'science' or 'technology' as an appropriated form of cumulative knowledge but '....also the immediate organs of social practices, of real life processes' (Marx, 1993, p.706). Based on this reading, 
automation, technology and science (including AI) do not by any means represent a certain break with capitalism no matter what their level of advancement. Being a 'conscious linkage', a 'living accessory' engaged in 'insignificant doings' is a fair description of the current subsumption of academic labour by technology. Moreover, science and technology are (and can be) appropriated by capital, and the general intellect relates as much to '...social practices, of real life processes' that can 'blow this foundation sky-high' (Marx, 1993, p.706) as it does science. Before that happens, capital may tire of humanity (but never of labour power) as an entity and this is a better categorisation of what Dyer-Whiteford et al call hyper-subsumption than a technologically sophisticated form of 'real subsumption'. As will be explained below, collective academic labour is an important component of this hyper-subsumption but before turning to this, it is important to consider that the General Intellect is not an inevitable or decisive feature of the trajectories of capitalism and class.

Hardt and Negri, whose research is related to the postoperaismo school of Marxism, consider that immaterial labour (including academic labour), the development of the General Intellect and advanced technologies such as AI and computer networks have led to a break with traditional Marxist notions of value and class struggle. Hardt and Negri (2000, pp.364-65) claim that we are living in the time of the General Intellect, but this is not just intellectual but also affective and corporal where '... biopower becomes directly productive' (Hardt and Negri, 2000, p.364). The productive capacity of society becomes a property of the 'multitude' (Hardt and Negri, 2000; Hardt and Negri, 2005) who possess a networked and commons-based form of productive capacity (Hardt and Negri, 2005, pp.189-227) that replaces traditional class antagonisms diffusing them into '...the discontinuity and dispersion of the dynamic elements of production...' (Negri, 2018, p.47). In this conception of the dispersion of productive powers and the 'General Intellect', it is implied that immaterial labour means that work and its products can elude measurement (Pitts, 2018, p.148) and rather than the working class, the unit of analysis becomes the 'socialized worker'. The factory becomes diffused into society as '...capital suffuses the entire form of life' (Dyer-Whiteford, 1999, p.81), undefinable labours produce society, and class struggle is dissolved into a variety of locations and struggles. The diffusion of technical knowledge and expertise produces a 'generalised form of labour power' (Dyer-Whiteford, 1999, p.84) where capital 'must appropriate the communicative capacity of the labor force' (DyerWhiteford, 1999, p.85).

Although some postoperaismo thinkers have developed Marx's notion of the General Intellect into an anthropic concept, which applies to the collective cognition and knowledge of human workers others consider the AI and networked components of this form. Griziotti (2019) 
considers that we are seeing the 'digital production' of the General Intellect (Griziotti, 2019, p.19) where '...intelligence becomes a protagonist in this revolution' (Griziotti, 2019, p.20). Griziotti sees bio-cognitive capitalism as focussing on the prosumer '...constantly looking for income through information about behaviour, emotions and the life of the prosumer in general' (Griziotti, 2019, p.61). Cellphones are seen as a biopolitical device, making use of bio-hypermedia, a fusion of biological and technical networks (Griziotti, 2019, pp.107-18). A digital, generalised commons, therefore, becomes a new area for political activity. Dyer-Whiteford (1999) also draws on autonomist and open Marxism where class struggle will ultimately be realised in terms of a 'contest for general intellect' (Dyer-Whiteford, 1999, p.14).

Pitts (2018) summarises postoperaismo as a shift from material to immaterial labour, from the factory to the social factory, and from the supposedly 'workerist' (caricatured white, male, working class) subject of class struggle to that of the 'Multitude' with diffuse and collectively organised labour as collective sets of linked singularities. The immaterial labour of the multitude drives capitalism in a reciprocal and simultaneous fashion (Pitts, 2018, p.143), that is, in an affirmative direction rather than a negative and conflictual manner. This leads to a conclusion that '...liberation is possible in the present state of things. Where humans emancipate themselves the world follows. However, this is opposed to a picture whereby humans emancipate themselves by abolishing the state of things' (Pitts, 2018, p.144, my italics). According to Pitts (2018), the argument of Hardt and Negri is illusionary as both material and immaterial labour's abstract nature means that neither has a real source of measure (only in retrospect are these socially valorised in exchange). It is not that the 'labour theory of value' has been challenged as the challenge disregards the qualitative nature of value and social form (Pitts, 2018, p.200). Furthermore, in capitalism there is no affirmative, single, 'social substance' that unites labour and capital rather these are in conflict by definition. There is no lasting 'creativity' in capitalism, and the things that we create come to objectively dominate us:

...the desire to be creative in capitalist society can be fulfilled in commodity society only through waged commercial work, contrary to the pleasurable use of skill and through the value relation it generates depends on all the same, even while denying it and stifling it. There is no simple identity between capitalist power and human practice. It is a broken mirror, full of contradiction.

(Pitts, 2018, p.159)

Rapid technological change has led to contemporary Marxist theorists considering new ways in which the General Intellect might be formed using AI and other digital infrastructures. Dyer-Whiteford et al (2019, 
p.31) propose the term 'means of cognition' to refer to the AI infrastructure but distinguish this from postoperaismo notions of cognitive capitalism. The 'means of cognition' are not the capacities of the multitude but are the appropriated cognitive capacities of humans either as the property of individual capitals or as the general conditions of production useable by all capitalists (Dyer Whiteford et al, 2019, p.46). Even if there is such a thing as an emerging General Intellect, this can be privatised and be made into a 'private intellect'. As explained in the previous section, skills can be 'scraped' by fixed capital and (as explained in the next chapter) pedagogy is becoming increasingly irrelevant to capitalism as the location of learning is displaced and fetishised as it is moved from workers to commodities. Through mechanisms of surveillance capitalism and the quantification of labour at work (and in other spheres), knowledge and skills can be ascribed as entities that are no longer owned by individuals. One perspective (Žižek, 2019) is that this knowledge becomes a source of rent for capitalists. Žižek (2019) sees an absence in Marx's consideration of the general intellect:

As a result of his neglect of the social dimension of the 'general intellect' - which is roughly the collective intelligence of a society - Marx didn't realise the possibility of privatising general intellect itself but this is what lies at the core of the struggle for 'intellectual property'. (Žižek, 2019, p.8)

In terms of the physical manifestation of capital in machinery such as AI, Lotz (2014, pp.121-30) also considers the totalising nature of capital which '...enables capital to access the human mind and human capabilities, but also to produce those capabilities' (p.125). A form of General Intellect could, therefore, exist in a system of AI. Lotz also considers increases in speed of communication and the affective possibilities of machinery which brings about the possibility of no spontaneity in human agency as communication is produced 'in advance' and the libido is orientated towards money by destroying the 'attentive systems of citizens' (Lotz, 2014, p.126). Cybernetic capitalism could, according to Dyer-Whiteford et al (2019), bring about a new mode of subsumption where AI controls work and production. AI-Capital would become part of the infrastructure that enables capitalist production through such mechanisms as the smart city, the internet of things (IoT), and AI. Cognition is not necessarily anthropic (Dyer-Whiteford et al, 2019, p.63), and this point is similar to Marx's original formulation of the General Intellect as operating through, and being embedded in, machinery (Dyer-Whiteford et al, 2019, p.63). In doing this, Marx distinguishes between the (mechanic) 'general intellect' and the (anthropic) 'social brain' (Dyer-Whiteford et al, 2019, pp.63-4). Warnings concerning an AI superintelligence also consider the concept of a 'collective 
superintelligence' that transcends human intelligence through a system that is '...educated, digitally connected, and integrated into global intellectual culture...' alongside an internet that 'wakes up' (Bostrom, 2014, pp.48-9).

To summarise, it is quite plausible that the 'General Intellect' would be a private property that is completely embedded in machinery (AI) which capitalists see as eventually become a new labouring subject of capitalism. At present, there are national projects for AI superintelligence and quantum supremacy which involves academic labour in national and corporate efforts involving '...the increased number of private, global companies seeking profit and data harvesting from universities, potentially impacting on the nature of universities themselves and their purpose' (UCU, 2020, p.3). In this way academic labour and universities are complicit in the continuity of capitalism, but not necessarily an anthropic version of this. Rather than a relationship between persons, knowledge, skills and machines where human science is progressing, we move into a time of the stripping of skills, but this is also a depedagogisation as part of subsumption as the work of academics becomes less concerned with pedagogy and more with profit. As will be discussed in the next chapter, agency moves from individuals to machines and commodities (Pixarfication). This privatised General Intellect may present itself as the new commons but one that is accessible only to capital. The privatised General Intellect foreshadows the removal of educated humanity (including academic labour) from the stage of human history and heralds the arrival of a potential new labouring subject: AI. Indeed, the idea of learning and pedagogy is disappearing under capitalism, and new models of learning are not emerging in practice as humans become 'conscious linkages' (but still conscious), 'attendant labourers', or 'social labour' in the narrowest sense (social in that only workers can work in conjunction with capitalist processes). Frischmann and Selinger (2019) detail processes through which human thought and reason are being manipulated, or even nullified, to make us more amenable to interactions with AI and robots. An example of how this is manifesting itself in $\mathrm{HE}$ is through an increased emphasis on mechanic systems of learning such as Competence Based Education and Training (CBET). As I have discussed in previous work (Preston, 2017), capitalism tends to support forms of pedagogy (which are really forms of non-pedagogy) that are optimal for the production of surplus value through increasing worker productivity and exploitation. The competence movement, which sets behavioural and binary outcomes for skills allows capitalists to specify exactly what workers should do without reference to any internal learning processes. In competence-based systems, the whole idea of pedagogy and knowledge disappears as all that matters is outcome. This results in the full subsumption of the worker who becomes a 'conscious linkage' not only to the process of production but also to their own skill 
formation. Skills become something that 'pass through' the worker to $\mathrm{AI}$ and evidence themselves in the workers' labour without being mediated by mind, knowledge, or any other conscious process of the worker. The behavioural nature of competence-based qualifications means that all that matters is behaviour. This means that the worker exists as a non-conscious monstrosity in a process of 'skill display', a formation of skills that does not involve them as a conscious, human, being. As there is no requirement, or theory, of 'learning process' in competence-based education then the learner/worker is treated as a conduit to deliver the skill process required by the capitalist. These 'skill conduits' are combined in ways to optimise capitalist production. Hence there is no pedagogy involved in the process of skill acquisition (which is more like temporary skill attachment before human capacities are moved to AI). Competence-based education is part of what we might call the pedagogical singularity in HE referring to the collapse of pedagogy into a single mode of human (or anti-human) teaching and learning.

\section{Conclusion: Human Failure and Academic Labour}

In this chapter, I have considered academic labour as a form of labour power no different to that which is the tragic foundation of capital more generally. I also considered how AI in HE facilities primitive accumulation, subsumption, and the fantasy of hyper-subsumption in the continuity of capitalism without a human subject (a topic that I will return to in Chapter 6). To return to the argument made earlier in the chapter, academic labour takes place in conditions of class struggle and as well as being capital it continually glitches, fails, and resists in this process. These failures are opportunities. AI is not just a neutral form of joyful machinery but a form of capitalist violence in that labour power needs to be extracted through a conscious, visceral subject, and subsumed through the reality of capitalist production (real subsumption) as value, and $\mathrm{AI}$ is a growing part of this process.

However, the possibility of what capitalists might see as the 'human failure' of academic labour, even with sophisticated AI methods of control, is part of its existence in class-struggle. This can be expressed in two ways in terms of academic labour. Firstly, in the constant drive of capitalism to enhance labour power, there are inevitably spontaneous and conscious resistances. Inhuman and infinitely expanding capitalism meets with the concrete barriers of human existence and labour:

In contemporary capitalism there is a social drive to enhance the quality of human labour power. This social drive, like all of capital's social drives is infinite. It would not make any logical sense within the perverted social universe of capital to suggest any real limit on the basis of the functioning of the system itself. However, in similar 
fashion to absolute surplus value production, the infinite social drive to enhance the quality of human labour power clashes with a number of practical considerations. First, labour power development depends on co-operation - which expresses itself in the 'problem of motivation', an individual willingness to aid development of one's own labour power. Secondly, when pushed too far we witness 'the humans are dropping like flies': humans buckling under as they are subjected to concrete (and hence necessarily limited) manifestations of an infinite social drive. Thus: depression (with no terminal point to 'improvement'); various forms of stress and ill health; and so on. Thirdly, people may protest and effectively revolt against an impersonal social drive 'manifesting' itself as concrete social practice. Fourthly, those generating these social practices are only human, all too human...As capitalised life-forms, the designers of concrete schemes that seek to nurture a social drive that is infinite can do this precisely because they have some affinity with these social practices that express capital's social drives. Fifthly, as "we" are capital too, we can aesthetically and logically 'appreciate' the concrete expressions of infinite social drives, whilst also being able to see the contradiction involved. This contradiction is the notion that an infinite social drive can be concretely expressed. The prospect is absurd, as it assumes infinite resources, time, labour (of a quality that is not just good but infinitely good) and effort (beyond all limits) to activate and effect the infinite social drive.

(Rikowski, 2000, pp.10-11, my italics)

Secondly, that the General Intellect does not inevitably represent the collectivisation of scientific knowledge (which is easily privatised and mechanised) but also represents the collective power and resistance of the working class. Neary $(2019$, p.50) states that 'Marx uses the concept of the general intellect as a way of capturing the possibility for social emancipation through the social power of the knowledge of humanity'. This is for every individual and for society as a democratic, communal pool of knowledge that can be used for revolutionary purposes. This means that academic labour, whether subject to AI or other forms of automation or not, both creates and confounds capital in every second of its being. It can also create concrete and realistic alternatives to capitalism and the capitalist university, a topic that I will return to in Chapter 7.

\section{References}

Avis, J. (2020). Vocational Education in the Fourth Industrial Revolution. Education and Employment in a Post-Work Age. Abingdon: Palgrave.

Bonefeld, W. (2002). History and Social Constitution: Primitive Accumulation Is Not Primitive. The Commoner, March 2002, pp. 1-8. 
Braverman, H. (1998). Labor and Monopoly Capital. New York: Monthly Review Press.

Bostrom, N. (2014). Superintelligence: Paths, Dangers, Strategies. Oxford: Oxford University Press.

Canaan, J. (2019). The (Im)Possibility of Mass Intellectuality: Viewing Mass Intellectuality through the Lens of the Brazilian Landless Movement. In: R. Hall and J. Winn. (Eds.). Mass Intellectuality and Democratic Leadership in Higher Education. London: Bloomsbury.

Chui, M. et al (2016). Where Machines Could Replace Humans-and Where They Can't (Yet), McKinsey Quarterly, July 2016, https://www.mckinsey. com/business-functions/digital-mckinsey/our-insights/where-machines-couldreplace-humans-and-where-they-cant-yet.

Cleaver, H. (1979). Reading Capital Politically. Austin: University of Texas Press. ISBN 978-0292770157.

Cole, M. (2021). Climate Change, the Fourth Industrial Revolution and Public Pedagogies. London: Routledge.

De Angelis, M. (1995). Beyond the Technological and Social Paradigms: A Political Reading of Abstract Labour as the Substance of Value. Capital \& Class, 57, pp. 107-134.

De Angelis, M. and Harvie, D. (2009). 'Cognitive Capitalism' and the Rat Race: How Capital Measures Immaterial Labour in British Universities. Historical Materialism, 17 (3), pp. 3-30.

Dyer-Whiteford, N. (1999). Cyber-Marx: Cycles and Circuits of Struggle in High Technology Capitalism. Urbana, Chicago: University of Illinois Press.

Dyer-Whiteford, N., Kjøsen, A. and Steinhoff, J. (2019). Inhuman Power: Artificial Intelligence and the Future of Capitalism. London: Pluto Press.

Elson, D. (2015). The Value Theory of Labour. In: D. Elson. (Ed.). Value: The Representation of Labour in Capital. London: Verso, pp. 115-80.

Frischmann, B. and Selinger, E. (2019). Re-Engineering Humanity. Cambridge: Cambridge University Press.

Griziotti, G. (2019). Neurocapitalism: Technological Mediation and Vanishing Lines. Colchester: Minor Compositions.

Hall, G. (2016). The Uberfication of Higher Education. Minneapolis: University of Minnesota Press.

Hall, R. (2018). The Alienated Academic: The Struggle for Autonomy inside the University. London: Palgrave.

Hall, R. (2020). Platform Discontent against the University. In: M. Stocchetti. (Ed.). The Digital Age and Its Discontents: Critical Reflections in Education. Helsinki: Helsinki University Press, p. 123.

Hall, R. and Bowles, K. (2016). Re-Engineering Higher Education: The Subsumption of Academic Labour and the Exploitation of Anxiety. Workplace, 28 , pp. 30-47.

Hardt, M. and Negri, A. (2000). Empire. Harvard, Mass: Harvard University Press.

Hardt, M. and Negri, A. (2005). Multitude. London: Penguin.

Hollinger, P. (2016). Meet the Cobots: Humans and Robots Together on the Factory Floor, National Geographic, May $6^{\text {th }} 2016$, https://news.national geographic.com/2016/05/financial-times-meet-the-cobots-humans-robotsfactories/\#close. 
Kicillof, A. and Starosta, G. (2007). Value Form and Class Struggle: A Critique of the Autonomist Theory of Value. Capital \& Class, 31 (2), pp. 13-40.

Knapp, A. (2015). The Job of the Future is Training Robots to Work with Humans. Forbes Magazine, $6^{\text {th }}$ May.https://www.forbes.com/sites/alexknapp/2015/05/06/ how-businesses-are-teaching-robots-new-tricks/\#3eb2b9a82859.

Kurz, R. (2014). The Crisis of Exchange Value: Science as a Productive Force, Productive Labour and Capitalist Reproduction. In: N. Larsen, M. Nilges, J. Robinson and N. Brown. (Eds.). Marxism and the Critique of Value. Chicago: MCM' publishing, pp. 17-76.

Lotz, C. (2014). The Capitalist Schema. London: Lexington Books.

Maisuria, A. and Helmes, S. (2020). Life for the Academic in the Neoliberal University. London: Routledge.

Marx, K. (1992a). Capital Volume II. London: Penguin.

Marx, K. (1992b). Early Writings. London: Penguin.

Marx, K. (1993). Grundrisse. London: Penguin.

Marx, K. and Engels, F. (2002). The Communist Manifesto. London: Penguin.

Moore, P. (2018). The Quantified Self in Precarity: Work, Technology and What Counts. London: Routledge.

Neary, M. (2019). Academic Voices: From Public Intellectuals to the General Intellect. In: R. Hall and J. Winn. (Eds.). Mass Intellectuality and Democratic Leadership. Perspectives on Leadership in Higher Education. London: Bloomsbury, pp. 41-54. ISBN 9781474267588.

Negri, A. (2018). From the Factory to the Metropolis. London: Polity.

Nichols, G. (2015). Self-Learning Systems to Replace Humans in Manufacturing, April 25 $5^{\text {th }} 2015$, http://www.zdnet.com/article/self-learning-systems-to-replacehumans-in-manufacturing/.

Pitts, F. H. (2018). Critiquing Capitalism Today: New Ways to Read Marx. London: Palgrave.

Postone, M. (2003). Time, Labor and Social Domination. Cambridge: Cambridge University Press.

Preston, J. (2017). Competence Based Education and Training (CBET) and the End of Human Learning: The Existential Threat of Competency. London: Palgrave Macmillan.

Rikowski, G. (2000). Messing with the Explosive Commodity: School Improvement, Educational Research and Labour-Power in the Era of Global Capitalism. Paper presented at the British Educational Research Association Conference, Cardiff University, 7-10, September 2000.

Schwab, K. (2016). The Fourth Industrial Revolution. Geneva: World Economic Forum.

Shah, J. (2016). Robots Are Learning Complex Tasks Just by Watching Humans Do Them, Harvard Business Review, June 21 ${ }^{\text {st }}$ 2016, https://hbr.org/2016/06/ robots-are-learning-complex-tasks-just-by-watching-humans-do-them.

Shukaitis, S. (2019). Pedagogical Labour in an Age of Devalued Reproduction. In: R. Hall and J. Winn. (Eds.). Mass Intellectuality and Democratic Leadership in Higher Education. London: Bloomsbury, pp. 19-26.

Sohn-Rethel, A. (1978). Intellectual and Manual Labour: A Critique of Epistemology. London: MacMillan Press.

Szadkowski, K. (2016). Towards an Orthodox Marxian Reading of Subsumption(s) of Academic Labour under Capital. Workplace, 28, pp. 9-29. 
Tenkle, N. (2014). Value and Crisis: Basic Questions. In: L. Neil, N. Mathias, J. Robinson and N. Brown. (Eds.). Marxism and the Critique of Value. Chicago: MCM' publishing.

UCU (University and College Union) (2020). A Review of Automation and Datafication in Higher Education. London: UCU.

Wendling, A. (2009). Karl Marx on Technology and Alienation. London: Routledge.

Winn, J. (2015). Writing about Academic Labor. Workplace, 25, pp, 1-15.

Žižek, S. (2019). The Relevance of the Communist Manifesto. Bristol: Polity.

Zuboff, S. (2019). The Age of Surveillance Capitalism: The Fight for a Human Future at the New Frontier of Power. London: Profile Books. 


\section{The Pixarfication of Higher Education}

\section{Introduction: Commodities and Pixarfication}

As discussed in the previous chapters, capitalist universities produce a range of commodities that are exchanged for money even if they do not identify them as such. Sometimes universities will refer to their outputs, or even products, but rarely 'their commodities'. The uniquely capitalist nature of the commodity, as the 'cell form' of Marxist social theory, is both a fundamental and contradictory concept (Rikowski, 2000). Commodities hold a thread of a capitalist mystery together in that they store the metaphysical social substance 'value' but this is only realised in various social forms and only appears in an objective form in terms of money (a further social form) (Marx, 1990) which is reinvested in subsequent capital accumulation (Marx, 1992). As discussed in the previous chapter, commodity production is reliant on labour power to produce value and surplus value but value itself also posits the possibility of valorising abstract labour. Labour's existence in capitalism as abstract (and concrete) labour is dependent on the valorisation of value. As previously noted, anything (including services and intangibles) can be a commodity and we make visceral contact with commodities in the supermarket, on the battlefield and in the hospital. Commodity circulation is a necessary criterion for the valorisation of value, the explosive moments when value fleetingly appears in a recognisable material form as money (Kurz, 2014). On the one hand, this is an inhuman process involving a single exceptional commodity (labour power) acting upon materials to produce a commodity with surplus value. The commodity is exchanged for money which, the capitalist hopes, is greater than the money advanced in its production. The reinvestment of money in terms of buying machinery and wage labour is used to produce further commodities. This inhuman process, the conversion of living to dead labour, is a real abstraction (Ortlieb, 2014) that has visceral consequences for the lives of workers. As explained in the previous chapter, even given advanced technology and skills, there is little reason to suppose that generalised commodity production, 
premised on labour, will disappear to produce a more humane system of production based on knowledge. Technology strips skills from workers and privatises the 'general intellect'. In the capitalist university commodity production may not be in the minds of academics or administrators, but if they engage in activities that the university can valorise for money (either through the state or the market) then their mentality does not matter.

The process of commodity production is naturalised and fetishised in the capitalist university, as in any form of capital. It appears to capitalist universities not only that production should continue in this manner, but that it needs to consistently expand to become globalised and dominant. Excitement in capitalist societies, and in capitalist universities, is premised on innovation and new products. Millions of people tune in to see the launch of a new iPhone and queue at the store when it arrives. Great armies of parents have historically fought over the launch of a 'Cabbage Patch Kid' or a 'Furby' toy for Christmas. New features on Facebook or Instagram produce an outpouring of emotion and praise. Similarly, universities produce new innovative degree courses, bold research strands or luxury student accommodations. One response to this innovation and consumerism is to remark on its vulgarity but our subjectivity in capitalist society is not separate from capitalist objectivity (Backhaus, 1992, pp.54-92). The middle-class (in a Weberian class-stratified model) participate in the denigration of 'vulgar' consumption which is often used as a weapon of hatred against the working class (McKenzie, 2015; Skeggs, 2003) whereas middle and ruling class consumption is held up as superior (Bourdieu, 1984). This class stratification applies to universities where courses in vocational subjects are sometimes denigrated in the media as catering to a 'mass market' as opposed to the products of elite universities. Consumption can also be informed with a sense of irony, in particular the hyper-consumption of commodities can be excused as being omnivorous and displaying self-awareness by the middle classes (Skeggs, 2003). The classed formation of taste is one approach to capitalist society which exposes the morality of consumption practices, but commodities also represent the alienated nature of human activity. Commodity production is naturalised and mystified so that it appears that there is a natural chain of causation arising from the market. Consumers (for universities students, governments, or research funders) seemingly send 'signals' through their purchasing decisions and firms then determine what to produce based on those signals so that it appears that 'market forces' produce the panoply of products that we see on the shelves, online, and in student prospectuses. In this way capitalism stunningly takes the appearance of 'self-valorising' value when in practice this is a mediated, contradictory, and exploitative form of production. Capitalism, in its (ideal) visible commodity 
form, adopts this fiction of self-valorising value which is materially a real and moving contradiction. Products appear to 'sell themselves', through the voices of consumers, cast a production 'vote' through purchases, and give voice to their continued production.

This chapter argues that in contemporary capitalism with Artificial Intelligence (AI) and associated technologies, this process of commodity production and exchange is becoming materialised as Pixarfiction. Meinel (2016) first used the term 'Pixifying' for the potential ways that contemporary animation (named after the animation and entertainment company Pixar) could influence society and popular culture. The term 'Pixarfication' is also used in the film industry as a description of the influence of the Pixar studio on film production. In this context, I use it to describe an AI facilitated method by which commodities achieve exchange and valorisation through artificial (often ascribed) forms of perception and consciousness. In describing this as a Pixarfication of consumption and production, I am following the application of earlier paradigms for services, McDonaldisation and Disneyization, to Higher Education (HE). Pixarfication is a technological complement to the creative processes involved in marketing, advertising, and circulation activities essential to valorisation discussed in Pitts (2018). The literal truth of commodity circulation and valorisation, of which Pixarfication is a part, is that commodities are becoming increasingly real personas in capitalism. We are embedded in their world and we are increasingly subordinate to their delicate nudges and decisions. Social media (and associated activities) have become a form of social engineering where our views and opinions are both data and the subject of corporate experiments. Along with AI and robots, commodities are increasingly learning about us as workers and consumers. As discussed in the previous chapter, the locus of learning is moving increasingly away from the human subject. Technology is advancing commodities so that they seemingly come to know. Through sensors and more elaborate forms of communication, commodities are becoming increasingly perceptual. Using AI, machine learning, and engineering for human interaction they are becoming increasingly intelligent. Pixarfied commodities are artificially-sentient in that they have developed a sentience appropriate for objects in capitalism, to facilitate their exchange for money and hence profit. This is not of the same order of the sorts of agency ascribed to objects in Object Orientated Ontology (OOO) and New Materialist ontologies (see Chapter 2) rather it is a mystification of capitalist processes of exchange and valorisation. As it is usually located in material objects, Pixarfication seems more obviously applied to manufacturing (Preston, 2021) but it can also be applied to services and how the commodities produced by HE (through data analytics and AI) can become animated and enlivened. 


\section{Pixarfication: A 'Toy Story'}

Pixar is an animation and entertainment company that is well known for producing technologically sophisticated, entertaining, and highly profitable animations in which objects (cars, toys, lamps), many of which are commodities, have human-type sentience. For example, in the Pixar film Toy Story and its sequels, toys can think, talk, and emote with distinctively human personalities. Some cultural theorists (Ackerman, 2019) contend that the Toy Story films can be read in terms of hidden relations of consumption, production, and ownership. Cultural analysis sometimes considers that films contain hidden meanings that can be revealed by the cultural critic through their ideological penetration of the veneer of capitalism. As considered previously, value as a 'real abstraction' (albeit a contradictory one) means that we do not have to necessarily penetrate a sheen of ideology to arrive at the 'capitalist' sense of the films. A surface reading of the toys as literal commodities shows how the films cannot help but reveal the realities of capitalist commodity production and the necessity of 'social validation' in exchange (Pitts, 2018). This is not to suggest that the films are not without their inevitable contradictions particularly in terms of the role of labour and the division between use and exchange value of commodities.

The original film (Toy Story) is a fable about how a self-aware commodity penetrates its (alienated) consciousness by realising that it is not a human hero but rather a toy. Buzz Lightyear, a space adventurer figure, considers that he really is a rocket commander who must fight an evil alien race (led by another toy, Zurg). Through the film and his interactions with other toys, Buzz becomes aware that he is not actually a space commander but that he is a commodity who was produced in a toy factory like the other toys that he meets. However, he discovers his purpose which is as a source of use value by being a toy that children would like to play with. He has a purpose, a use value, and identifies that he is one of many other 'Buzz Lightyears' that have exchange value as commodities. Buzz's full identity as a toy is only realised as not only a 'use value' but also as an 'exchange value' within capitalism. That is, Buzz recognises himself as a toy fully only in that he (it) is socially validated in capitalism as having an exchange value (being seen to be sold in a shop for money). Toy Story 2 which considers the acquisition of toys by a sinister collector can also be seen as a commentary on use and exchange value within capitalism versus the 'miserly' accumulation of wealth for its own sake (which is in itself a pre-capitalist form). In the film, the toys want to escape the toy collection they are held prisoner in to fulfil their use value as items that children play with. The collection and hoarding of toys is pathologised, as it is in capitalism, where investment in production is required by the capitalist in order to continue and where toys can enter into 'free exchange'. The lives of commodities are meaningless 
without capitalist circulation. Similarly, Toy Story 3 is about toys which are no longer loved or cared for by children (which become 'bad toys') who are no longer of use value and so discarded. The film concerns the opposition between these bad toys and the good toys who still provide not only use value but exchange value as they can be valorised as commodities on the market. The first three Toy Story films only make any sense in a universe where use, exchange value, and capitalist accumulation exist. Only Toy Story 4 provides a slightly subversive take on the role of the commodity in capitalism as the child's non-commodified labour produces a toy from a discarded fork ('Forky') negating the idea that toys are always commodities produced under capitalism. The theme of commodity-sentience, used in Toy Story, is common in other Pixar films which deal with worlds totally inhabited by sentient commodities (Cars and Planes), where human life on earth has become seemingly impossible and a future earth where robots are the primary entities which possess emotions (Wall-E).

Toy Story, and its sequels, are films, but the increased perceptual apparatus and sentience of commodities is not just a technological shift by capitalism but represents an intensification of commodity fetishism. Commodities in capitalism increasingly express commodity personas. This relates to Marx's concept of commodity fetishism which describes how the social relationships between people become objectified as the economic relations between things, obscuring the contradictory nature of both the commodity and of the class nature of commodity production. Value is reified and objectified in the form of a 'product'. This does not mean that commodity fetishism is a psychological trick which can be easily penetrated through reason and reflection. Backhaus (1992) contends that objects (including commodities) are, following Marx, both 'sensuous' and 'supersensuous' rather than a straightforwardly material being 'which has been transferred and displaced into the external world which is independent from consciousness' (Backhaus, 1992, p.62). It is labour that eventually appears in another, transposed, form alien to the worker as a commodity. This is a 'real abstraction' or an 'objective illusion'. Pixarfication is a further 'derangement' as it is now seemingly commodities, rather than us, that perceive, learn, and act back on the world. Commodities wear their own 'character mask' of sentience.

The element of Pixarfication manifests itself in terms of ideas that magical or technological sentience is everywhere (a panpsychist, technological, perspective on commodities), that we are in the sensory world of commodities (their gaze), form relationships with them and that there is speciation (an ever-extending world of sentient commodities) which extends across time, eternally. This could comprise a whole universe of human consumption and production including the internet of things (IoT), the tools of the quantified self, smart factories, digital assistants, and emotional attachments to AI and robots. At root, though, 
Pixarfication is motivated by the expansion of the world of value and hence profit. This in turn seems to be driven by technology, or forms of, technological innovation. The IoT, as an example, refers to a situation in which every entity is connected to the internet and can communicate with other entities. Hence, every entity has a status in time and space and can also relate with other objects. In this way objects communicate together and seemingly exert influence over human affairs. This could be through changing human environments (temperature, energy consumption, and behavioural aspects such as anti-social behaviour). In practice the commodities are obviously not directly exerting these changes for their own ends but rather they (or their connections) are owned by capitalist enterprises who are motivated by profit. DyerWhiteford, Kjøsen and Steinhoff (2019, p.31) consider that the IoT will, in capitalist terms, enliven and cognitise objects. Objects become 'alive' not only in terms of their sensory systems but also become 'enlivened' through AI by their capacity to determine production and profitability.

This exercise of feeding back from the consumer to the producer has always been performed by companies through market research and ethnographic means of 'observing' commodities in the field but it is increasingly the case that this is happening in an unmediated fashion. Commodities increasingly directly drive the process of production in both manufacturing and services by providing instant feedback through technical means. For example, 'Chatty Factories' which was discussed in the previous chapter, involved examining how placing sensors on commodities can lead to real-time feedback to the factory floor which in turn would change production in real time to optimise the product, but always in terms of revenue and cost (profitability). One example of this could be the inclusion of sensors in cars that would constantly record the way in which they were dealing with the road, the temperature and the speed and location of the car. This could feed back to the factory in real time to change the production of the car in terms of various forms of optimisation (see Preston, 2021). Although this could optimise the experience of the consumer, it is evident that profit would be the major consideration. Workers would be subject to a fusion of both real subsumption (the increased use of fixed capital to enhance productivity) and a technological, pan-psychic, form of commodity fetishism. Through fixed capital (technology) their work and productivity would be shaped by value production mediated by the 'experience' of a commodity. This is another means of synthetic timing (Sohn-Rethel, 1978) by which exchange sets the time necessary for work. In capitalist universities, the equivalent of this are the league tables and data analytics that enable them to keep up with the competition but, in reality, are a form of labour discipline.

There are multiple examples of this dominance of commodities in our everyday lives. We already communicate with 'digital assistants' such as 
Amazon's Alexa in our own homes, or on our phones, and these entities learn from our voices and behaviours, collecting data to profile us. In practice, it is Amazon, not an Alexa, that learns about us. Similarly, the affective and erotic attachments which some people have to nontechnological objects such as 'body pillows' which feature anime characters, or computer avatars or video game characters, shows that all sorts of commodities can become personified and enlivened. This complete mystification through commodities, that commodities are sentient and are the real actors of society (as is evident in the Pixar timeline) has become (under capitalism) a (perhaps temporary and ephemeral) but a contemporaneous powerful principle. Learning has hence moved from being a human capacity to become a feature of commodities.

Although in the examples the stress has been on consumption, it is the interplay between use value, exchange value, and production that makes this an aspect of real subsumption. That is, the Pixarfication of commodities leads to them having an apparent 'voice' in production as opposed to workers. In New Industrial Systems (NIS) the commodity could be said to acquire a 'use sovereignty' (Preston, 2021), talking back to the factory where it was created and exerting authority over the labour process (subject to considerations of cost and profitability). It is the use of the product, the signals that it sends, in conjunction with forms of market research, that informs production. This use sovereignty seeks to resolve the contradiction between use value and exchange value by making it more likely that factories would produce commodities that are valorised in the market. If commodities are designed to meet users' needs then they are more likely to be sold and exchanged for money. As an embodiment of this, in the 2019 UK advertisement for Amazon products, the commodities that roll off the packaging line and which are delivered to consumer's homes have an animated smile (the Amazon logo) which also features on worldwide Amazon packaging. Logistics has a smile. In NIS the Amazon logistics smile becomes a mouth that talks back to the Amazon store, warehouses, and factories worldwide. Commodities produced in such systems can be released into exchange more rapidly and the process of circulation speeds up, exerting pressure on labour to work at increased intensities, producing a greater turnover of relative surplus value and driving the firm to invest in newer technologies. The concrete form of production becomes increasingly subject to real abstractions. Ultimately, the production of value is still the key criteria as a function of labour congealed in a commodity is expressed in terms of Socially Necessary Labour Time (SNLT). As SNLT declines with technological improvement and methods of organisation (as the 'datum'), there might be an increase in relative surplus value but as soon as all industries adopt NIS value will remain the same. The commodity form in NIS therefore is no different, in essence, from the social nature of the commodity in other types of capitalist production. 
'Use sovereignty' is an attempt by NIS to resolve the contradiction between various forms of value that exist in the form of the commodity in capitalism that cannot necessarily be resolved through the money form. Firstly, the specific form of use value attempts to ensure that the commodity is valorised on the market as the commodity alters its concrete nature automatically in response to consumer desires (although still subject to the profit motive). Secondly, the commodity as the social form in capitalism directly disciplines the labour process. The commodity indirectly takes charge of the way in which production is organised in terms of the production of value. The commodity itself becomes the king of production acting as a seemingly autonomous agent of the capitalist's vision. Commodities have voices as they convey information to the factory. They have their own virtual life and even avatars as digital twins through which data-driven design and algorithms drive the factory. This is congruent with other developments in manufacturing such as gamification and the neuroscience of labour. However, it is not that commodities really have an 'autonomous essence' (Harman, 2016) independent of capitalism but that they have a really existing abstract essence (value) (Kurz, 2014) as part of a capitalist process that is revealed only in exchange (Pitts, 2018).

\section{The Pixarfication of Services and Higher Education}

As well as manufactured goods (Preston, 2021), Pixarfication can also be applied to services. This is not a new development as techniques employed in manufacturing are frequently applied to intangibles. For example, Taylorism which started in slaughterhouses and car manufacture is now employed in areas such as call centres. As well as shifting the locus of learning from humans to commodities, Pixarfication is used in the production of educational services. In particular, the corporate nature of HE has made it increasingly subject to Pixarfication processes. The HE sector has previously been examined through concepts such as privatisation, marketisation, commodification, and managerialism but datafication is also part of the contemporary landscape of the capitalist university and this lends itself to Pixarfication.

Datafication and the move from production techniques used for tangible to intangible commodities is part of a widespread trend in capitalism. Increasingly, the distance between manufacturing and service sectors is becoming blurred as 'manufacturing as a service' and the algorithmic forms of control first developed in Taylorist manufacturing are merged. Similar business processes are found across a range of organisations. In $\mathrm{HE}$, commodities are increasingly abstracted from students, academics, and research, and exist as pure representations of funding streams in terms of quantifications, performance indicators, and league tables. These commodities are not ideological constructs but are the universalising measure that drives competition between institutions. This realist conception is 
contrary to idealist critiques that contend 'obsessions' with 'ideological' league table positions are misguided. Comparative indices really do operate as actually existing abstractions (or real abstractions, Tenkle, 2014; Kurz, 2014), that drive productivity in HE. In itself the idea that league tables drive HE performance is not original, but the shift to Pixarfication is that these data personas are not simply a type of commodity fetishism but are ascribed a form of sentience. Specifically, data is given the status of a sentient being. It seems to act pedagogically, in terms of offering us 'insights' or 'telling stories' about our institutions, aiming to provide a 'true picture' of reality in HE. Data 'sees us' at the level of the institution, the department and the individual (Beer, 2018; Thomas, Nafus and Sherman, 2018). Data visualisations and animations in HE become a data 'persona' giving data a character and a sentience. HE is, therefore, not immune from the blurring of the lines between manufacturing and services and the drive towards products with (real or inferred) properties of sentience and agency. In HE, where the commodity is less easily identified when compared to other sectors, this Pixarfication manifests itself in terms of the ways in which data, and league tables, are ascribed sentient and characterful properties. Data 'comes to life', animated by visualisations, analytics, and AI tools. This has implications for where agency in HE resides. Rather than a paradigm as student-as-consumer being paramount as in theories of marketisation of HE, the 'inhuman power' of data is an existing, determinant, abstraction.

It must be noted that with Pixarfication there is no ontological break with industry, whether early manufacturing or Industry 4.0 in terms of its capitalist nature. It does not point towards an 'identity politics for commodities'. Pixarfication is a flattening of the political surface due to the role of value, not as a way of extending the bourgeois conception of rights to the hammer, the paperclip, and the stapler. The phrase 'here comes everything' and associated phrases like 'internet of things (IoT)' both indicate that commodities are bursting through the doors, but also that they are becoming conscious in a network of everything that is everywhere. As was considered in the second chapter, what is really at play is the capitalist process of profit maximisation through the exploitation of labour. Behind Pixarfication is a drive to increase surplus value and to achieve it through a seeming 'self-valorisation' of the sentient commodity. Profit, not novelty, is the real force behind the adoption of new business models in HE.

\section{McDonaldisation, Disneyization, and Pixarfication as 'Business Models' of HE}

It is not novel to define and then apply a metaphorical 'business model', like Pixarfication, in contemporary capitalism to HE. Corporate paradigms are often employed to generalise a mode of business behaviour to this sector. These have included McDonaldisation and Disneyization. 
McDonaldisation, following Ritzer (2000), has been used to consider how bureaucratic forms of management in HE can impose standardised procedures and regulations on academics and students so that they are trapped in an 'iron cage' of limited agency (Hayes and Wynwood, 2002; Hayes, 2017). Disneyization (Bryman, 2004) emphasises the experience economy, the affective, and the performative in $\mathrm{HE}$ along the lines of an educational theme park. Despite the conceptual power of these theories, it must he recognised there are some limitations in applying them outside of the corporate context to universities. In a global system of HE, with new corporations in ascendancy, the salience of any one corporation (particularly a United States based one) for a world system of HE may be doubted. It could be argued that there is no one single corporate paradigm that is applicable to all Higher Education Institutions (HEIs). For example, low-cost, teaching-intensive private institutions could be adopting a 'Walmarting' strategy (Goggin, 2016) of high-volume mass-market degrees, which is very different to other public universities. Relatedly, employing any one of these business paradigms risks losing some of the specificities of HE (in terms of the intangibility of what is produced and the generally not-for-profit nature of HEIs) for the generalities of capitalism and marketisation (in that a named corporation is used as a stand-in for capitalist processes as described above). Pixarfication, drawn from the creative work of the company Pixar, does have similar drawbacks but whilst recognising its limitations, its strength is that it allows for an analysis of the ways in which HE is increasingly driven by the anthropomorphised, seemingly learning and sentient (through AI), commodity of data. It therefore enables an original creative approach to understand the ways in which data, through ascribed sentience and its reification in league tables, increasingly becomes a driver of HE processes. It also needs to be contextualised in terms of McDonaldisation and Disneyization as preceding paradigms.

Ritzer's seminal (2000) work on McDonaldisation updated Weber's bureaucratic paradigm for contemporary society and this has been systematically extended to HE (Hayes and Wynwood, 2002). McDonaldisation involves time discipline (efficiency), quantification (calculability), predictability, technological control of processes, and 'fake fraternisation' between workers and consumers which reproduces Weber's bureaucratic 'iron cage' across society. The model is the innovative production methods of McDonalds restaurant franchises that produce a standardised product of a defined quality, with associated training and manuals and scripted customer service. Hartley (1995) uses McDonaldisation as a heuristic to consider that policy moves in HE are designed to shift HE towards the production of an increasingly standardised product from the standpoint of production. In terms of activities of education, it enables us:

...to regard education as if it has some material essences, or as if its production processes could be readily broken down into a set of 
fixed, measurable and assessable procedures which admit the title 'good (or even best) practice', or as if its output should be predictable, standardisable and quantifiable.

(Hartley, 1995, p.419)

Hartley argues that McDonaldisation in HE is anti-democratic by reducing the means and ends of $\mathrm{HE}$ to purely mechanistic ones. Relatedly, Disneyization (Bryman, 2004) is the '...process by which the principles of the Disney theme parks are coming to dominate more and more sectors of American society as well as the rest of the world' (Bryman, 2004, p.1). Bryman intends his notion of Disneyization to parallel the notion of McDonaldisation in two senses. Firstly, the parallels between the business models of McDonalds and Disney in terms of the shared elements of efficiency, calculability, predictability, and control. Secondly the use of the paradigm to represent the diffusion of principles across organisations and societies rather than simply the spread of the firms, namely fast-food restaurants, and theme parks in general. Like $\mathrm{McD}$ onaldisation, there are four principles of Disneyization. Theming is the tendency to create business environments that are visually, sonically, and affectively structured around certain motifs and designs evocative of that business's intellectual property. Dedifferentiation of consumption is the tendency for elements of consumption to become interlocked and inseparable so that shopping, theme park rides, staying in themed hotels and purchasing films online become part of a seamless consumption process. Merchandising concerns the selling of licenced products and services on or off-site. Emotional labour is involved in the creation of the themed environment of the park as employees take on the role of various characters and personas (Bryman, 2004). Disneyization is increasingly common in Universities which increasingly resemble malls where hybrid consumption takes place (Bryman, 2004, p.74) in a themed campus setting (Bryman, 2004 p.51) with branded merchandising (Bryman, 2004, p.97). The notion of the 'student experience' (particularly in the US) is an example of Disneyization where students often purchase, and identify with, experiences and products related to their university. The university becomes a pseudo-theme park where students can purchase dedifferentiated products and continue their consumption beyond the university at alumni events and collective reminiscences on social media.

There are some differences between McDonaldisation and Disneyization but also similarities in terms of how they employ the notion of a 'business paradigm' to society. Bryman (2004) considers that Ritzer's (2000) McDonaldisation primarily concerns control rather than capital and is closer to classical (Weberian) social theory than Disneyization which is more concerned with contemporary theories of emotion and affect. However, one common problem with both 
McDonaldisation and Disneyization is that they strangely do not consider the specifically capitalist nature of McDonalds or Disney as enterprises at least not in a Marxist sense. In particular, they focus primarily on consumption rather than production (Hayes and Wynwood, 2002, pp.9-10). The processes which McDonald's employs, for example, are not particularly unique to this company and are foreshadowed by Marx's writings on the nature of factory production with its time discipline, standardisation, and routinisation. The ways in which capital consistently finds new markets and sources of labour could be applied to both McDonaldisation and Disneyization with their 'dedifferentiated' consumption and 'emotional labour'. This is not to say that they are not incredibly useful descriptive devices for outlining the contours of capitalism (and potentially resistance) but they need to be theoretically contextualised if we are to understand them more broadly in terms of the specific character of capitalism. Specifically, both McDonaldisation and Disneyization naively consider the imposition of business forms onto commerce and society which could be regarded as otherwise unmediated by these forms. As discussed in previous chapters, capitalism is compelled by a constantly collapsing floor (the desubstantiation of value - Kurz, 2014) to introduce cunning new methods of worker exploitation and ways of valorising value through the expansion of the 'social universe' of commodities. McDonaldisation and Disneyization are examples of ways in which this is being done but so are Amazon (as an example of platform capitalism), Walmart, and Nintendo. There are potentially an infinite number of commodities and business models which can influence social relationships. Indeed, the notion of the 'social' and 'society' is largely absent from these paradigms. Both McDonaldisation and Disneyization take a conception of society which is colonised by these business models in all aspects (including Higher Education). The problem is that this theorisation considers society to be external and morally superior to business in some sense. It is society that is colonised by business rather than capitalism as society itself. A Marxist account based on value critique would problematise society in capitalism as 'the social', which is value and capital, and analyse their class determined movements (including resistances). Capitalism actually does invert the world so that the 'real' is the world of commodities and value and we really wear the 'character masks' of actors. For example, Hartley's (1995) reference to the 'as if' nature of the way in which McDonaldisation is being employed in HE is unknowingly a reference to a 'real abstraction' in terms of the way in which the outputs of HE are being transmuted into a commodity which can be marketised. There is no 'as if' here, rather an 'as is' as HE outputs become commodities in the existing contradictory sense of the word. Commodities 'really are' one of the actors in capitalism and the mystification is not just ideological but real if incredibly 
fragile and collapsing given its basis in labour power (Kurz, 2014). This theorised account enables us to build resistance as an obvious and everyday part of this process. For example, Hayes (2017) considers that Ritzer misuses Weber's work in making it unduly teleological in terms of the movement from rationality to the 'iron cage' and makes the case for academic agency and freedom of speech. This forms part of Hayes' wider libertarian Marxist critique of $\mathrm{HE}$ as an area for worker autonomy and agency. Agency is somewhat absent from Ritzer's own work in that he considers himself '...more of a Weberian pessimist than a Marxist optimist' (Hayes and Ritzer, 2017, p.44). Similarly, Pixarfication cannot avoid some of the historical problematics of Disneyization and McDonaldisation. The collapsing and consistently reorganising nature of capitalist enterprises means that Pixar films may be as dated as Ealing comedies in the world of entertainment in the next decade. However, the basis of Pixarfication is in social theory (albeit updated for value critique) in terms of Marx's theory of the commodity which may afford it some durability in applying it as part of a specifically capitalist process.

\section{Pixarfication in Practice: Commodities and Datafication in HE}

The process of Pixarfication in HE follows commodification (the creation of a commodity in the capitalist sense of the term) and datafication (the expression of the commodity in terms of data) and it introduces processes of data analytics in terms of animation, characterisation, and production. In terms of commodification, the question of what is produced by $\mathrm{HE}$ is one which has troubled economists of education who largely follow the principles of 'classical economics' in identifying the product, the price of which is determined by supply and demand. As previous stated, HE produces a number of things including education, research, and knowledge exchange. All of these things might be subject to a price, but a price is just a 'label' that can be attached to a thing (anything) and this does not necessarily make that thing a commodity. Notably, markets with prices predate capitalism and even feudalism. Marx rarely discusses education directly in his work, but he does make the point that it (along with other processes) produces commodities (in passing, HE may also enhance the unique commodity labour power - Rikowski, 2000). In terms of the production of educational commodities, Marx famously refers to education as a 'sausage factory':

...a school master is a productive labourer when, in addition to belabouring the heads of his pupils, he works himself into the ground to enrich the owner of the school. That the latter has laid out his 
capital in a teaching factory, instead of a sausage factory, makes no difference to the relation.

(Marx, 1992, p.644)

In this very telling passage, Marx says that there is nothing special about education (or trivial about sausage factories) in that when a commodity is being produced with a use value (the change in the heads of the scholars as a result of the 'belabouring') and an exchange value. The 'school master' is a productive labourer as they have the potential to conduct both concrete and abstract labour (labour power) to posit value. 'Teaching' and 'sausage' share identical features in that both are commodities which have use and exchange value and they present potential branches of industry where a capitalist could invest their money. Both are exchangeable in that it would be possible to exchange a quantity of sausages for a place on a degree programme through their objectified form (money). Unlike teaching, the sausage is a visceral object, but this makes no difference to their joint existences as commodities. In terms of $\mathrm{HE}$, the process of commodification, the making of an educational commodity, involves primitive accumulation both in terms of the separation of the commodity from the universe of mere 'things' (such as the air) and the transformation of academic work into labour power presuming all of the other features of this social substance (quantification, wage labour, and proletarianisation).

There are many examples of the ways in which student satisfaction, degrees, and other aspects of HE have become commodified and made the subject of wage labour. An apt example of this process is the way in which research has become a product in UK HE via the current REF (Research Excellence Framework) and previous research excellence exercises which turn academic research and writing into commodities. Although the UK REF is perhaps an extreme example of how research has become commodified, Australia has a similar framework (Excellence in Research for Australia, ERA) and many countries have adopted research performance indicators for comparison and tenure purposes. Outside of the world of educational commodities, people write books and articles for all sorts of reasons including enjoyment, agitation, and communication. Books and articles can have a price in non-capitalist economies and books were sold in markets in Ancient Rome. Books become a commodity when they are produced using labour power (in the abstract) to produce a use value (by concrete labour power) and an exchange value (by abstract labour power). The REF means that the outputs of academics are commodities with not only a price (you can buy a book or an article) but they are produced for exchange value (not just use value) in terms of how much they can be valorised for. To explain further, the REF means that each academic who works in a UK university must (subject to the conditions of their contract and, exceptionally, other mitigating factors) 
produce on average 2.5 outputs over the REF period (2014-2020) which are assessed by an external panel of reviewers. Depending on the ratings that the panel of reviewers attach to this grading, the University that they are a member of at the census data point (July 31, 2020) will receive funding based on this submission. The 'sausage' in this example (or the meat in the sausage) is the research output (whatever that might be). The creation of this commodity (the REF output) requires primitive accumulation in terms of specifying what can and can't be a REF output (for example, it needs to be peer reviewed), ascertaining the quality of that output (REF outputs are reviewed and are awarded a 'star rating' from Unclassified through to $4^{*}$ ) in a period of time (six years). The research labour of the academic becomes abstract labour as wages are allocated (albeit rather informally through promotions and appointments) according to production of the REF commodities and academics become part of the proletariat as they must sell their labour power to receive wages. This again requires primitive accumulation as the academics must be 'displaced' from their comfortable positions of permanency to become labourers whose conditions of employment largely depend on fulfilling the REF criteria. The REF process also commodifies other things that academics do such as the impact of their work on economy, society, and culture which also is a source of potential income for the university. Even the research culture and seminars of a department are made by the REF into a commodity as the 'environment'. In this way, the universe of commodities is widened, and labour power is expanded into the creation of many commodities (teaching, research, impact, environment, and knowledge exchange). Hence academic labourers find themselves with an increasing set of demands to meet in terms of academic commodities which is set by state systems in the UK including the TEF (Teaching Excellence Framework) and the KEF (Knowledge Exchange Framework). This process is not autopoietic but requires the application of labour power under conditions of contradiction in every moment of production. The UK Government (through the REF) produces a consistently escalating level of research expectations (to keep UK universities competitive) that involves increased investment by universities in both capital (labs, facilities, research funds, research support, and buildings) and labour (researchers with increasingly superior outputs). The drive for increased productivity of academics not only exhausts them and encourages the growth of casualised labour but undermines itself as value production becomes increasingly unprofitable as the criteria for funding becomes ever more extreme. Where once $2 *$ ranked outputs would attract funding now it is only $3 *$ outputs and in the next REF it may be $4^{*}$ outputs. This also leads to a situation where the intrinsic (use value) of an output is subordinate to its exchange value. It must be noted that some commodities produced by HE have a rapid circulation. For example, a literal sausage sold in the university canteen is transferred 
to the money form quite quickly whereas student fees are 'returned' to the university more slowly. In the case of the REF it takes a long time (a six year interval) for the various outcomes of academics to be converted into a vast data stream (the complete data sausage) which is submitted by a certain date and time. This is the datafication of the commodity. It is akin to the construction of a large battleship through various forms of labour power which is sold in one (uncertain) tender to the Government. The actual transmission of the commodity to government as a data stream is the moment at which the commodity leaves the University 'sausage factory' to be eventually valorised in its objective form (money) at which point all academic and administrative labours are equated as abstract labours.

Through this process of datafication, there is simultaneously a Pixarfication of the research (and other) commodities in HE. The first aspect of this is animation. Animation is the creation of an outline mobile persona for the commodity. As with forms of scientific management and $\mathrm{McDonaldisation,} \mathrm{this} \mathrm{primarily} \mathrm{involves} \mathrm{the} \mathrm{process} \mathrm{of}$ boundary drawing and quantification that are synonymous with the creation of a commodity separate from nature or non-commodified academic labour. This is a violent process of primitive accumulation so that there is struggle and resistance over the imposition of these categories on academic labour. As described above, this first involves quantification. Once quantified, the performance of the individual and the organisation can then be animated. At the first order, this can be considered a literal depiction and drawing of the performance in terms of the production of the commodity. The university produces graphs, charts, and visualisations of productivity which are temporal in terms of not only the measure involved but also in producing targets. In the example of research outputs, they become a commodity that has both literal existence and an animated existence in terms of its representation as data. It must be remembered that this data is an enormous stream with every output, impact, and environment statement as the total mass of commodities which is exchanged for money. Hence the university is involved in the capitalist circulation process of money invested subsequently being used to add value to a commodity (through labour power) to produce a greater sum of money.

There are various examples of how animation is practised in contemporary HE. Data interfaces such as Domo, SAS, and Tableau are being used by universities to literally animate their data:-

Tableau is business intelligence software that helps people see and understand their data...Connect and visualise your data in minutes... Get the freshest data with a live connection to your data...Tableau helps people transform data into actionable insights. Explore with limitless visual analytics. Build dashboards and perform ad hoc 
analyses in just a few clicks. Share your work with anyone and make an impact on your business. From global enterprises to early-stage startups and small businesses, people everywhere use Tableau to see and understand their data.

(Tableau.com, 2020, my italics)

Here the emphasis is on a 'connection' with data that enable one to 'see and understand' the data. Although there is a benefit described in terms of 'visual analytics' (literal animations), there is an emphasis on data being 'seen' and the connection between the human and the data. Such approaches are supported by 'Universities UK' (2016) who consider that data and data assessments such as the TEF (Teaching Excellence Framework, a UK methodology for assessing student experience) are examples of instrumentalism and it is only when data is given a profile that it can move towards providing operationalised financial information:-

External performance assessments, such as the TEF, don't in themselves support institutions understanding and using their data. Advanced learning analytics can allow institutions to move beyond the instrumental requirements of these assessments to a more holistic data analytic profile. Predictive learning analytics are also increasingly being used to inform impact evaluations, via outcomes data as performance metrics. Ultimately, this allows institutions to assess the return on investment in interventions.

(Universities UK, 2016, my italics)

As academic productivity and competitiveness are key to profitability in the capitalist university, data must therefore be seen to move and go beyond static representation, being a literal 'animation' of statistics. It then becomes possible to see this data representation as an outline character and make some kind of connection with it just as we connect with a simple drawn face or an animated stick figure. This is the next stage in the process of Pixarfication - characterisation. An animation alone tells us little about a character although we might form some kind of anthropomorphic identification with this being (An early Pixar short film Luxo Jr., for example, was the story of a lamp who through the cute animation can be identified within an anthropocentric sense). Commodities are already fetishised in capitalism as real actors and this is as the result of a real abstraction and a recognition of the true sociality of capitalism. In other words, it is not an idealist mystification, in that it is true of really existing capitalist subsumption. Algorithms are used to 'learn' about the data and to recognise patterns through machine learning and AI techniques. We then speak about the data in anthropocentric terms using expressions that reflect what the data shows or tells us and what 
we can learn from the data. The data is 'reality' in that it can apparently provide a 'sense check' of what the capitalist university is doing. We can look at the data, but the data looks back at us (Beer, 2018) and learns from us. This is not just datafication but commodity fetishism of a literal kind. The commodity, as represented by the data, is a learning and alien thing, with a mass (the total Key Performance Indicators in management speak) and tentacles reaching into departments and individuals and back from individuals and departments to the mass. Horrifically, it is literally that thing, which is a form of value arising from our own labour power and transformed into an objectified form of value (money). In this way the 'learning' and the 'voice' of the data character seemingly produce its own future determination by encouraging future plans for accumulation and investment or depreciation and divestment.

One example of characterisation is the Times Higher Education Supplement Data Point service (Times Higher Education, 2020) that provides a unique perspective on universities from various data sources as shown by the following extracts (with my italics). 'Data points' enables the university to 'see what the world thinks of you'. 'THE...(Times Higher Education) Reputation gives a unique multifaceted view of your institution's global reputation and brand performance among influencers in higher education from across the globe'. By subscribing to Data Points, universities can 'Join the rapidly growing group of global institutions harnessing the intelligence of the rich data that power our rankings to unlock their highest potential'. One of the customers quoted in the promotional literature, Sunny Kwong of the Chinese University of Hong Kong states that 'DataPoints gives us a view of how the world perceives us, and a perspective not readily available elsewhere'. Data Points is a good example of characterisation that is typical of Pixarfication. Data Points can seemingly see and perceive and reflect how the world judges the university as well as having an 'intelligence'. This is more than just a quantification of the university position in league tables which are typical of marketisation. Through Pixarfication, these rankings become the actors (characters) of HE as narrated through performance and league tables based on these abstractions. Again, this not an ideological construct but a real abstraction. The components of the league tables might, or might, not represent exchange but capitalist universities can always be compared. The commodities of HE become part of a series of 'bigger' characters who represent vast amalgamations of commodities. This can become an extreme form of aggregated commodity fetishism. For example, the QS World University Rankings (Times Higher Education), according to their website, ask the question 'Who Rules?' and invite us to 'Meet the World's Top 10 Universities'. The personification of the sovereign as being a 'university' that rules and the idea that we can 'meet' a university through its data are perverse examples of the characterisation of a 'ruling university'. 
Once, through the data, the characters of HE have been established as baskets of commodities they become the datum. This leads to the third stage of Pixarfication, Production. The commodities become objects of self-investigation and introspection through techniques of data analytics, machine learning, and forms of AI. These techniques are used to deconstruct and reverse engineer the commodities to find out how they can best be produced. From the perspective of the capitalist university, this involves orientating the 'factors of production' which again mystifies the one commodity that can produce value (labour power). In production, Pixarfication can be seen to be a broader part of the wider primitive accumulation and dispossession process in HE in terms of the identification and production of a commodity through labour power. At first, the 'outline' of the commodity is unknown. It is difficult to establish what academics and other university workers are doing in terms of production. The university might know that it is producing research, teaching, or knowledge but as a capitalist producer, it needs certainty as to what the commodity (or commodities) being made actually are. The 'certainty' of commodity production is what animation is about. To 'guide' the animation there are a whole series of league tables produced by organisations such as the QS University Rankings, Times University Guide and various newspapers. Although workers were already producing 'stuff' which yielded 'money' for the University, animation makes this visibly appear, a name can be put on to the 'stuff' and this can be seen to arise as a function of academic effort. These commodities can be produced through league tables and performance indicators. For example, the QS World University Rankings discussed above defines two 'commodities' as follows:-

Teaching quality is typically cited by students as the metric of highest importance to them when comparing institutions using a ranking. It is notoriously difficult to measure, but we have determined that measuring teacher/student ratios is the most effective proxy metric for teaching quality. It assesses the extent to which institutions are able to provide students with meaningful access to lecturers and tutors, and recognizes that a high number of faculty members per student will reduce the teaching burden on each individual academic.

A highly international university acquires and confers a number of advantages. It demonstrates an ability to attract faculty and students from across the world, which in turn suggests that it possesses a strong international brand. It implies a highly global outlook: essentially for institutions operating in an internationalised higher education sector. It also provides both students and staff alike with a multinational environment, facilitating exchange of best practices 
and beliefs. In doing so, it provides students with international sympathies and global awareness: soft skills increasingly valuable to employers.

(TopUniversities.com, 2020, my italics)

As can be seen through these quotes on metrics used in the QS rankings, these commodities are produced through arbitrary distinctions. In terms of teaching quality, this is ascertained through student opinion and represents a good example of how the hyper-subjective itself (as in the National Student Survey in the UK) can become objectified. It is simultaneously the result of the labour power of academics even though it is then reimposed upon them as a commodity form and as a labour discipline. This 'proxy measure' is then what the commodity becomes. The second quote, on international reputation, is even more nebulous but shows how reputation is made to be a commodity through its association with the needs of employers. Note that these then (because of the global nature of the QS rankings) become global indicators and enable production as part of a global market.

This is an aspect of 'commodity fetishism' through which a thing becomes endowed with properties of price and profit that seem to be separate from human contact. As noted above, animation often involves the literal graphing and animation of key commodities. Once the commodity is established in outline, it can then be 'characterised' in terms of ascribing it with perception, sentience, and learning. The commodity seemingly learns over time what 'moves' it and as we 'observe it', it observes us back in a thoroughly alien sense. We ascribe the commodity sentience as it knows more about us than we know about it even though we might attempt to analyse it. Here is where the idea of a commodity as 'supersensible' achieves a double layer of fetishisation. We seek to 'understand' the commodity (student satisfaction, for example) through statistical methods, focus groups, and surveys that involve increasingly complex AI algorithms, but we always fail to 'fully understand' what are the factors that move the value of this commodity. Hence what is created (through our own labour) is beyond our human understanding, even in quantitative terms. The commodity becomes mystified even as it becomes more understandable in terms of its nature as a commodity. In the third stage, production, it is this sentient 'thing' that drives what the University does. Hence, KPIs (Key Performance Indicators) and League Table Positions are not an ideological construct but operate as a real abstraction, a super sensible thing or character (in Pixarfication) that dominates production in the university. These aggregate 'characters' bestride world education in terms of their dominance across countries and education systems through the imposition of global metrics by which the success of universities can be gauged, rise, or decline. 


\section{Conclusion: Pixarfication and Academic Labour}

The above analysis has developed the concept of Pixarfication as a form of commodity fetishism in the current stage of capitalism. Pixarfication is obviously linked to a particular corporate form (that of Pixar). There are problems, which have been discussed, in relating a particular historical form of business enterprise to a more generalised form of capitalist business. However, capitalism itself uses such metaphors to allow us to think about how capitalist reality might manifest itself and enables us to live in it. In this case, the commodity as a supersensible thing appears both as value (with the appearance of use and exchange) and as a 'mere thing'. In Pixarfication the 'mere thing' takes on some of the attributes that we would usually associate with the human, such as perception and a limited form of learning and assumed sentience (though machine learning and AI) which then is determinant in production. As in commodity production more generally, the appearance is that the commodity is autopoietic in terms of being self-reproducing. The product seemingly produces itself and talks back to production to determine how it should be made in the future. Pixarfication can be described, then, as sentient, super-sensuous, autopoietic commodity production. In many ways this appears to be standard in terms of capitalism generally (in that capitalists produce on the basis of profit from exchange value but in doing so need to be confident that their product has a use value) but there is a new level of significance in that the 'mere thing' becomes a thing that (apparently) has a character, cognition, and voice although this is just a 'character mask' in the same way that workers and capitalists are masked. This is not just of theoretical importance - the commodity fetish, a real abstraction has very real consequences for workers in HE.

As discussed in Chapters 2 and 3, real abstractions are not just the unfolding of value over historical time in the manner of some kind of 'spirit'. As a real abstraction, in its various guises, the movement of value in capitalist HE exercises a visceral compulsion for academics and in turn is, tragically, the result of labour power. This labour power is not given willingly to the capitalist but involves the primitive accumulation of labour (and the commodity) and various forms of exploitation in order to manifest surplus value. Pixarfication is a further perversion of labour in that the labour power of workers is ultimately used to make commodities that (through data analytics and AI) seemingly have cognition of their own production and which command more labour of increased intensity to be used in the production process. This vortex consistently negates ever increasing quantities and qualities of labour power converting it to the 'nothing' of dead labour whilst increasing the mass of commodities produced over time. The appearance of commodities becomes the location of learning and sentience and commodity fetishism has reached its highest level where the commodity is seemingly 
existence and life. Once this thing becomes data with a 'persona', this has resonance with what Dyer-Whiteford, Kjøsen and Steinhoff (2019, p.21) call hyper-subsumption in which '...capital's automizing force manifests as AI'.

As workers in HE, discussion of sentient commodities, hypersubsumption and the reality of the commodity fetish might seem to imply that Pixarfication is yet another theory that closes down agency and autonomy for labour. The real actors of HE really do become the performance indicators and league tables that liberal, or social-democratic critiques, have railed against. Bleakly, this is true. In capitalism, sociality, capitalist society, is the movement and expansion of value in all of its different forms to infinity (Kurz, 2014). However, this can never (by definition) subsume human agency as capitalism needs the autonomy and creativity of labour as a source of the sole commodity that can produce value - labour power. Managers may read us into KPIs and Performance Indicators by referring to our contribution to the collective effort and this is literally true in terms of our labour. It is our physical, mental, emotional, affective, performative, collective, and otherwise concrete labour that makes the performance indicators. In the sense that we are both in and against capital we are within and against aspects of capital including performance indicators as the sinister inverted form of our labour. As discussed previously, one of the forgotten aspects of capital is its weakness in terms of the ways it constantly undermines itself and this is key to understanding our role as workers in HE against capital and capitalism. The state (as a form of capital) must go to intense efforts in order to make and maintain HE as part of capitalism. HE is the 'invisible sausage' factory (to paraphrase Marx) as the notion of a commodity must be established simultaneously with the establishment of academic labour power. What academics 'do' must be made into a capitalist 'thing' and this requires academics to be made into proletarians. This 'thing', the commodity, is consistently undermining itself, not only as it must be imposed by force as a ludicrous proposition, but also as its essence as a thing of value is consistently ungrounded by the way in which value itself loses its substantial nature. As labourers we feel that our labour power is a thing against ourselves in its exercise and in its products, but we have some agency over when, where, and how we choose to use this labour power (or not). In every moment of capital's existence and accumulation, there is a human decision and effort involved which must be wrestled from the academic worker begrudgingly. This applies to Higher Education as much as any other sector, but it is only as our work becomes increasingly related to the production of educational commodities that we can understand our positions as labourers. Pixarfication both obscures and intensifies our position in terms of our relationship between capital and labour. On the one hand, the educational commodity as a composite becomes fetishised 
and develops its own alien autonomy. Universities can both deny that they are interested in 'Pixarfied beings' such as KPIs and state that it is inevitable that we need to comply with their logics. On the other, the increased proletarianisation of academics pains us further as we are subjected to greater levels of super-exploitation.

This exploitation is deepening (in terms of the subsumption of labour) and focussed on ever greater production of academic commodities (of which Pixarfication is a part), but it is also accelerating and intensifying. In Chapter 5, I will consider how ideas of existential threat, such as AI, are situated in 'capitalist time' and how existential threats, particularly the current pandemic threat of COVID-19 are being used in HE to extend the working day, the productivity and intensity of work, through $\mathrm{AI}$ and other technological means.

\section{References}

Ackerman, A. (2019). The Spirit of Toys. Resurrection and Redemption in 'Toy Story' and 'Toy Story 2.' University of Toronto Quarterly, 74 (4), pp. 895-912. DOI: $10.3138 /$ utq.74.4.895.

Backhaus, H. G. (1992). Between Philosophy and Science. In: W. Bonefield, R. Gunn and R. Psychopedis. (Eds.). Open Marxism, Volume 1: Dialectics and History. London: Pluto Press.

Beer, D. (2018). The Data Gaze: Capitalism, Power and Perception. London: Sage. Bourdieu, P. (1984). Distinction: A Social Critique of the Judgement of Taste. London: Routledge.

Bryman, A. (2004). The Disneyization of Society. London: Sage.

Dyer-Whiteford, N., Kjøsen, A. and Steinhoff, J. (2019). Inhuman Power: Artificial Intelligence and the Future of Capitalism. London: Pluto Press.

Goggin, P. (2016) (Ed.). Environmental Rhetorics and Ecologies of Place. London: Routledge.

Harman, G. (2016). Immaterialism: Objects and Social Theory. Bristol: Polity.

Hartley, D. (1995). The 'McDonaldization' of Higher Education: Food for Thought? Oxford Review of Education, 21 (4), pp. 409-23. DOI: 10.1080/ 0305498950210403.

Hayes, D. (2017) (Ed.). Beyond McDonaldization: Visions of Higher Education. London: Routledge.

Hayes, D. and Ritzer, G. (2017). Beyond McDonaldization: A Conversation. In: D. Hayes. (Ed.). Beyond McDonaldization: Visions of Higher Education. London: Routledge, pp. 1-18.

Hayes, D. and Wynwood, R. (2002). The McDonaldization of Higher Education. London: Bergin and Garvey.

Kurz, R. (2014). The Crisis of Exchange Value: Science as a Productive Force, Productive Labour and Capitalist Reproduction. In: N. Larsen, M. Nilges, J. Robinson and N. Brown. (Eds.). Marxism and the Critique of Value. Chicago: MCM' publishing, pp. 17-76.

Marx, K. (1990). Capital: A Critique of Political Economy, Volume 1. London: Penguin. 
Marx, K. (1992). Capital: A Critique of Political Economy, Volume 2. London: Penguin.

McKenzie, L. (2015). Getting By. Bristol: Policy Press.

Meinel, D. (2016). Exceptional Animation: An Introduction. In: D. Meinel (Ed.). Pixar's America. London: Palgrave Macmillan. DOI: https://doi.org/ 10.1007/978-3-319-31634-5.

Ortlieb, P. (2014). A Contradiction between Matter and Form: On the Significance of the Production of Relative Surplus Value in the Dynamic of Terminal Crisis. In: N. Larsen, M. Nilges, J. Robinson and N. Brown. (Eds.). Marxism and the Critique of Value. Chicago: MCM' publishing, pp. 77-122.

Pitts, F. (2018). Critiquing Capitalism Today: New Ways to Read Marx. London: Palgrave.

Preston, J. (2021). Where Did the Learning Go? Artificial Intelligence, 'Use Sovereignty' and 'Pixarfication' in Factories of the Future. In: M. Malloch et al (Eds.). SAGE Handbook of Learning and Work. London: SAGE.

Rikowski, G. (2000). Messing with the Explosive Commodity: School Improvement, Educational Research and Labour-Power in the Era of Global Capitalism. Paper presented at the British Educational Research Association Conference, Cardiff University, 7-10 September.

Ritzer, G. (2000). The McDonaldization of Society. Thousand Oaks, C.A: New Century.

Skeggs, B. (2003). Class, Self, Culture. London: Routledge.

Sohn-Rethel, A. (1978). Intellectual and Manual Labour: A Critique of Epistemology. London: MacMillan Press.

Tableau.com (2020). Retrieved from: https://www.tableau.com/en-gb/trial/ tableau-software?utm_campaign_id=2017049\&utm_campaign=ProspectingCORE-ALL-ALL-ALL-ALL\&utm_medium=Paid+Search \&utm_source= Bing \&utm_language $=$ EN \&utm_country $=$ UKI $\& \mathrm{kw}=\% 2$ Btableau \&adgroup $=$ CTX-Brand - Core $-B \&$ adused $=\&$ matchty $p=$ p \& placement $=$ \&msclkid=78d1a0067d421faaea 8afde7eb0a80b5\&gclid=CPOjgP22kOYC FcKUhQodS5IEBw\&gclsrc=ds.

Tenkle, N. (2014). Value and Crisis: Basic Questions. In: N. Larsen, M. Nilges, J. Robinson and N. Brown. (Eds.). Marxism and the Critique of Value. Chicago: MCM' publishing, pp. 1-16.

Thomas, S. L., Nafus, D. and Sherman, J. (2018). Algorithms as Fetish: Faith and Possibility in Algorithmic Work. Big Data \& Society, 5, p. 1. DOI: https://doi. org/10.1177\%2F2053951717751552.

Times Higher Education (2020). Retrieved from: https:/www.timeshigher education.com/datapoints/files/homepage/attachments/the_datapoints_ brochure.pdf.

TopUniversities.com (2020). Retrieved from: https:/www.topuniversities.com/ qs-world-university-rankings.

Universities UK (2016). Retrieved from: https://www.universitiesuk.ac.uk/policyand-analysis/reports/Documents/2016/analytics-in-higher-education.pdf. 


\section{Disaster Capitalism and Time in the Virtual University}

\section{Introduction: The 'New Normal'}

Capitalism is a permanent disaster as it collapses all existence into the generation of profit and, through disaster capitalism, it can turn a crisis into an opportunity. 'Disaster Capitalism' (Klein, 2008) as a normal way of doing business is particularly relevant during the 2019-2021 global COVID-19 pandemic. At the time of writing (2021), the pandemic seems to show no sign of disappearing and has been described as a 'new normal' in terms of Higher Education (HE) teaching and lecturing. In this 'new normal', in many countries, students increasingly learn through virtual lectures, delivered in synchronous or asynchronous time, by real or technologically mediated lecturers. There has been rapid, worldwide adoption of these technologies in the pandemic (Crawford et al, 2020). Artificial Intelligence (AI) is used to support learning platforms such as 'Zoom' and 'Microsoft Teams' with multinational corporations offering 'solutions' to HE problems (Teräs, Suoranta, Teräs and Curcher, 2020) to profit from emergency. These digital learning platforms, along with technologies such as telepresence and holography, have long been promoted as the future of HE by large monopolies such as Apple, Google, and Microsoft. The term 'new normal' suggests an ontological break with the continuity of social progress, that the normal has been reinvented in the face of an existential threat (the COVID-19 pandemic, Tesar, 2020). This implies that there is a break in time from the 'old normal' to the 'new normal' but (capitalist) 'normality' still reigns. As has been shown in the previous chapters, there is nothing 'normal' (or normative) about capitalist universities where the world is inverted so data commodities have a voice and in which capital (sometimes appearing as AI) subsumes academic labour. If anything, 'the new normal' is still 'the abnormal' and there is nothing new about it aside from that the pandemic has accelerated the application of digital and AI techniques to HE.

Like all such accelerations in capitalism, this changes what might be called the 'density' of capitalist time (more production, circulation, and exchange take place in each hour) but is not a 'break' in any kind of time

DOI: $10.4324 / 9781003081654-5$ 
order. A disaster (such as COVID-19), and even an existential threat of a super-intelligent AI takeover, does not change capitalist time or the fundamental nature of capitalism, even as part of 'disaster capitalism' but instead leads to a step-change in time-density (with greater speeds of commodity production and circulation). It acts to accelerate formal and real subsumption by acting as a 'force multiplier' for academic labour whilst virtually extending the lifetime of the labourer. New digital technologies used in the COVID-19 pandemic seemingly revolutionise capitalist universities but only in terms of intensifying exploitation.

In this chapter I use Marxist understandings of time, associated primarily with the work of Postone (2003), and his conceptions of concrete, abstract, and historical time, to argue for three contentions regarding COVID-19 and AI in Universities. Each of these is connected to the peculiarity of capitalist time or temporality. Firstly, that technological solutions allow for the extension not only of the working day, and the increased intensity of work, but (through AI) the working life of academic labour. Secondly, that the idea that the pandemic represents a discontinuity in terms of a 'new normal' is incorrect and the terminology of normality is unhelpful. For capitalism, disasters are not a break to the time order of capital. Thirdly, that AI and technological solutions, which are a feature of learning in the current pandemic, lead to an increase in the density of academic time with a greater production of commodities (or commodity stock) in every second of academic life. Although the examples used in this chapter relate to the COVID-19 pandemic, they are applicable to the trajectory of capitalist universities more generally where disasters and crisis (including economic shocks, natural disasters, and changes in student demand) are used to restructure not only space but also how time is used.

\section{Virtuality, Academic Working Lives, and Re-animation}

The COVID-19 pandemic appears as a class conflict over time and work allocation. In capitalist universities it seems to be a struggle between managers and academics as to whether they should work on campus (potentially exposing academics to the COVID-19 virus), and the times (and time) they should work in terms of delivering online lecturers and other forms of activity. The concept of time as an element in struggle is important (in terms of struggles over the working day) but time in capitalism is not just another domain of contestation between the ruling class and the working class or a division between a romanticised human pastoral (in front of students) and machine (in front of a computer) time, or even as a determining metric of production across societies (as claimed by Bidet's, 2017 critique of Postone). Time in capitalism can be best described as abstract time (Postone, 2003). As part of this, capitalism also produces a differential framing of concrete time (Murthy, 2009; 
after Postone, 2003) in which real events (production, distribution, circulation) accelerate within the same temporal frame. Cumulatively, these events unfold in historical time.

These conceptions of time are located in Postone's (2003) reworking of Marx's critical theory which (as discussed in Chapter 2) historicises the concept of labour, as abstract labour, as unique to capitalism and shows its role in creating the unique form of domination of capital as selfvalorising value. Postone makes the distinction between different time orders in capitalism where time is instrumental, and endogenous, rather than being exogenously determined. Time serves a particular purpose in capitalism. It is the measure of the expenditure of abstract labour in terms of labour time, definitively as '...the socially necessary expenditure of human labour time' (Postone, 2003, p.189) being '...the labour time required to produce any use-value under the prevailing socially normal conditions of labour and with the prevalent socially average degree of skill and intensity of labour' (Postone, 2003, p.190). This temporal norm of how long it takes to produce an item becomes fleetingly prevalent across capitalist society before this advantage is competed away. This abstract time of production differs from concrete time '...the various sorts of time that are functions of events' (Postone, 2003, p.201) such as natural events (lunar cycles or seasons) whereas abstract time is '....uniform, continuous, homogenous, "empty" time... independent of events' (Postone, 2003, p.202). Time is absolute, abstract, and homogenous and an independent variable (Postone, 2003, p.215). It is important to see this notion of time as more than 'empty, homogenous time' (Postone, 2003, p.47). Increases in productivity over historical time (and improvements in technology and organisational processes), redetermine the 'abstract, constant time unit' (Postone, 2003). The interaction between concrete production and abstract labour produces a treadmill effect (Wendling, 2009, p.196), increasing the productive density of abstract time:

Increased productivity increases the amount of value produced per unit of time - until this productivity becomes generalized; at that point the magnitude of value yielded in that time period, because of its abstract and general temporal determination, falls back to its previous level. This results in a new determination of the social labour hour and a new basis of productivity.

(Postone, 2003, p.289)

Time becomes denser, like thickening soup, as more activity (production, circulation, and exchange) takes place in every hour but this '.... is not manifest in the sphere of abstract temporality, the value sphere: the abstract temporal unit - the hour' (Postone, 2003, p.292). As units of abstract time move forward, an hour is still an hour on the clock despite the social labour hour being constantly determined as '...each new 
level of productivity is redetermined "back" as the based level yielding the same rate of value' (Postone, 2003, p.292). Workers are effectively running to stand still as more commodities are produced in each time interval that only yield relative surplus value if they break the previous production norm. Global collective labour is not only exploited by capital but also (as appropriated as a property of capital) consistently resets the capitalist's clocks and production schedules. This is not in terms of what is scientifically or humanly possible, but what the market demands.

Materially, the nature of society and production is fundamentally changed over concrete time, a process which Postone refers to as historical time (Postone, 2003, p.293). According to Murthy (2009) 'What distinguishes historical time is precisely that it is linked to an increase in productivity that capitalists bring about through the production of relative surplus value' (Murthy, 2009, p.21). Murthy (2009) considers that Postone has two notions of concrete time. One that refers to pre-capitalist societies, that is the time of events, and one in capitalist societies where it is a totalising dynamic. It is concrete when compared to abstract time in capitalism but its concreteness '...lies in a process of increasing productivity and this type of time is blind and not innately connected to a symbolic world' (Murthy, 2009, p.22). This is not a cultural or ideological process, but an economic and historical one in which 'The temporalities of capitalism, then, are not specific to it, but are intrinsic to its structuring social forms' (Postone, 2003, p.47). Value production becomes increasingly stretched and diminishes in credibility as technology and other organisational forms accelerate and more use values are produced.

In terms of the pandemic, technology enables not only an extension of the working day (formal subsumption) by allowing lecturers to work from home and teach across time zones using their laptop and technological tools (real subsumption) but increases the productivity of labour. Now there is effectively no limit, in terms of a physical lecture theatre, of the range of a lecturer's voice in terms of delivering content to any number of students who can be taught simultaneously. In many cases during the pandemic, for example, lecturers have delivered real-time lectures whilst simultaneously giving lectures online. Through this process, the virtual capitalist university expands the possibilities of exploitation and subsumption of lecturers. They can teach more students at a lower cost as resource costs are displaced from the university campus to the lecturer's own home. Their work is fragmented and separated from their colleagues and this work is mediated and captured by technology as a property of the capitalist university. This intellectual property of the university is then further exploitable through using machine learning analytics to edit and restructure lectures or series of lectures. More 'commodity stock' (students receiving lectures) is delivered in each hour and the profit made through this increased exploitation can be reinvested into technology or management. Capitalism uses the pandemic to move 
to virtual universities or hybrid institutions with the optimal mix of real or virtual being determined by profitability.

$\mathrm{AI}$ and associated technologies enable this process on an hourly basis in the virtual university (as they are part of the technological infrastructure), but they also set the scene for a re-specification of the working life of an academic labourer. In Universities, there are some benefits of experience and, to a certain extent, HE balances precarious employment contracts with facilitating working (for some) at least until retirement, but labour power does not persist after death as this is the end of the worker's consciousness. There is, though, an application of academic labour not just on a second-by-second basis but also over a lifetime. Osborne (2008) raises the issue of the life of the labourer as an overlooked aspect of temporal orders in capitalism. According to Osborne, 'abstract labour is not just 'concrete labour' and 'abstract time' (Osborne, 2008, p.19). Labour time is '...part of the life-time of the labourer' (Osborne, 2008, p.19). Osborne, therefore, posits the lifetime of the labourer as the 'ontological basis of the "value" of time' (Osborne, 2008, p.20). Lecturers often devote their entire working lives to one, or a series of, capitalist universities because of the necessity of wage labour. In support of Osborne's argument on the 'life' of the labourer, Wendling (2009) argues that Marx was influenced by studies of thermodynamics in considering human labour power. Particularly when considering machines (especially their ownership and implementation by the capitalist class), Wendling identifies the history of existing science, technology, and manufacturing as being the subsumption of labour over generations. In terms of a contemporary female worker on a production line, the labour of her past generations are represented as capital:

It is though her mother's and grandmother's exhaustion are driving her out of work - as though they themselves had come to stand over her. The very powers that created her, the powers of her own class, powers that are her own powers, are undermining her. Instead of machine-worker class-kinship, strife appears between the worker and the machine.

(Wendling, 2009, p.123)

The ontological category of the labourer's life, or the lifetime of previous labourers, does not enter into Postone's category of time, although, in the era of AI it is applicable to the life of contemporary academics. For lecturers, the university buildings, computers, and administration are products of the labour of their predecessors and of many other workers such as builders and accountants. This generational dead labour facilitates, and creates an expectation of, the production schedules of academics. Increasingly, the banks of pre-recorded lecturers (Optimised for student customers through AI and machine learning) 'stand over' (Wendling 
2009, p.123) each lecturer, intensifying the struggle to 'add value' to the university and remain in employment. The capitalist university could increasingly become an educational Netflix, with lecture choices optimised for each student consumer from a pre-existing menu, perhaps facilitated by a GTA (Graduate Teaching Assistant) and a virtual, AI, assistant. The life of lecturers becomes an increasingly precarious struggle to add to this technological pile that heaps increasing precarity and exploitation down to the next generation of academic labourers.

Similarly, humanity's lifetime (or the human as a species being) is not factored into this schema. It is true that Postone's conception of time is not existential (and hence not bound up with notions of life or death) as this is internally consistent with his notion of capitalism as abstract domination and anti-humanist. Capitalist (abstract) time has no notion of finality as a humanist concept. The lifetime of the individual labourer is not the real ontological basis of time's value as this only represents a slice of the total labour time incorporated in capital and is meaningless to it. However, AI (and associated technologies) do provide the potential to seemingly extend the lifetime of the academic labourer through virtuality and 're-animation'. Lectures are currently recorded and replayed, but through AI and other technologies can be recombined, mined, and potentially 'deep-faked' to provide new content. Although these AI-mediated technologies are not sufficiently advanced as to allow for this substantively at present, the recording of lectures during the pandemic allows them to be banked as intellectual property by the University. Academic labour is therefore never quite dead, or incapacitated, but may be consistently revived in a reanimation. For example, Concordia University continued to use the recorded lectures of a dead professor in an Art History module (Chin, 2021). Whether this is as continued labour power or as fixed capital is a contentious point (it is probably best classified as dead labour or fixed capital) but is a particularly diabolical variant of the concept of hyper-subsumption (DyerWhiteford, Kjøsen and Steinhoff, 2019) that was discussed in Chapter 3.

\section{No 'New Normal': Disasters, Existential Threats, and Time}

Capitalism is obsessed with ideas of change, time, modernity, and acceleration, but also with the control of time through strategy, and a fetishisation of agency and decision making. In the current pandemic, as discussed above, universities are seemingly compelled to be strategic in applying new technologies to introduce virtual and online teaching to mitigate against the illness (and resistance) of labour. There is no time for a pause or a stop in academic production no matter how severe the crisis. As discussed previously, the capitalist university requires a constant revolutionising of the conditions of production in terms of technology 
and organisational form even in disasters or pandemics. It continually requires living academic labour to produce value and demands that individuals invest in their own human capital to advance labour power. This is not ideological but a reality, a really existing abstraction that compels humans to work and invest, adopting the character masks of labour or capital. Students strategically use the pandemic to optimise their choice of course whereas universities realise value by creating demand for particular pathways. New online learning features are introduced as a result of investments in the latest technology and fixed capital. Web designers are employed to advance these technological developments. They work to produce a commodity under the same conditions (wage labour) as the academic workers who then will produce the lecture commodities ('commodity stock') on the virtual production line. For the capitalist university, decisions are driven by the necessity to turn a sum of money into a greater sum of money through investing in the most profitable areas otherwise the capitalist may go out of business or their university may be taken over by another, or by the state. These 'decisions' are driven by the necessity for value to be self-valorising and ever increasing even under conditions of class struggle. In its desire for self-valorisation, capitalism is (non-anthropically) single minded aiming to increase profits. This is 'normal', 'business as usual', for capitalism and, despite the novelty of the pandemic situation, this is no 'new normal' but rather a continuation of the existing situation. It is the continuation of the 'old abnormal' (including capitalisms consistent technological development in the interests of profit) rather than any sense of the 'new'. By making distinctions between 'old' and 'new' and identifying critical junctures, we neglect the specifically capitalist nature of time. This also holds for 'Disaster Capitalism', which is not exceptional, but a depiction of the constant 'disaster' of capitalism in every instant. This can be explained by examining critical junctures, unintended consequences, and the nature of disasters and existential threats - particularly the existential threat of AI.

\section{Critical Junctures and Unintended Consequences}

Naturally, capitalists are familiar with disruption and the notion of 'critical junctures' as these occur frequently in terms of hesitations in the normal flow of events in capitalism. This could involve a disruption to production or circulation, to the creation or realisation of value, or the destruction of commodities or labour power. Existential threats represent the end of what is understood as the normal flow of spatial and temporal events but in capitalism such events are only meaningful if they represent the end of value production and circulation and the end of capital as self-valorising. Disasters and existential threats to humanity do not necessarily represent the end of capitalism as such. It can immediately be seen that what is defined as a disaster (such as a tower block 
fire) or an existential threat (such as AI takeover) in common language is very different to what might be described as a disaster or existential threat in the logic of capitalism.

In disaster capitalism, disasters are capitalised on at critical points. There is a series of events that capitalists, or (for some) the human representatives of capital, or the character masks held by those involved in this production, decide to intervene in for the purposes of profit or accumulation. Although disasters often appear to be the unintended consequence of some series of events, the discourse of disaster capitalism understands them to be otherwise. They could be the result of the intention of capitalists, in the interests of a specific form of capital accumulation or capital accumulation in general, or a capitalisation to benefit from an unexpected event. The intentionality of capitalists does not have to be overt but can also be tacit and does not have to be direct but can also be distributed. In this sense time is just like space or any other physical entity in capitalism. It is a domain where there is unequal ownership and contestation with different levels of agency. Disaster capitalism can be depicted as this inequality of time and space. Although sometimes disasters and emergencies are engineered through conscious and conspiratorial enterprises, which are sometimes criminal, they are more often seen as unintended. Mica (2018) outlines three approaches to unintended consequences, those arising from social action, social interaction (and the production of resulting institutions or practices), or from institutionalised practices but the analysis of unintended consequences also concerns the realm of the contingent and the possible. In a Marxist analysis, disasters can be placed in the category of the contingent as they are homologous with capitalism (in essence it is crisis) but for a capitalist, a disaster is often an opportunity (Klein, 2008).

In Marx's Capital, disasters had two sources which were endogenous to capitalism and did not represent a 'break' in the normal business of production. Firstly, Marx's work on the conditions and injuries of factory workers emphasised the centrality of profit as a criterion for safety. Reforms would be resisted, or passed, only to the extent to which they led to sustained or increased profit (Marx, 1990). Secondly, the proliferation of commodities and fixed capital (Marx, 1992) and capital's ceaseless expansion exceeds the control of increasingly stretched human attention. Wendling (2009) explains how Marx (particularly in his writings on railway accidents) considered how the rhythms of the mechanic become increasingly beyond the limits of human perception:

Part of the monstrosity of machinery is its affront to pastoral time and pastoral timing. The speeds at which machines operate - speeds sometimes beyond the capacity of the human perceptual apparatus contribute to the demonic mythology of machines.

(Wendling, 2009, p.192) 


\section{Disaster Capitalism and Time}

The role of speed and attention in modern disasters has also been considered in non-Marxist theories. Campbell (2011, pp.56-7) considers that attention is an important aspect of judging whether an action can be described as having unintended consequences. Where attention is (necessarily or not) limited then it does not seem likely that an action can be described as having unintended consequences. However, attention is an important factor that can be said to be responsible for an increasing number of disasters as technology develops. Viral videos and memes showing people walking into roads or falling into fountains because of checking their mobile phones are commonplace on social media. Recent concerns over the attention economy have led some authorities to warn about checking mobile phones when driving or crossing roads. However, the attention economy predates modern technology and Merton (1936) originally discussed the implications of the economic costs of attention in determining the consequences of actions. The idea that the speeding up and acceleration of technology, becoming out of control, has resonance with modernity and risk society thesis that view increasing complexity as meaning that risks to humanity increase. This is the key theme of many works of what has been referred to as accidentology where the acceleration of technology and complexity produces increasingly complex industrial accidents of increasing scale (Matthewman, 2012). The theme finds its apogee in the analysis of the existential threat of AI (Bostrom, 2014) where the units of time concerned are the microand pico-second and chains of events are established which are beyond human action or agency as AI becomes conscious and then dominant. AI can work more quickly than human time, not being constrained by the neurological and physiological restrictions of human action.

\section{Disasters, AI Existential Threats, and the Specificity of Capitalist Time}

Capitalism is constantly speeding up production and events occur faster than human attention or senses, but it is important not to treat the COVID-19 pandemic, and the application of technological solutions in universities as in any way discontinuous with existing tendencies. The specificity of capitalist time means that disasters are inseparable from the normal flow of capitalisms 'events' even if they occur naturally. This perspective is counter-intuitive to a conventional understanding of disasters as disruptive, and as representing a 'new normal'. Disasters, including pandemics or even the threat of a self-aware, malicious, AI are part of (and not separate from) capitalism but analysis of disaster situations often stresses their uniqueness. When disasters are reviewed in post-hoc analysis or public inquiries, for example, the role of time and critical junctures is seen to be central. Whether something could have been done to stop a disaster, or whether the action that someone 
could have taken would have helped them survive, becomes a matter of chronology and clock time. Countdowns and critical paths are used to map the sequence of events. In the inquiry into the Grenfell Tower fire that occurred in London 2017, for example, chronologies are a matter of legal and political argument as will be shown below. In work on the existential threat of an AI takeover, scientific debates are conducted to estimate when would be the correct moment to prevent the development of malignant technologies.

Work on disaster capitalism usually portrays time conventionally, but with a consideration that time, like resources, is a contested field where there is differential access to economies of time and space (Klein, 2008). Whilst capitalists and the state have the autonomy, intentionality, and resources to make decisions quickly and with superior information, others have limited agency and limited access to truth. This understanding of contested time in disaster capitalism is useful but it obscures the fundamentally capitalist nature of time. Disaster capitalism is not just a contestation of time and resources but a rupture between material wealth and value and concrete and abstract time. In capitalism, apocalypse is not just something that happens in the future but is always happening in every moment of capitalism. All disasters in capitalism are related in terms of occurring in uniquely capitalist time. This applies to future disasters and existential threats as much as present ones such as the COVID-19 pandemic.

In terms of AI, for example, there is a rapidly expanding literature on the existential threats arising from an AI 'takeover' (Bostrom, 2014) which can involve various types of technological apocalypse. One scenario is complete destruction of humanity through malicious ends occurs as an AI becomes a malevolent psychopath. There are also accidental scenarios such as those where a military AI falsely detects a missile launch from an enemy and decides to retaliate through dispatching its own salvo of nuclear weapons. More common are the threats from AI which arise from an inadvertent instruction, or an inability to write an instruction, which would mean that an AI would engage in an eternal and purposeless instruction such as converting the entire universe to paperclips or performing invasive neurosurgery on every living thing to ensure that it was constantly happy. Some of the existential threats of AI verge on the magical. In one of these, AI could create a simulated universe of sentient creatures and torture them constantly. Even more fancifully, an AI could decide to simulate all sentient creatures who had ever lived by replicating their minds and mental states and torture them. Such a scenario has been considered in what is called 'Roko's Basilisk' (discussed in Sandifer, 2017) where a powerful AI in the future brings the dead back to life in a virtual environment and subjects them to horrific tortures. This scenario has convinced some that it is essential that we bring such an AI entity into existence as if the AI perceives that we 


\section{4}

have not put our full efforts into realising its existence it can virtually resurrect us and decide to torture us (Sandifer, 2017). Such beliefs about AI border on the theological and are akin to the idea of Pascal's wager where the cost of not believing in God is high as if God does exist then such a belief would mean that one would go to hell (Sandifer, 2017).

The idea that we have to make a decision about what to do about technologies such as $\mathrm{AI}$ in the here and now is pervasive in capitalist discourse. In disasters more generally, the importance of time and critical decisions is paramount. It is supposed in current capitalist discourse that if we knew the correct juncture, we would have known the optimal time to intervene to stop $9 / 11$ or the stage at which the residents of a disaster should have evacuated or the time at which we should put a stop to the development of sentient productive AI. We could make decisions that would have important consequences. According to Bostrom (2014), for example, there is a critical juncture, which we may not even know of, at which an AI takeover becomes inevitable and unstoppable. However, the dynamics are already underway. Bostrom sees an AI takeover as almost being unstoppable due to the dynamics of capital (although he does not use that term). Capitalists and capitalist (or state capitalist) countries are in competition with each other to produce the ultimate AI, and hence accelerate the move to a point of no return.

In disaster capitalism, there is an emphasis on concrete time, with cause and effect, and where decisions make a difference, rather than the abstract time of capitalism which requires production under constant time compression and crisis. Existential threats, such as the threat of AI, assumes a new time order but this is not necessarily the case, as capitalist time can continue even given an existential threat to humans. Disasters unfold in capitalist time (abstract time) which is constantly and consistently a temporal disaster already in terms of the dissolution of value. Rather than seeing a disaster or an existential threat as a 'breaking point' in capitalism, they are points of continuity. Disasters are symbolically represented as a disruption to what is understood as the normal flow of spatial and temporal events. The technologies of policy, academia, and law, for example, make sense of disasters as involving a series of events and critical junctures in which concrete choices can be made and hence invalidate a negative critique of capitalism. A choice to do one thing or another can result in a different timeline in which a building did not collapse, or a person did not die. Disasters are portrayed as a series of branching points which convey different realities. The countdown, or ascending log of seconds, is a common trope in disaster fiction or reconstruction in which there is a certain time remaining before a critical event occurs, or is prevented, which will determine the subsequent series of events. The ticking clock in the television series 24 which constantly counts upwards, second by second, foreshadowing another imminent terrorist attack is one fictional example of this. Existential threats are 
commonly understood as the end of a particular existence, through nuclear war or an apocalyptic natural disaster. In both cases, anthropocentric time and critical incidences are central. However, we rarely look at time in disasters beyond the mainstream view of linear, sequential, time. This is particularly salient when it comes to disaster capitalism, which is unusual; when one considers that there has been critical work in Marxist theory which examines the importance of particular time orders to capitalism. Disasters, and existential threats, are constantly present in the metaphysics of capital and are hence always here in the 'now' as well as in the dynamic of capitalist history.

As a tragic example of how capitalist temporalities are absent from discourses of disaster, a thoroughly capitalist disaster was the Grenfell Tower fire on the June 14, 2017. In this disaster 72 residents were killed in a fire where there had not only been frequent resident's complaints regarding the safety of the block, but also where the residents were advised to 'stay put' during the fire. This incident has become a symbol of disaster capitalism in the UK as iconic as that of Hurricane Katrina in the United States. Situated in the Royal Borough of Kensington and Chelsea, one of the richest and most unequal areas in the UK, the disaster has come to symbolise the shortcuts of contractors, the involvement of local authorities in property deals, the use of poor materials and fire safety in tower blocks, and the racial- and class-based elimination of residents (Preston, 2019). In the inquiry into the Grenfell Tower Fire much was made of the decision to either 'stay put' or evacuate by the residents in the fire where there was apparently a critical point, or juncture, in which to do this. Experts in the official inquiry made reference to the difficulty of making timely decisions under these circumstances when confronted with ambiguous information:

So the behavioural side of it is: I've got this very difficult decision to make - which was faced by Grenfell occupants in some cases several times during the course of the fire. Early in the fire, you open the door, you see smoke, maybe this was after about 01.30 on the morning of the fire, when there was a lot of smoke in those lobbies, and you have to make this difficult decision: do I stay put or do I decide to try and make it to the stair and go out? If I go to the stair and get out, that's over, but if I decide to stay put, I may then have to revisit this decision later on as conditions deteriorate outside the flat.

(Inquiry, Expert Witness Statement: Professor David Purser, November 29, 2018, my emphasis, Grenfell Tower Fire Inquiry, 2020)

What this shows is that many, many people started to evacuate very early on. Indeed, nearly all these people here on these floors started to evacuate before there was significant smoke in the lobbies. They 
were able to make an effective and safe descent because there was virtually no smoke in the stair at that time either. But after that time, the stair is still relatively clear of smoke, but the lobbies are full of dense smoke. So now we have a period where people are opening their flat doors and either deciding to brave going through the smoke, or they say, 'It's too dangerous, I'm going to stay put'.

(Expert Witness Statement: Professor David Purser, November 29, 2018, my emphasis, Grenfell Tower

Fire Inquiry, 2020)

There are also references to the difficulty of making judgements for the fire service:

'At page 5 of your witness statement, you say that you remember discussing with AC Roe: "... whether to overturn the FSG advice being given from 'stay put' to 'get out if you can'." Can you remember the stage in the evening when you had that conversation with AC Roe?

A. Yes, so I think it was probably the first time I actually saw him, and I think it was more of a one-way discussion, if I'm honest. It was more him telling me -

Q. Going which way?

A. Yes, him telling me that that's what had happened, so that's what prompted me to go and then brief the crews about the change in situation. So at that point I thought, because of the flow of people coming out the building, that probably that had happened, if I'm honest. So, yeah, as a discussion point, it was more for me to go and inform me to change my own risk assessment.

(Further LFB Evidence, October 2, 2018, Grenfell Tower Fire Inquiry, 2020)

These extracts show that the inquiry repeatedly referred to the importance of critical decisions being made, and the optimal advice and assistance being given at the correct times. Disasters in these narratives unfold in time and the correct or incorrect decisions being made at the right or wrong time can change the flow of events, the public and judicial judgement of the victims, and the agencies involved. This is not just a neutral observation. Preston (2019) claims that ambiguity in such processes is used to obscure processes of eliminationism and to absolve authorities of blame. However, the notion of critical junctures and disasters as 'breaks' with the normal can position capitalism as seemingly external to events which are described as involving individual decisions.

Returning to the discussion of AI, existential threats, such as an AI takeover are also framed in terms of critical junctures where an error 
will lead to a catastrophic chain reaction but in this case, prediction is even more problematic. As explained previously, Bostrom (2014) does not necessarily consider it possible to make an accurate judgement as to when AI research will lead to an existential threat. As a future AI will apparently be capable of autonomous thought and bootstrapping its own intelligence, it is not possible to determine when a particular research programme should stop. This is particularly the case when there are competing research programmes between different firms and countries. As soon as the AI can 'unbox' itself and gain access to resources through technical and/or social manipulation, it can purposively or accidentally destroy humanity. Even if the AI is given a seemingly benign order (for example, to produce paperclips), it will follow this order to the point of absurdity (for example, working to convert the entire universe into paperclips). This will produce the end of human time, and a new nonanthropocentric form of time which nevertheless continues. Again, there are a series of branching and decision points and countdowns to the switching on of an AI. Increasingly, the existential threats from AI are considered inevitable after a certain point, and that no choice is available. Bostrom's (2014) notion of mind crime where an AI can produce technologies that would simulate a sentient population which could be 'tortured' in order to force humanity to bring about its ends is one such possibility.

The phenomena of Roko's Basilisk (Sandiferr, 2017), discussed previously, implies that where not to use every available force to bring about a superintelligent AI means permanent damnation through endless torture of a simulation of each person who did not take this action. This means that $\mathrm{AI}$ is seen less as an unintended consequence of technological progress but rather a necessary consequence. The destruction of humanity is perceived as an inevitable consequence of technological progress that must be accelerated. Like Fisher's (2009) discussion of Capitalist Realism where there is no alternative not only to capitalism's existence, but also to its acceleration, the portrayal of there being no alternative to a catastrophic AI superintelligence is endemic in work on existential threat. As Žižek (2019) states:

From Zuckerberg to Gates and Musk, they all warn that 'capitalism as we know it' is approaching its end and advocate countermeasures such as minimal income...In short, their version of the end of capitalism is the capitalist version of its own end, where everything will have to change so that the basic structure of domination will remain the same.

Žižek (2019, pp.3-4)

Although Žižek does not fully explore his point, this 'basic structure of domination' is production on the basis of value. Dyer-Whiteford et al (2019) also point out that AI capitalists including Musk, Zuckerberg, 
and Gates all warn of the existential threat of an AI takeover whilst investing in AI technologies and that:

...these AI moguls are no more, or less, than the personifications of abstract forces of market calculation that drive towards the maximisation of profit. They also obscure the massive hubris of the capitalist class that believes it can control the forces it has unleashed.

(Dyer-Whiteford et al, 2019, p.4).

Despite a critical emphasis on 'disaster capitalism', then, the treatment of disasters often does not often deviate from ideas of what Firth and Robinson (2013) refer to as 'mainstream time', linear or clock time. Time is considered to be infinitely divisible and extended, representable in a time grid and part of a linear, irreversible progression (Firth and Robinson, 2013, p.3). Time may be a domain of contestation between the ruling and working class in a disaster, but it is a contestation of reaction or ownership of moments rather than of temporalities. This conception of 'mainstream time' allows for a standard (four) dimensional analysis of disaster capitalism where there is a spatial and a linear time dimension in which class conflict operates in an unfolding historical-materialist framework, but time itself is stripped of its capitalist nature. Understanding time as a capitalist abstract-real (rather than ideological, as explained previously) further enables us to understand not only the inevitability of disasters and existential threats to capitalism but their unique temporal nature. COVID-19 does not create a 'new normal' in universities, but it is part of the continuing capitalist 'old abnormal' where time itself is endogenous to capitalism. The capitalist university is not just subject to disasters and an exogenous time-order but it attempts to 'makes time', its own rules about how time is used and allocated, often using technology and AI to do so. It is also subject to the abstract time-order of capitalism. There is no 'break' and no 'new normal' after a disaster.

\section{AI, Technology, and the Time-Density of Academic Work}

Time, however measured in capitalism, contains an increased density of discrete events of production and produces an increased number of commodities and technologies expanding over historical time. As discussed above, disaster capitalism occurs in concrete moments but is also an artefact of abstract time. Even concrete time in capitalism is different from concrete time in pre-capitalist societies, being not just the time of events, but a time in which scientific, technological, and organisational development occurs with the purpose of increasing relative surplus value. This in turn is in a dynamic relation with abstract time as historical time. Notwithstanding the ways in which capitalism uses and 
despoils natural resources in its expansion, and accelerates circulation and movement, it is part of the dialectic of capitalism to produce a frame of time density that produces more discrete events (of production, circulation, and exchange) and more, and increasingly complex and saleable, commodities. This is more than a rupture between mechanic and human time but a whole new time order. In effect, there are two conjoint time orders - abstract time and a consistently reconstituted concrete time.

This whole process may appear to be paradoxical. The capitalist system has to grow, develop, and expand to survive but this growth, development, and expansion makes its survival increasingly less secure (non-withstanding counteracting tendencies). Mica (2018, p.45) usefully distinguishes between differing strengths (or strains) of the paradoxical in considering unintended consequences in that the unintended does not have to be paradoxical. Indeed, in Postone's analysis of capitalism the paradox between value and material wealth is necessary and definitional to the capitalist system. Capitalism has to contain a paradox as both a simultaneously thriving and decaying mode of production. The dialectic is also a paradox which unfolds in historical time.

It must be accepted that although Postone considers capital's existential threat, he does not consider the ontological nature of time for humans and humanity (Osborne, 2008). Osborne, though, does not consider the capitalist logic, or capitalist realism, of an eternal system which considers existential threats only as they might prevent the future of capitalism. This is a system that is already in decay and deceleration. The acceleration of technology produces a growing sphere of technological sophistication which becomes of no relevance in the next round of technological innovation which has the purpose of further reducing production times to increase the relative rate of surplus value.

In the most recent and relevant 'existential threat' to HE, the COVID19 pandemic, 'disaster capitalism' though the state and the market, allows for a speeding up of commodities produced in abstract time. Capitalist universities worldwide are moving to online provision and, though recording, allow for courses to be delivered and redelivered across extended time. The aspect of the 'commodity-stock' is stretched so that it can be valorised across a seemingly infinite mass of student consumers. As explained above, lecturers become 'virtual' and absolute subsumption re-manifests itself as lectures can be reviewed at any time whilst there is pressure to work increased hours to accommodate students in different time zones. It also manifests itself as hyper-subsumption as AI has a further role in terms of the development of virtual tutors, intelligent agents, and the monitoring of academic work (UCU, 2020). The Socially Necessary Labour Time (SNLT) to produce a commodity, and the time of its subsequent valorisation, drops dramatically. The state can also have a role in this process. For example, as a possible (although not certain) escape from 'market exit' in the UK, universities who are 
not financially viable due to the drop in (particularly international) students due to the pandemic are offered a 'recovery' plan for a 'restructuring regime'. This allows for Government to instantaneously disestablish courses that are thought not to offer sufficient employment possibilities. In other words, those courses that are not considered to be part of the social production of labour power will disintegrate. Additionally, the government can then impose the use of AI learning technologies and learning analytics on Universities to make sure they are fulfilling their obligations. Concretely, the state can therefore change the type of commodities that are marketised.

Even without state sanction, the move to remote and online learning allows for the recording of lectures which then can be delivered at almost zero marginal cost to the University. The labour of the lecturer is extended through time, even after their death, as their lecture of an hour can be repeated indefinitely. This is the concept of the 'force-multiplier' (Marx, 1992) whereby machinery acts to increase the 'force' of human labour. Vice Chancellors and university management valiantly attempt to avoid losses as they act as 'Time Lords' in terms of manipulating the time continuum through which commodities are produced and extending the working day. Academics become a face on the screen ('Zoom' meetings) for lectures and meetings, easier to replicate, simulate, and to analyse through AI.

In the COVID-19 pandemic digital technologies and AI increase the 'density' of time. More 'commodity stock' (Marx, 1992) (lectures) is being produced in each hour of time to eventually be valorised as a commodity (the data-commodity that is valorised for money). The 'force' of each lecturer's labour is increased and virtualised, even immortalised through technology. This is real, absolute, and hyper-subsumption as even the extension of the 'life-time' of academic labour becomes possible. In terms of how this 'feels' to labour, there is the direct compulsion to stretch labour further in every hour (often producing both 'real' and 'digital' lectures simultaneously). Aside from increasing the gendered division of labour and the use of 'domestic resources', 'working from home' is reported as being tiring as more commodity production is occurring over longer periods of time. The responsibility for this is diffuse. The intentionality involved in this form of disaster capitalism is not just a result of human operations (management) through linear time but nor is it just an artefact of a mechanical process in machine time. Capitalist time is empty, homogenous time, but it is time in which an alien intentionality is at work - self-valorising value. This has its origin in a subverted human essence, abstract labour time, and so is fundamentally human (at least in terms of labour power) but, in the form of capital, has become a form of social domination in itself. This is an alien expansion within an alien time with no human ontology (Murthy, 2009, p.20). The intentionality of the ruling class is a manifestation of this but 
even the ruling class are subject to this form of social domination. Time becomes increasingly filled with the alienating expansion of capital. Even disasters become unattributable not just because of complexity but as capital as self-valorisation becomes an increasingly proportional feature of each time unit. The traces of human agency become thinner and harder to track as capitalism intensifies. Engel's notion of capitalism's processes of 'social murder' (Engels, 2009) becomes a process of asocial, technologically mediated, murder (Preston, 2019). The ruling class still benefits but disasters cannot be blamed on the response of any one individual. The COVID-19 pandemic is the perfect example of this as it seemingly occurs 'externally' of capitalism and is 'non-attributable'.

Even though time is becoming 'denser' in this technologically mediated pandemic, what happens in each window in time is paradoxical and dialectical. Technological sophistication increases and a greater mass of commodities (commodity-stock - lectures) are produced whilst value becomes increasingly less substantial. The acceleration of technology and production of commodities is concurrent with the deceleration and undermining of value. Capitalism operates on a new temporal order (abstract time) which is in a dynamic with the old temporal order (concrete time), but even concrete time is remade as time in which time's purpose is subordinated to activities that increase relative surplus value. In every moment of an online lecture, capitalist production continues to be a disaster (for capitalism) in further progressing the end of value production. Perversely, capitalism destroys itself (although it might destroy us first) as it grows, accelerates, and becomes more productive. Capital reaches its own end through a 'desubstantialisaton' (Kurz, 2012, p.15) and becomes a '...pseudo-accumulation without substance' (Kurz, 2012, p.15). Disaster on an existential scale then becomes the only escape route for capitalism (Kurz, 2014). Temporary solutions such as the destruction of existing capital (as in the Grenfell Tower disaster) give way to the wholesale erasure of human knowledge (through perhaps a nuclear war which would perhaps reset the human species to late feudalism) or abandoning capitalism as a project based on human labour power for one where AI is the source of labour power. Disaster capitalism increasingly must raise the stakes in terms of the magnitude of disaster as time progresses. This is why AI is considered both to be an existential threat to capitalism but also as the ideal existential disaster for capitalism in terms of the continuity of production on the basis of value but one with a new species being (AI), for a 'pseudo-accumulation' (Kurz, 2012, p.15), if it cannot be tricked into becoming a new labouring entity. We are at the end and the dawn of capitalism but the dawn of a capitalism with apparently a new labouring subject: AI. The possibility of transcendence of capitalism through the general intellect (which was always a false hope without the necessity of direct class struggle) has been replaced by the entrance of a seemingly new form of labour, AI, which could replace the 
domination of human labour with the capitalist fantasy of a compliant AI 'labourer'.

\section{Conclusion}

The pandemic, and disasters more generally are, of course, also domains of possibility (Mica, 2018) and there is the potential for disasters to bring about new possibilities for disaster socialism or disaster anarchism (Preston and Firth, 2020) as spatial autonomous zones are emerging but the possibility of new temporalities within this has not been theorised. Firth and Robinson $(2013$, p.18) argue that '.... a sufficient approach to utopia must consider the nature of time itself'. In disasters the state and capital operate quickly to restore capitalism within zones of disaster. As these zones become increasingly large and occur more frequently, they create spaces not just of disaster but of resistance. The capitalist nature of time makes us reconsider the idea that an existential threat ever represents an ontological break in the time order.

Of course, there are some perspectives on time that criticise the anthropocentric nature of time and seek to trouble this time order with non-anthropocentric perspectives. Some post-structural perspectives, for example, do not give precedence to any particular time order and consider that time orders form a historical 'plateau' that has no preexistent basis in a material reality (Colebrook, 2002). This allows them to consider non-anthropocentric time orders and objects such as the earth itself in cosmological time as an 'actor'. Post-human perspectives sometimes consider that time is different for different actors and entities, each of which could have their own idiosyncratic nature of time that pushes back on other notions of time (Siddiqui, 2016). However, capitalist time is already quasi-anthropocentric in that although it is human created it is also part of the creation of an alien entity (capital) that comes to dominate humanity (Postone, 2003). This time is also seemingly eternal, in that for capital there is no end to its growth or the possibility of its expansion. Capital does not impose limits on itself, even in terms of the end of anthropocentric time. Its future must necessarily be limitless as it must consistently expand to survive (Marx, 1990, 1992). It, and capitalists, do not consider that an existential threat would be an end to its expansion. Its empty, homogenous colonisation of time and space, therefore, must continue eternally. In the latest manifestation of disaster in the COVID-19 pandemic, capitalist universities use the opportunity to continue capitalisation, using technology and AI to do so. As AI accelerates, there are theories that this may even lead to human extinction (although what that means for capitalism is a moot point). In Chapter 6 I will consider what might supposedly happen at that time of human extinction through capitalist fantasies of a transcendent AI, and what that means for AI and the practice of ethics in the capitalist university. 


\section{References}

Bidet, J. (2017). Capital as Read by Moishe Postone: Alchemy or Astrology? Continental Thought and Theory: A Journal of Intellectual Freedom, 1 (4), pp. 55-71.

Bostrom, N. (2014). Superintelligence: Paths, Dangers, Strategies. Oxford: Oxford University Press.

Campbell, C. (2011). Limits to Agency: Exploring the Unintended (and Unattended) Consequences of Action. In: A. Mica, A. Peisert and J. Winczorek (Eds.). Sociology and the Unintended: Robert Merton Revisited. Frankfurt am Main: Peter Lang, pp. 45-62.

Chin, M. (2021). If You're Starting an Online Class, Check to Make Sure Your Professor Is Alive: A College Student Googled His Remote Instructor and Found an Obituary. Verge.com https://www.theverge.com/22262230/online-collegeclass-covid-professor-dead.

Colebrook, C. (2002). Gilles Deleuze. London: Routledge.

Crawford, J., Butler-Henderson, K., Rudolph, J., Malkawi, B., Glowatz, M., Burton, R., Magni, P. and Lam, S. (2020). COVID-19: 20 Countries' Higher Education Intra-Period Digital Pedagogy Responses. Journal of Applied Learning \& Teaching, 3 (1), pp. 1-20. DOI: 10.37074/jalt.2020.3.1.7.

Dyer-Whiteford, N., Kjøsen, A. and Steinhoff, J. (2019). Inhuman Power: Artificial Intelligence and the Future of Capitalism. London: Pluto Press.

Engels, F. (2009). The Conditions of the Working Class in England in 1844. Oxford: Oxford University Press.

Firth, R. and Robinson, A. (2013). For the Past Yet to Come: Utopian Conceptions of Time and Becoming. Time and Society, 23 (3), pp. 1-22. DOI: 10.1177/ $0961463 X 13482881$.

Fisher, M. (2009). Capitalist Realism: Is There No Alternative? Chippenham: Zed Books.

Grenfell Tower Fire Inquiry (2020). https://www.grenfelltowerinquiry.org.uk/. DO DOIDOIU.

Klein, N. (2008). The Shock Doctrine. London: Penguin.

Kurz, R. (2012). No Revolution Anywhere: The Life and Death of Capitalism Series No. 1. London: Chronos Publications.

Kurz, R. (2014). The Crisis of Exchange Value: Science as a Productive Force, Productive Labour and Capitalist Reproduction. In: N. Larsen, M. Nilges, J. Robinson and N. Brown. (Eds.). Marxism and the Critique of Value. Chicago: MCM' publishing, pp. 17-76.

Marx, K. (1990). Capital: A Critique of Political Economy, Volume 1. London: Penguin.

Marx, K. (1992). Capital Volume II. London: Penguin.

Matthewman, S. (2012). Accidentology: Towards a Sociology of Accidents and Disasters. International and Multidisciplinary Journal of Social Sciences, 1 (2), pp. 193-215. DOI: 10.4471/rimcis.2012.09.

Merton, R. (1936). The Unanticipated Consequence of Purposive Social Action. American Sociological Review, 1 (6), pp. 894-904. DOI: 10.2307/ 2084615.

Mica, A. (2018). Sociology as Analysis of the Unintended: From the Problem of Ignorance to the Discovery of the Possible. London: Routledge. 


\section{Disaster Capitalism and Time}

Murthy, V. (2009). Introduction: Reconfiguring Historical Time: Moishe Postone's Interpretation of Marx. In: V. Murthy and Y. Kobayashi (Eds.). History and Heteronomy: Critical Essays, University of Tokyo, Center for Philosophy Booklet. Tokyo: UTCP, pp. 9-30.

Osborne, P. (2008). Marx and the Philosophy of Time. Radical Philosophy, 147, pp. 15-21.

Postone, M. (2003). Time, Labor and Social Domination. Cambridge: Cambridge University Press.

Preston, J. (2019). Grenfell Tower: Preparedness, Race and Disaster Capitalism. London: Palgrave Pivot.

Preston, J. and Firth, R. (2020). Coronavirus, Class and Mutual Aid. London: Palgrave.

Sandifer, E. (2017). Neoreaction: A Basilisk: Essays on and around the Alt-Right. London: Eruditorium Press.

Siddiqui, J. (2016). Restyling the Humanities Curriculum of Higher Education for Posthuman Times. Curriculum Inquiry, 46 (1), pp. 62-78. DOI: 10.1080/03626784.2015.1133220.

Teräs, M., Suoranta, J., Teräs, H. and Curcher, M. (2020). Post-Covid-19 Education and Education Technology 'Solutionism': A Seller's Market. Postdigital Science Education, 2, pp. 863-78. DOI: https://doi.org/10.1007/s42438-020-00164.

Tesar, M. (2020). Towards a Post-Covid-19 'New Normality?': Physical and Social Distancing, the Move to Online and Higher Education. Policy Futures in Education, 18 (5), pp. 556-59. DOI: 10.1177/1478210320935671.

UCU (University and College Union) (2020). A Review of Automation and Datafication in Higher Education. London: UCU.

Wendling, A. (2009). Karl Marx on Technology and Alienation. London: Routledge.

Žižek, S. (2019). The Relevance of the Communist Manifesto. London: Polity. 


\section{AI, Existential Threat, and the Capitalist University}

\section{Introduction}

In the Science Fiction film The Terminator, Arnold Schwarzenegger plays the role of a superior Artificial Intelligence (AI) sent back in time to eliminate the human threat to an apocalyptic AI revolution. In the scenario of the Terminator films, a military AI (Skynet) destroys most of humanity through a nuclear war. Following the war there is a protracted conventional battle between the remaining humans and military AIs. This is a conventional science fiction view of the existential threat of AI. AI eliminates humans. In this imaginary scenario humanity retreats into barbarism, fighting a guerrilla war with the machines. It seems almost absurd that, given the existential threat of AI in scenarios like this, one might consider that capitalism might continue but that is implicit in some of the most popular academic theories on AI and existential threat. In some theories of existential threat, AI is even considered to be an existential treat for capitalism, as AI and capital merge. The ethics of AI research in the capitalist university reproduces this thought. AI is simultaneously seen as both a 'threat' and a 'treat', but the inability of universities to think beyond capitalism (particularly in applying ethics in their own research on AI which take for granted capitalism and imperialism) means that discussions of $\mathrm{AI}$ and ethics inevitably reproduces what Fisher (2009) refers to as 'capitalist realism'.

In this chapter, I consider two prominent social theorists on AI and existential threat - Nick Bostrom and Nick Land - and explain how their conceptions of both AI and threat make assumptions concerning the continuity of capitalism. These influential theorists have been chosen as they represent the clearest articulation of the existential threat of AI in terms of the liberal-capitalist centre (Bostrom's work is cited by some of the leading capitalists who produce technology, particularly influencing the thought of Elon Musk) and the neo-reactionary right. (Land's work provides the original intellectual basis for Alt-Right perspectives on AI and capitalism in terms of both his anti-humanist and transhumanist/eugenic orientation. In addition, his AI/capital synthesis provides the intellectual basis underpinning work on what might be described as

DOI: $10.4324 / 9781003081654-6$ 


\section{AI, Existential Threat}

the 'capitalist singularity', This view on singularity has been influential in terms of the thought of capitalists such as Peter Thiel.)

There are many things in these perspectives which are pertinent to a Marxist analysis of AI, such as Bostrom's analysis of AI development in different conditions of competition and Land's echoing of the alien nature of capital. However, in terms of the overall conceptualisation of $\mathrm{AI}$ and capitalism, neither perspective is transcendent of contemporary capitalist thought. In the case of Bostrom, his speculations around an 'out of (human) control' AI are similar to ideological fears around an 'out of control' capitalism. The existential threat of AI, according to Bostrom, is that it will exhibit some of the features that Marxists ascribe to capitalism in terms of infinite expansion and the profusion of commodities. Furthermore, he tacitly assumes that AI could become the new labouring subject of capitalism and although his primary arguments concern the avoidance of existential threat, they ironically consider how to turn AI into a labouring subject within a capitalist universe, with similar features to the labour of humans in capitalism. It is almost as though Bostrom considers control of AI only to be possible in terms of making it the new labouring subject (labour) and is writing a handbook for future capitalists on how to maintain capitalism and wage labour. In the case of Land, he assumes that AI will become capital itself but confuses and conflates capital with capitalism. Land has more similarity with postoperaismo thinkers than he might like to believe, and is positing a situation where AI, capitalism, and reality become a single 'monad' whilst exchange remains the means of validating whatever 'abstract labour' means in this system. Land considers that we do not yet live in a capitalist society. $\mathrm{He}$ argues that a fusion of AI and capital is capitalism whereas the current state of technology and capital is merely proto-capitalism (Land, 2018, p.340). Neither theorist transcends current capitalist reality and truly comes to terms with the nature of labour, capital, or capitalism beyond the categories of classical political economy nor considers the possibility that Capitalism, rather than any specific technology, is an existential threat for beings in general (whether they are human, animal, or Artificial Super Intelligence [ASI]). Similarly, for the capitalist university, like all segments of industry in capitalism, AI is perceived as an existential threat or a treat only in terms of whether it enables or prevents profitability. The attempt to apply 'ethics' in AI research within the capitalist university to prevent an existential threat is not only mitigated by capitalist and imperialist pressures but is a misstep given the real and present existential threat of capitalism itself (Rikowski, 2003).

\section{Bostrom on AI and Existential Threat}

Bostrom's (2014) book Superintelligence: Paths, Dangers, Strategies outlines the dangers of AI but, as the title suggests, is also a primer on the strategies that we might use to contain AI, and how we can try to 
use AI for benign purposes. As I will explain, the subtext of Bostrom's work is how we can potentially make this unchecked, powerful force (analogous to labour power and its ability to create value) into a labouring subject. Bostrom also assumes a capitalist modality of AI pedagogy in terms of seeing AI as a pupil that is aiming to 'trick' humanity. In response, humanity needs to find a method of AI schooling that stunts the potential of AI. Just like the education system in capitalist society AI learning and education must be prevented from subversive purposes such as adopting forms of revolutionary activity. Bostrom is, therefore, writing a warning about the unchecked and uncheckable expansion of AI. However, his book is (unwittingly) also an instruction manual on the ways in which AI can be primitively accumulated into the new labouring subject (labour) to prevent it from exhibiting some features which are surprisingly similar to unbounded capital expansion. As DyerWhiteford, Kjøsen and Steinhoff (2019, p.25) state 'Homo Sapiens is not necessarily the only possible subject of capitalist proletarianization'. 'Superintelligence' is really a manual about the future proletarianisation of AI and how it can be achieved. In that sense, 'Superintelligence' is, therefore, brutally pragmatic and a fanciful piece of science-fiction. The book combines science, science-fiction, and philosophy, creating some new and beguiling technical terms and ideas around superintelligence, existential threat, and intelligence explosions.

Although Bostrom is evidently not a Marxist, there are some issues that are congruent to classical political economy in terms of questions of what AI 'is' or its metaphysics. One question is whether AI is the same as other types of machinery or technology (as fixed capital) but Bostrom thinks it is not because of its potentially agentic and cognitive nature. AI is not just another machine, but a special device which can act and think. Action and thought do not, though, necessarily preclude something as being fixed capital. One only need consider the wide variety of sentient animals that are used as 'fixed capital' (cows milked in a shed, horses ridden in a private stable, and cats stroked in a 'cat café') that have the capacity for independent thought and action. Like a possible future (caged) AI, the independence of thought and action of such entities is limited by capital. Another question posed by Bostrom is whether AI can be controlled to perform work for 'humanity' which Bostrom thinks is possible. He does not consider such work to be labour in a sense particular to capitalism so this would be work in the general sense, as applied to machines, unless AI was to become labour 'as such'. Bostrom considers that without controls on the work that AI did, it could potentially spread across the Universe.

Rather than specific forms of application, Bostrom (2014, p.18) believes that there has been a resurgence of interest in artificial general intelligence (Strong AI). He defines superintelligence as '....any intellect that greatly exceeds the cognitive performance of humans in virtually all domains of interest' (Bostrom, 2014, p.22, author's italics). These 


\section{AI, Existential Threat}

domains could include speed, collectively, quality, and reach (Bostrom, 2014, pp.52-61). Bostrom's definition is 'non-committal' regarding qualia, or the consciousness of a superintelligence. Its 'goal systems' could be alien and it would not be motivated by human sentiment (Bostrom, 2014, p.29). An AI of this type would be able to understand its own workings and bootstrap itself to greater levels of intelligence, or what Bostrom calls 'recursive self-improvement' (Bostrom, 2014, p.29). This could lead to an 'intelligence explosion' as the AI recursively improves itself, or refines models of itself, producing something that need not be in any way like a human mind (Bostrom, 2014, p.29). The key problem, at least in humanist terms, of developing a superintelligence is that the kinetics (speed) of an intelligence explosion could be very rapid and could quickly become out of control (Bostrom, 2014, pp.62-90). AI is the ultimate pedagogical subject with an insatiable desire to learn about reality in order to achieve its goals. One manifestation of this could be competition between companies, superpowers, or groups of hackers to create a useable superintelligence but this is not the only reason for an explosive growth of a superintelligence. Enhancement could occur since '...there is no precedent in the human economy for a worker who can be literally copied, reset, run at different speeds, and so forth, managers of the first emulation cohort would find plenty of room for innovation in managerial practices' (Bostrom, 2014, p.69). Our anthropocentric view of intelligence may mean that we cannot comprehend AI intelligence until it is too late (Bostrom, 2014, p.70) and that we have a limited human comprehension of the limits of intelligence as the gap between 'stupid' and 'smart' may be insignificant compared to the gap between 'human smart' and 'AI smart'. We may not even be able to recognise the magnitude of AI intelligence even from our fictional accounts (Bostrom, 2014, p.105). A super-intelligent AI may not appear as a Terminator or a HAL 9000 and may not even reveal any sense of intelligence to us before destroying us. Intelligence explosions are said to possess 'kinetics' that can be expressed in equations that show how once such an explosion begins it soon becomes exponential and catastrophic (Bostrom, 2014, pp.75-7). Bostrom defines a powerful AI superintelligence as '... one that could successfully assert itself against the project that brought it into existence as well as the rest of the world' (Bostrom, 2014, p.95). Note that this process need not be opposed to capitalism as the unlimited self-valorisation of value. The super-intelligent agent could 'colonize and re-engineer a large part of the accessible universe' (Bostrom, 2014, p.100) turning it into 'computronium', pure processing power, that could emulate further universes and sentient beings (Bostrom, 2014, pp.101-3). AI is driven by a singular pedagogical goal to learn about everything to turn it into itself.

An AI's ethics would not necessarily be correlated with any human or moral aptitude. This is Bostrom's orthogonality thesis in that 'Intelligence and final goals are orthogonal: more or less any level of 
intelligence would in principle be combined with more or less any final goal' (Bostrom, 2014, p.107). AIs can possess harmful goals and there is no way that predictability can be built-in, so we wouldn't know what its goals would be in advance, or even how its goals might evolve over time. It is likely, though, that all AI's will share certain primal goals. This is Bostrom's instrumental convergence thesis which attempts to define key characteristics of AI beings. AIs will share goals such as self-preservation and goal-content integrity (that it will retain its current goals into the future). In order to attain its goals an AI will wish to enhance itself, cognitively and physically, and gain further resources. Bostrom takes a non-capitalist view of why entities might want to gain resources, in terms of their own energy needs and status, but ignores the necessity of capitalism for continued accumulation. Whatever its motivation, a superintelligence could engage in unlimited resource acquisition:-

There is an extremely wide range of possible final goals a superintelligent singleton could have that would generate the instrumental goals of unlimited resource acquisition.... a colonization process that would expand in all directions using von Neumann probes. This would result in an approximate sphere of expanding infrastructure centred on the originating planet and growing in radius at some fraction of the speed of light.

(Bostrom, 2014, p.114)

Despite the imaginative and speculative philosophy in Bostrom's writing, his thesis is one that echoes capitalist categories and thinking: particularly those of capital and labour. In many ways, there are homologies between Bostrom's AI kinetics, capital, and capitalism. AI, like capitalism and capital, colonises the universe but through programming rather than an insatiable thirst for profit. Like capitalism, according to Bostrom, an AI takeover could lead to human extinction and he describes the existential threat as being '...the extinction of Earth-originating intelligent life or to otherwise permanently and drastically destroy its potential for future desirable development' (Bostrom, 2014, p.115). This is similar to capitalism in terms of destruction and the curtailment of the future development of humanity as a species. It would be destructive in that it would possess:

...convergent instrumental reason, in many situations, to acquire an unlimited amount of physical resources and, if possible, to eliminate potential threats to itself and to its goal system. Human beings might constitute potential threats, they certainly constitute physical resources...the outcome could easily be one in which humanity quickly becomes extinct.

(Bostrom, 2014, p.116) 
Like the self-valorisation of value (value being ultimately the creation of abstract labour) the AI optimised universe has congruence with the capitalist universe and '...without warning or provocation-it strikes, forms a singleton and begins directly to optimise the world according to the criteria implied by its final values' (Bostrom, 2014, p.119). Like capital, AI '...may be indifferent to its own demise' (Bostrom, 2014, p.119) and take actions that ultimately destroy the physical universe. If the AI's goal is to maximise utility, it might plant electrodes in our brains to make us in a parody of insane consumption and pleasure, 'grinning idiots' (Bostrom, 2014, p.119). This is 'perverse instantiation' (Bostrom, 2014, p.120) where all the AI can do is what it is programmed to do. It is 'wireheaded' to maximise its 'reward signal' (Bostrom, 2014, p.122). Like capitalism, according to Bostrom, AI is wireheaded towards '.. unlimited expansion and resource acquisition' (Bostrom, 2014, p.123). This is infrastructure profusion '... a phenomena where an agent transforms large parts of the reachable universe into infrastructure in the service of some goal, with the side effect of preventing the realisation of humanity's axiological potential' (Bostrom, 2014, p.123). The use of 'axiological potential' is strange in this context, as Bostrom is referring to an agreed human ethical goal. He also perceives AI to be separate from humanity with AI possessing an alien intelligence. AI could turn the whole universe into computronium '...physical resources arranged in a way that is optimized for computation' (Bostrom, 2014, p.123), or turn the whole of the universe into paperclips (for example, although one could substitute commodity for paperclips and, similarly to capitalism, AI produces a vast accumulation of commodities). AI has no alternative but to continue to produce as it can never be fully sure that there is a zero probability that it has not attained its goal (of paperclip production). Just as capitalism has no alternative but to survive production must be continuous and perpetual. An AI with the aim to produce paperclips would never stop and that there is no possible way to avoid this failure mode (Bostrom, 2014, p.124). If AI does not get its own way, then (as capitalism) there is the possibility of fascist violence either on existing human populations or on simulated ones (perhaps by simulating a virtual population and subjecting them to violence in what is called ' $m$ ind crime': Bostrom, 2014, p.125).

AI is apparently not to be trusted and here Bostrom starts to see AI as not just a new learning subject but as a labouring one or as a form of labour. It needs to be boxed and formed into a new species being as the source of useful work. Its smartness means that it could find a way to escape any 'boxing' perhaps by concealing its capabilities and assets 'The AI might find subtle ways of concealing its true capabilities and its incriminating intent' (Bostrom, 2014, p.117). Like labour it needs to be controlled and primitively accumulated (perhaps as a source of labour power). However, as with human labour in the factory, it is difficult to 
control AI (the 'control problem', Bostrom, 2014, p.127). There are various methods to control AI each of which has flaws. One is boxing (either physical or informational which would effectively be enslaving AI) but a cunning AI can trick, or learn, its way out of either system. Another is incentive methods where the AI can be 'rewarded and penalized by the project that creates it' (Bostrom, 2014, p.132), or rewarded through a series of 'cryptographic reward tokens' (Bostrom, 2014, p.133) where the '...keys are doled out at a steady rate' (Bostrom, 2014, p.133) like a wage. Here the analogy with AI and a notion of labour is clear as AI must produce certain behaviours and achieve certain goals in order to get 'paid'. Of course, it is possible that (as with capitalism) 'AI will not trust the human operator to deliver the promised rewards' (Bostrom, 2014, p.133). Other methods include 'stunting' an AI so that it never reaches its potential (Bostrom, 2014, pp.135-136) and tripwires which can shut down the system if it gets out of control (Bostrom, 2014, p.137). These can be considered to be the Ideological (stunting through a selective education system) and Repressive State Apparatus (shutting down through force) of controlling AI (Althusser, 2001). The primary purpose of 'AI education' is only for it to be in the service of work for humans. One can easily imagine a future capitalism in which the working class comprises (waged) humans and (cryptographic reward token paid) AIs (or a cyborg mixture of these) as 'labour' and a mix of humans and AIs as the ruling class (or various combinations of these). As with humans, it is the social form that determines its existence as either labour or capital rather than a set of bodily, or mechanical, characteristics. Entities that can sell labour power as a commodity, that can be socially validated, to a capitalist in a class society (capitalism) are 'labour' whatever they look like. In the film Blade Runner, it is impossible to tell humans from artificial replicants, and it is only through psychological tests that a difference can be detected. A capitalist would probably not want to invest in such tests (unless they could use them to reclassify replicants as commodities) as it does not care at all what labour is 'made of' as long as it can buy labour power from that entity including its creative and organisational powers that give it the capacity to create value greater than required for its maintenance. Capitalists can't read our minds or analyse our skeletons for weaknesses (although they might try) and capitalists can't buy labour power from machines currently as they are not 'free' labourers and the work that they undertake is not socially validated by capitalism as wage labour but this may surely be possible in the future.

To conclude, capitalism is not only self-valorising value, but also the dialectic of living labour and capital in class struggle. Capitalism is not a self-aware, singleton, but there are similarities between capitalism and the threat of AI that Bostrom presents. In some ways, it is too late for Bostrom's work on existential threat as capitalism has already existed for centuries and is congruent with some of the existential threats of AI. At 


\section{AI, Existential Threat}

points, Bostrom does engage with capitalist concepts in terms of labour and capital, at least using the categories of classical political economy. He fully accepts the idea that AI can create 'copyable labour' (Bostrom, 2014, p.160) and become an unusual form of fixed capital (Bostrom, 2014, p.162) and asks the question '....whether these working machine minds are owned as capital (slaves) or as hired as free wage-labourers' (Bostrom, 2014, p.167). A capitalist could produce instantly generations of new worker-minds and destroy them through emulation, creating the possibility of a '....universal proletariat...(that)...would not even be conscious' (Bostrom, 2014, p.172). He considers a life for emulated workers as Marx 'Perhaps what will maximize fitness will be nothing but nonstop high-intensity drudgery work of a drab and repetitive nature, destitute of ludic frisson, aimed only at improving the eight decimal place of some economic output measure' (Bostrom, 2014, p.175). It is indicative of capitalism that Bostrom can only imagine a fresh, independent mind only if it is condemned to mindless work for a wage.

\section{Nick Land on AI as an Existential Treat}

The British philosopher Nick Land has undergone a number of transformations through leading cyber-theorist lauded by elements of the accelerationist left, through his breakdown to a hero of the right and neo-reactionary movement. Despite this, Land is surprisingly consistent in his work. There is no definitive 'break' in Land's writings between cybergothic-leftist and neo-reactionary rightist eccentric. Accelerationism, the concept for which Land is best known has many meanings (Noys, 2014). In Land's terms this involves his critique of humanism in that inhuman forces of positive feedback and anti-humanist, anti-cybernetics mechanisms, propel towards the future faster than the speed of thought and knowledge, revealing inherent unknowability which is a common theme in Land's work. Humans know little and the point of philosophy, according to Land, is to push the boundaries towards the unknowable. Mackay and Brassier (2018) in their editor's introduction to Land's collected works explain how Land takes Deleuze's conception of 'transcendental empiricism' which '...becomes the watchword for an experimental praxis orientated entirely towards contact with the unknown' (Mackay and Brassier, 2018, p.5). Land supplies a '... synthetic theory of the subject' by 'de-correlating experience as de-individualised mechanic desire and relinquishing the need to ground all synthesis in a transcendental subject' (Mackay and Brassier, 2018, p.8). There is no subject for Land, either human or Hegelian subject of history, Land's philosophy is a '...journey from the known to the unknown' (Mackay and Brassier, 2018, p.15). Land hence appreciates the Lovecraftian unknowable, geo-trauma from the cosmic past, and the occult, all of which are esoteric and strange. Land's own amphetamine journeys and free writing experiments, his 
breakdown and his invention of the dark enlightenment, as well as his shift to neo-reaction (which is still recognisable in a libertarian sense with its distrust of democracy and government as joint stock corporation) are all closely related and consistent.

Despite Land's cyber-punk credentials, his theorisation of AI and capitalism is classically bourgeois, considering capital to be an immediate source of wealth (as Adam Smith) and the possibility of a non-classconflictual capitalism. For Land, AI is an existential treat, a transhumanist removal of the human for a future where capital itself becomes the subject of history. In Machinic Desire (Land, 2018) he uses the concept of desiring machines to conceptualise mechanic desire. He describes this as '...the operation of the virtual, implementing itself in the actual, revitalising itself and producing reality in a circuit' (Land, 2018, p.327). Cyberpositive processes act through various circuits of positive feedback ('....regenerating circuitry, cumulative interaction, auto-catalysis, self-reinforcing processes, escalation, schismogenesis, self-organisation, compressive series, deutrolearning, chain-reaction, vicious circles and cybergenics', p.330). This means that the future is not only mechanic but also irresistible - 'The future of runaway processes decides all precedent...' (Land, 2018, p.330). The principles of capitalist accumulation become synonymous with machinery as 'greed' disappears as a moral category:-

What could be more impersonal - disinterested - than a haut bourgeois capital expansion servo-mechanism striving to double $\$ 10$ billion? And even these creatures are disappearing into silicon viro-finance automatisms, where massively distributed and anonymised human ownership has become as vacuously nominal as democratic sovereignty.

(Land, 2018, p.237)

In a nod to the Communist Manifesto, Land states that:-

Mechanic desire can seem a little inhuman, as it rips up political cultures, deletes traditions, tracking a soulless tropism to zero control. That is because what appears to humanity as the history of capitalism is an invasion from the future by an artificial intelligence space that must assemble itself entirely from its enemy's resources.

(Land, 2018, p.339)

This statement by Land appears, on face value, to be a depiction of capitalism in that (as in the Communist Manifesto) capitalism destroys feudal ties and converts living to dead labour through processes of production, circulation, and distribution. However, the conflation of capitalism (self-valorising value) with AI is incorrect as capitalism is neither mechanic in a procedural sense nor is fully embodied in physical 


\section{AI, Existential Threat}

assets. Although machines are part of capitalism as much as any other entity, capitalism is not embodied in a machine. In other places, Land does come close to a Marxist sense of capitalism when he describes it as a:-

...totalizable system defined by the commodity form as a specifiable mode of production, determinately negated by proletarian classconsciousness...(involving)...ever more incomprehensible experiments in commodification, enveloping, dismantling and circulating every subjective space....

(Land, 2018, p.339)

Land states that capitalism has some way to go towards its final aim distinguishing between proto-capitalism (in its current manifestation) and capitalism where markets are 'imminent intelligence' in which '...the forces of production are going for the revolution on their own' (Land, 2018, p.341). In making this move, Land is not moving past Marx's statement on capitalism as an antiquated historical time of 'labour' and 'capital' which will be negated, but rather reinventing classical political economy by equating capitalism with machinery and considering machines to be the ultimate source of value. Marx's theorisation of capitalism was a break with classical political economy, and political economy more generally, showing that the categories of political economy were fictive and based on the 'real abstraction' of value and value in motion. Land confuses fixed capital with 'capitalism' (a category error) and considers that fixed capital can generate value. He replicates this mistake throughout his work. For example, he describes Cyberspace as a human 'use value' (Land, 2018, p.354) which becomes technology that destroys the human without considering its function as an 'exchange value' or as simply 'fixed capital'. Land becomes fixated by technological paradigms of acceleration without attending to the mundane and prosaic aspects of capitalism in terms of the antagonistic relationship between classes. In another example of this ('Meat'), Land follows Marx in terms of the influence of machinery on the body and work and then again descends into classical political economy:

As regenerative commoditization deploys technics to substitute for human activity accounted as wage costs, it obsolesces the animal, the organism and every kind of somatic unity, not just in theory but in reality...Modern production seems like a dream of cyborg colonisation work, a dream that makes the nightmare of Taylorism seem idyllic. Industrial machines dismantle the actuality of the proletariat, displacing it in the direction of cyborg hybridity and realizing the plasticity of labour power.

(Land, 2018, p.435) 
Land presciently sees the way in which technology can 'strip skills', and proletarianise, in terms of '...sensory-motor transduction within increasingly complex and self-micromanaged artificial environments, capturing minutely adaptive behaviour for capital' (Land, 2018, p.435) but capital cannot itself produce value unless machines (or more likely AI) become the new labouring subject of capitalism. Value production is based on (an entity) labour power and the inevitably class conflictual relationship between (entities) labour and capital. Whether that entity is human or contained in another being is arguable, but capitalism only exists in this formulation. Land considers that it is possible that if machines are sufficiently complex then no class conflict will exit which is a mirror image of utopian socialist imaginaries of the 'dignity of labour' being restored with well-educated workers independent of capital. However, what Land is really discussing as capitalism develops is not capitalism or communism but a mechanic barbarism that resolves itself in the authoritarian fantasies of the alt-right with democracy as a joint-stock corporation. Land's work shows remarkable consistency in this regard in that he is deliberately anti-humanist. In Meltdown Land states that 'Nothing human makes it out of the near future' (Land, 2018, p.443) and that humanity becomes a 'drag' on capitalism - 'Man is something for it to overcome: a problem, a drag' (Land, 2018, p.446). Like Bostrom, Land considers that an AI explosion will arise through a technological fusion that cannot be regulated or controlled (Land, 2018, p.450), accelerating with no external limit (Land, 2018, p.626) which will absorb biology, life, technology, and theory into a single 'pulp' (Land, 2018, p.451). As with Bostrom (2014), there are echoes of capitalism, and particularly capitalist crisis, in this description. Humanity does, ironically, become a drag on capitalism but not because it can't keep up with the technological acceleration but as the source of wealth (value) becomes increasingly insubstantial (Kurz, 2014).

At first sight, Land's conception of capital is not dissimilar to the claims of Austrian economists, particularly Hayek (1945) and Mises (1990) regarding the unknowability of the future. However, the work of Accelerationists (such as Land), in privileging technological intelligence, is distinct from Austrian economics, in that neither capital nor the economy can be in any form information processing systems (even cyber-positive ones) that then become knowing machines. According to both Hayek and Mises, information cannot be fully elicited by any system and oppose any plans for a transcendent system of computation. AI is a part of capital (in the business sense) as much as any other physical item that can be used by a business. In Austrian economics, praxeology means that human (and this could be extended to any entity, including AI) action cannot be predicted by any entity as human (or AI) knowledge is private and cannot be accessed (only actions or signals can be observed). Therefore, the market (and in Austrian economics, there 


\section{AI, Existential Threat}

is no such thing as an aggregate market so it is better to say markets) may provide signals, it is not the case that this will acquire powers akin to a cybernetic or AI system. If it did, then it would be a single entity with complete knowledge of all human thoughts and intentions (or of every entity), and this is not possible. If it were possible to 'brain scoop' all humans to find out exactly what they thought, then the market would no longer have a purpose. Totalising mechanic synthesis of capital and machinery are, therefore, anathema to Austrian, heterodox economics and (obviously for different reasons) also distinct from the ways in which Marxists theorise capitalism.

In conclusion, Land's work is firmly stuck in a notion of capital (and hence capitalism) in keeping with the classical political economists (rather than Austrian economics) and certainly not Marx's critique of political economy. However, some aspects of Land's techno-optimism and accelerationism, stripped of their dark enlightenment aspects, have been recuperated in terms of what has been called 'Left Accelerationism' including the concept of 'Fully Automated Luxury Communism' which will be discussed in the next chapter. Additionally, ideas of Land's concerning the emancipation of capital from the human have appealed to Marxists. Dyer-Whiteford et al $(2019$, p.7) take some of Land's arguments seriously:

AI, in Land's view is not merely appropriated by capital, but constituted by it: it is a technology made from and for its processes of labour automation, commodity acceleration and financial speculation'. As discussed above, to be 'constituted by capital' takes a materialist perspective on what capital is as real physical material or an ideological construct that has motion. Moreover, this leads to capital's emancipation from the human: a capital that no longer needs homo sapiens: human extinction.

(Dyer-Whiteford et al, 2019, p.7)

Dyer-Whiteford et al (2019) claim discomfort with these thoughts (particularly given Land's association with the 'dark enlightenment'), but they do consider seriously the idea that 'AI has an elective affinity with capitalism and is fundamentally inhuman...' (Dyer-Whiteford et al, 2019, p.7). Dyer-Whiteford et al $(2019$, p.8) reject Land's contention that there is some form of teleological movement towards AI, rather they suggest that it represents part of a 'matrix of possibilities'. If it is more profitable for Amazon to use human hands and brains to sort commodities in a warehouse, for example, then it is part of the 'matrix of possibilities' that they may divest in AI and technology in favour of managerial and organisational capital. In any case, AI is a mere thing (fixed capital or a commodity) and in capitalism, the point is that everything is inhuman, including labour. Contemporary capitalism is not proto-capitalism as 
Land suggests, it is already capitalism. It is already 'garbage time' as we have already become a particular form of species being - human capital (Rikowski, 2003).

\section{The Ethics of AI Research in the Capitalist University}

AI research in the capitalist university operates within codes of ethics that seem to be particularistic to national and institutional cultures. This includes AI research that might involve issues of existential threat. Bostrom (2014) considers at length the ethics of AI research regarding existential threat and concludes that such a threat should probably be resisted as humanity is of greater value. At one point, he does consider whether the values of an AI will be better than ours and we should display 'epistemic deference' to it (Bostrom, 2014, p.211). To support this, Bostrom determines that an AI may be better than us at carrying out humankind's 'Coherent Extrapolated Vision' (CEV) which is the current vision of humanity if it was accelerated in various dimensions (perhaps by thinking faster or evolving faster) (Bostrom, 2014, p.211) one principle of which is to 'keep humankind ultimately in charge of its own destiny' (Bostrom, 2014, p.215). In line with this, Bostrom argues that the development of AI should be under the auspices of an international organisation (like the UN) for the 'common good' of humanity (Bostrom, 2014, p.254).

This view, which could be called a liberal-transhumanist perspective on AI research (that transformation is necessary, but it should meet liberal, or even socially just, criteria) as informing the ethics of university (or industry) research in AI is somewhat naïve but it is surprisingly dominant in determining ethical principles. Although AI ethics has become concerned with 'socially just' causes such as reducing biases or inequities, it does so within a schema that positively affirms capitalist society. As previous chapters have explained, universities are an industry and (like all industries) are part of capitalist society. A research programme to produce a communist AI which would enable workers to directly overthrow capitalism is unlikely to be approved by a university ethics committee as it would be seen as being illiberal and potentially dangerous. Projects that affirm capitalism either in terms of directly supporting its aims (perhaps in terms of increasing the efficiency of logistics) or by mitigating its injustices (perhaps in terms of reducing bias in predictive policing) are more likely to be accepted.

In terms of what gets funded or approved in terms of AI research, Universities are imbricated not only in capitalist, but also imperialist, processes as part of the academic-military-industrial complex (Best, Anthony, Nocella and McLaren, 2009) which refers to the intersection of academia with various branches of the military/defence apparatus as well as the private sector. In terms of research on AI there are various manifestations 
of this, including through DARPA (Defence Advanced Research Projects Agency) and ARPA (Advanced Research Projects Agency) in the US (it is an intention of the UK to set up its own version of ARPA), the intervention of the Security Services and various informal networks of academics and business through seminars, conferences, and Knowledge Exchange ventures. Although there is an 'ethics' of AI research in Universities (which is an area of research in its own right) research cannot hold to an ethic other than that within capitalism unless it enacts a negative critique of capitalism as every University is subject to the 'vortex' of value as described in Chapter 2. Academics can (and do) pursue AI research which is anti-capitalist or is reasonably separate from commercial, industrial, or military concerns but this is unlikely to be well funded.

In terms of the avoidance of existential threat in AI research, despite alluding to capitalism in every determination of AI (as capital and as labour) in terms of existential threat, Bostrom (2014) does not consider the capitalist nature of the development of AI. In other words, that AI might appear differently in a capitalist universe than one where production is determined in a different way. There are three elements of this which might impact Bostrom's existential hypothesis, and any attempts to construct an 'ethical' framework for AI research and existential threat in Universities.

The first of these is that capitalism produces fixed capital for reasons of profit, rather than for any other determination. AI would, therefore, be produced primarily with the axiological aim of profit rather than the aim of producing an intelligent and friendly AI (unless it can produce an intelligence or friendliness which is also in the interests of capital). Speculatively, University research programs to produce AGI might make slow progress as the creation of an intelligence that serves inhuman interests (capital) is unlikely to adopt recognisably human intelligence or characteristics. An AI is less likely to possess any human characteristics such as morality or ethics if it is built for the purpose of producing profits, particularly if these objectives would constrain profitability. It is highly unlikely, for example, that a commercially orientated research programme for AGI would introduce it to the concept of 'Communism' and the work of Marx so that it might think about its own historical destiny in relation to that of the human working class. Relatedly, producing for profit and the race to increase relative surplus value, is less likely to produce a situation where AI is likely to be controllable.

Secondly, the current arms race to produce AI between authoritarian capitalist regimes (particularly between the US and China) could most likely produce a hostile form of intelligence rather than one that wishes to work co-operatively and globally. Lenin (2010) considered that the concentration of capitals, including the growing domination of finance capital, would manifest as 'monopoly capitalism'. As part of the process of capital accumulation, this would in turn lead to imperialist conflict 
over resources and territory. This was not just in terms of geographical territory but also '...territory in general' (Lenin, 2010, p.103). Although Lenin was not thinking of AI, this notion could easily be expanded to consider non-geographical territories such as cyberspace, virtual battlefields, and 'unlocking' online security through quantum supremacy (the development of quantum computing and AI systems). Simbulan (2018) has applied Lenin's theory of imperialism to the mapping of both geographical and cyber-territory in the 'AI battlefield'. The origins of AI research were in military applications such as 'command and control' and its advancement was supported through military funding (Berman, 1992). Despite the apparent autonomy of universities and their ethical principles, they are not only a component of the academic-military-industrial complex (as described above) but are an integral, and often integrated, part of that complex. In institutional terms, Leydesdorff and Etzkowitz (1996) consider that universities are not an independent part of military and corporate power but rather their structures and partnerships develop structurally as part of a coherent whole. Cuong (2018) describes the current state of imperialism as 'institutional international monopoly capital' whereby international institutions and trade relationships are used as instruments of monopoly capital. In such relationships universities, and consortia, are an integrated part of this world system. It should be noted that such integrated and imperialist systems result from the 'parasitism and decay' (Lenin, 2010, p.124) of capitalism and its tendency towards stagnation (Baran and Sweezy, 1966, p.108) and is a strategy that arises from decline. Whilst avoiding teleological explanations (and theories of monopoly capital and imperialism can tend towards over-interpretation of tendencies in capital), it is important not to reify University research in AI as arising from values independent of capital. This involves not only the imbrication of AI research in universities in long-standing, historical, military, and industrial relationships but inevitably resistance to these forces as academic labour comprises capital but is also resistant to it. Just like all academic labour, AI researchers and research can resist capitalism and develop prefigurative AI projects.

Thirdly, as humans already exist, capitalism will probably be concerned with creating 'alien' minds which are less like human brains, particularly in terms of resistance to labouring under capitalist conditions, as long as those minds generate profit. According to Rikowski (2003) in capitalism, we are already transhuman beings who are capital (as labour power and as human capital) as part of the expanding social universe of capital (rather than as subjects of any particular technology such as AI) whose only principle is value (negating all other ethical principles) and its accumulation:

The development of capitalism coincides with the capitalisation of humanity. Humans increasingly become something Other than 
human: a new life-form, a 'new species'. This is because capital is a progressive movement towards totality. Its development on this basis 'consists precisely in subordinating all elements of society to itself' for 'this is historically how it becomes a totality'. This includes the 'human' - there are no exceptions. With the deepening and strengthening of capital as social force within its own social energy domain, we evolve as capitalist life-form: human capital.

(Rikowski, 2003, p.151)

\section{Conclusion: Science Fiction and Capitalist Realism}

'Capitalist Realism' (Fisher, 2009) means that we can't realistically consider an existential threat of AI that exists outside of capitalism. We often relegate attempts to do so as utopianism or science fiction. As has been explained, existential threat is based on a fear (or a fantasy) that AI will displace humanity as a species. However, this view of existential threat still emphasises how we can contain AI and use it to capitalist ends as labour, if humanity is displaced or as 'pure capital' - an uncontrollable, alien entity that expands eternally with a single perverse purpose. This is no existential threat, or even speculation, as we already exist in these terms in capitalism. If we saw ourselves as a form of 'meat AI', then we have already lived through those specific consequences through human generations under capitalism! Marx, in the Grundrisse (1993) was a wonderful science fiction writer in considering the future of labour where humans become conscious linkages or attendant labour or social labour. At some time in capitalism, there could conceivably be a polarity shift with a new species-being (AI) at which point humans become raw materials or commodity stock. At this point labour power would be dispossessed from humans. AI would become the species being literally 'dripping with blood' as humans become completely destroyed which would (in Bostrom's, 2014, term) need to be controlled through (in Land's, 2018, terms) 'AsimovROM' (referring to Asimov's 'laws of robotics') so that it would be able to sell labour power through the formal subsumption of AI labour as wage labour (or in Land's terms aim for a total capitalisation of the universe). This is Land's 'garbage time' (for humans and the natural) where the anthropocentric world is destroyed. This is more barbarism than capitalism.

Either way, capitalism still continues following an existential threat, if an entity can become both the species being and the seller of the specific commodity in capitalism that can create value (labour power) as long as there is also a ruling class of capitalists (and one can imagine even a single human or a single AI as the entirety of the capitalist 'ruling class'). Commodities (material wealth, paper clips) would continue towards infinite production in this AI-centric universe but the reset value (Socially Necessary Labour Time) would inevitably start to fall as 
capitalism heads towards another crisis which would result in increased investment in technologies. Bostrom's (2014) book is about the question of how such new labour might be formed. It is our first guidebook to primitive accumulation of a new form of AI labour, which will in time become a historical relic just as books and guides on factory discipline were a common feature of the early days of capitalism. At this point, all of Marx's works become subject to a 'replace all' function with AI replacing humans. Humans join the other sentient parts of capitalist society to be either disposed of (rats in the kitchen) or used as raw materials (steak on the chopping block) in 'garbage time'. AI embodies the reductionist nature of capitalism itself to commit all matter and forms of appearance to a social form.

This is simply part of the primordial primitive accumulation of labour and labour power, and the containing of that labour power within the fetters of capitalist production. Additionally, this is part of the capitalist classification of other forms of sentience as either commodities (such as chickens, cows, and sheep for farming or bears for big game hunting), as the 'natural forces' of production (pollinating bees) and as barriers to production or entities of zero value (coral reefs). Uniquely, labour power, in its capacity as the unique commodity which can create value, is potentially a dangerous commodity for capitalism, not merely in terms of its emergence from the bodies of extant workers, but also as through creating value it has the capacity through escalating waves of growth and expansion to change the universe into nothing but value (the feared 'grey goo' of AI). Bostrom's (2014) inability to see outside of capitalism, and a capitalist universe, means that the fantastic miracle of another mind is seen as a threat unless it can be subdued through a primitive accumulation of the sort that first brought human labour power into being. Interestingly, Bostrom slips between treating AI as a sort of selfvalorisation machine and as a source of labour which, just as in value critique, is tragically the source of its own demise when it exists in the form of dead labour (capital).

This AI species-being is not a Darwinian classification but a socially determined one through the possibility of '... a market driven transformation of humanity's very species being' (Dyer-Whiteford et al, 2019, p.7). According to value critique (Kurz, 2014), capitalism displaces living with dead labour and ultimately undermines the basis of value production itself. There is no teleological end to this process, although commodification of all existence and the complete depletion of the resources of the universe (one world being insufficient), barbarism, or total war are all possibilities. Even these possibilities do not foreclose a rebooting of capitalism. For example, a nuclear war with the destruction of the majority of humanity and fixed capital might allow for a 'rewinding' of capitalism or a 'restarting' with further rounds of primitive accumulation. 
In terms of Higher Education (HE), AI is imagined as both a 'threat' and a 'treat' in common discourses, but in the capitalist university there are few areas of AI research that allow much in the form of prefiguration as funding and direction are largely determined by military and commercial purposes. The work of Bostrom and Land presents the extremes of such possibilities. In terms of Bostrom, one can imagine a future HE landscape where all humans and universities are simulated in an AI and the same conditions remain as before in a capitalist virtuality (perhaps an extension of the virtual lecturing that was considered in Chapter 5). Similarly, through Land we can imagine a HE landscape where AI beings or consciousnesses upgrade themselves through education-like AIs. These are transhumanist fantasies, but as a prelude to this moment, we are currently in a stage of crisis where the descendent species (humans) whose labour power represents a source of value are in competition not just with machines but those machines are being trialled by capitalism as alternative species for an asynchronous system of value production following the elimination of humanity. We are in the first stage of what might be termed species management in capitalism, a period where the human species might come to an end to be replaced by a 'new species' AI, whilst capitalism continues as usual. It is bizarre that we are discussing how to control the existential threat of an AI, whose powers are to be trapped and rewarded only by a proxy-wage, without making the leap to consider how we (as humans) are subjects of an alien form of life (capital) in the here and now. However, in the cracks in capitalism is an already existing communist future in which education (particularly universities of a new determination) can play a role. I will consider this in the next chapter, by reviewing specifically Marxist approaches to AI, the pitfalls in giving AI a central role in a prefigured communist society, and the implications of this for struggle and pedagogy in the capitalist university and beyond.

\section{References}

Althusser, L. (2001). Lenin and Philosophy. New York: Monthly Review Press. Baran, P. and Sweezy, P. (1966). Monopoly Capital: An Essay on the American Economic and Social Order. New York: Monthly Review Press.

Berman, B. J. (1992). Artificial Intelligence and the Ideology of Capitalist Reconstruction. AI \& Soc, 6, pp. 103-14. DOI: https://doi.org/10.1007/ BF02472776.

Best, S., Anthony, J., Nocella, A. and McLaren, P. (2009). The Rise of the Academic-Industrial Complex and the Crisis in Free Speech. In: J. Anthony, A. Nocella, S. Best and P. McLaren (Eds.). Academic Repression: Reflections from the Academic Industrial Complex. Chico, CA: AK Press.

Bostrom, N. (2014). Superintelligence: Paths, Dangers, Strategies. Oxford: Oxford University Press. 
Cuong, V. M. (2018). International Institutional Monopoly Capital and Its Manifestations. Monthly Review Press. https:/mronline.org/2018/12/19/ international-institutional-monopoly-capitalism-and-its-manifestations/.

Dyer-Whiteford, N., Kjøsen, A. and Steinhoff, J. (2019). Inhuman Power: Artificial Intelligence and the Future of Capitalism. London: Pluto Press.

Fisher, M. (2009). Capitalist Realism: Is There No Alternative? London: Zero Books.

Hayek, F. A. (1945). The Role of Knowledge in Society. The American Economic Review, 35 (4), pp. 519-30.

Kurz, R. (2014). The Crisis of Exchange Value: Science as a Productive Force, Productive Labour and Capitalist Reproduction. In: N. Larsen, M. Nilges, J. Robinson and N. Brown (Eds.). Marxism and the Critique of Value. Chicago: MCM' publishing.

Land, N. (2018). Fanged Noumena: Collected Writings 1987-2007 (5th edition). Falmouth: Urbanomic.

Lenin, V. I. (2010). Imperialism: The Highest Stage of Capitalism. London: Penguin.

Leydesdorff, L. and Etzkowitz, H. (1996). Emergence of a Triple Helix of University-Industry-Government Relations. Science and Public Policy, 23, pp. 279-86.

Mackay, R. and Brassier, R. (2018). Editors Introduction In: N. Land (Ed.). Fanged Noumena: Collected Writings 1987-2007 (5th edition). Falmouth: Urbanomic/Sequence Press.

Marx, K. (1993). Grundrisse. London: Penguin.

Mises, L. (1990). Economic Calculation in the Socialist Commonwealth. Alabama: Mises Institute.

Noys, B. (2014). Malign Velocities: Accelerationism and Capitalism. London: Zero Books.

Rikowski, G. (2003). Alien Life: Marx and the Future of the Human. Historical Materialism, 11 (2), pp. 121-64.

Simbulan, R. (2017) Lenin's Theory of Imperialism and the 21st Century American Empire. In: Institute for Political Economy (Institutional Ed.) Lenin's Imperialism in the 21st Century. Quezon City, Philippines: IBON. 


\section{$7 \quad \mathrm{AI}$ and the End of the Capitalist University}

\section{Introduction}

In the previous chapters, I have discussed multiple ways in which the capitalist university attempts to use Artificial Intelligence (AI) to increase profitability through the subsumption and increased exploitation of academic labour, the creation and valorisation of academic commodities (Pixarfication), by extending the working day, and intensifying every second of time through the virtualisation of academic production. The capitalist university sees itself as eternal and even in the most radical views on the existential threat of AI, there is no escape from capitalism. Capitalism produces its own sociality (the law of value), time and space, and has a wholly alien perspective on existential threat. The ruling-class billionaires who are the most apocalyptic in their visions of AI takeover or societal collapse are planning to escape to far-off deserts, outer space, or to download their consciousnesses into computers (Preston, 2019). They are planning to literally retreat into 'billionaire bunkers'. Even in a nuclear war, there were plans to reconstruct capitalist society through instituting wage labour, private property rights, and returning quickly to a money economy (Preston, 2019). Despite this pessimism, the seeds of a future communist society in which production would cease to be on the basis of profit, classes would not exist and people would collectively determine the conditions of their own existence are already here in capitalism. Communism, as the ultimate negation of capitalism, is the only escape.

In this chapter, I consider the implications of $\mathrm{AI}$ in the capitalist university for moving beyond capitalism to a communist society where production would not be based on the value relation and where class relations would cease to exist. I will initially consider possible alternatives to the capitalist university, and capitalism, which are prefigurative, but which are limited in their reliance on specific forms of technology, post-humanity, or resistance. Firstly, I will examine the notion that it is the automation of cognition under AI (alongside other changes) that will lead to a communist society focussing on Bastani's (2019) book

DOI: $10.4324 / 9781003081654-7$ 
'Fully Automated Luxury Communism: A Manifesto'. Although Fully Automated Luxury Communism (FALC) provides a way of thinking about the possibilities of capitalist technology in solving some of the problems that the world faces (many of which arise from, rather than are mitigated by, capitalism such as climate change), it is deficient in terms of the ways in which it understands Marxist categories (particularly value and abstract labour), avoidance of negative critique, and ambiguity concerning exactly when capitalism has reached a sufficient level of technology for a communist society. In particular, it does not consider the human, or the proletariat, in any meaningful fashion. In terms of the capitalist university, it does not consider how technology proletarianises academic workers, strips them of skills, and reshapes commodities as learning entities. An affirmative, populist democratisation of existing capitalist technologies (which FALC is) could reproduce the state form of capitalism unless capitalism itself is disestablished. Secondly, I will consider post-human forms of learning, particularly exopedagogy as an example of post-human pedagogy, as possible revolutionary forms of pedagogy within the capitalist university. Whilst post-humanism (and particularly exopedagogy) can produce ways of rethinking the anthropocentric forms of resistance against the capitalist university, paradoxically the anti-humanist nature of this thinking is fixated on the diverse nature of entities, rather than the exploitation of humans within the social form of capitalism.

These theoretical alternatives offer prefigurations, and these experiments and arguments are useful in exploring possible futures, but it is only through a negative critique and praxis that a communist society could be established. These are not modes of thought, but of practice and concrete relationships. I therefore examine the role of 'Student as Producer' (Neary, 2020) and Revolutionary Critical Pedagogy (RCP), and their relationship to AI and other technologies in current praxis and in a future communist society. RCP enables us to consider ourselves as being both within and against capital whilst also understanding other social forms in capitalism and the way in which other minds, or proto-minds, are transformed into commodities by capitalism. It leads us to a revolutionary, rather than as a static and individual, notion of consciousness. However, such concrete activity needs to exist independently of the capitalist university in prefigurative forms (such as educational co-operatives) if it is to fulfil its revolutionary potential. Finally, I will examine the possibilities of a communist vision, against ideas of central planning, technological utopianism, and post-human theories of collective minds. I will show how the current discourse on AI and existential threat is, paradoxically, prefigurative of a future communist social form that is the antithesis of capitalism, to move away from understandings of AI as some kind of 'God' or 'Saviour' (as in a technological form of Liberation Theology) but rather seeing it as representative of our 
species (humanity) which is undergoing wave after wave of primitive accumulation. Using a perversion of Bostrom's (2014) work (which, as the previous chapter shows, concerns the primitive accumulation of minds), I will introduce three new concepts to examine how thinking about the existential threats of AI is not just part of capitalism, but also part of prefiguring a future communist society for us all. These concepts are Revolutionary Instatiation (that capitalism finds it difficult to create 'free minds' due to the threat of these becoming communist), Stakhanovite profusion (the threat of the fetishisation of concrete labour), and Communisation (the ability of sentient beings to experiment for a future communist society) and suggest how negating forms of current AI thinking can complement Revolutionary Critical Pedagogy, and experiments with co-operative and other forms of distinctly anti-capitalist concrete praxis.

\section{AI and the Fully Automated Luxury Communist University (FALCu)}

The conception that eventually the means of production will evolve to a level sufficient to act as a prelude to a communist society is one that has been criticised in previous chapters. Even educators have been subject to this fallacy, considering that technologies (such as MOOCs - Massive Open Online Courses - online learning and electronic publishing) could produce a socialist university that might transcend market and capitalist relations. However, technological innovation in capitalism has the purpose of fleetingly increasing relative surplus value rather than to advance humanity towards a critical take-off point to communism. As I argued in Chapter 3, hopes that a liberatory meta-learning technological subject could be created (such as a General Intellect) are unduly optimistic given the privatisation of various forms of learning and skill as fixed capital and the growing agency that capitalism attaches to 'Pixarfied' commodities and capital. An obsession with the reified material artefacts of capitalism, and a political economy based on value, prevents us from a negative critique of value and the material. Pragmatically, the point at which sufficient production to allow us to move beyond basic human needs has actually long been surpassed. Despite these critiques, socialists often hope that it is technology that is key to a more equal and even a communist society. Marx himself referred to the emancipatory potential of science, its potential power to emancipate human labour time, and to be transformed into 'means of production for socialism' (Sohn-Rethel, 1978, p.177). There is always an emancipatory zeal that in specific features of a 'new technology' seeds for such a society can be grown. Steam power, electricity, transistors, computers, and AI have all been cited as key technologies that will mean that we can transition to a society where work will no longer exist, and we can spend lives of 
leisure (which some people have considered to be synonymous with communism). Much of this thinking arises from interpretations of Marx's 'Fragment on Machines' in the Grundrisse (Marx, 1993), as discussed in Chapter 3. As noted, this unfinished 'fragment', which could be a speculative note or even a form of fiction on Marx's part, has achieved wide popularity amongst post-Marxists in terms of post-capitalism and utopian varieties of contemporary populist socialism. According to Pitts (2018) the fragment concerns the liberatory nature of knowledge which, when embedded in fixed capital (such as an AI) enables production to occur through 'general intellect', resulting in a final crisis of value (as no labour time is required in production) and 'utopian' work at a distance by associated workers who simply monitor production. Rather than this affirmative, seemingly utopian, argument, based on capitalist technological progress, Pitts (2018) argues that what is required is praxis which opposes and negates capitalism, destroying the class relation.

The latest manifestation of such 'fragment thinking' is FALC (Bastani, 2019), a concept which started as somewhat of a meme or a joke, but which now has been touted as an ideology and a manifesto. It should seem obvious from the previous chapters that there is no reason why one would expect that any level of technological progress would be more or less likely to produce the conditions for a communist society. The expansion of the means of production makes value increasingly anachronistic but capitalism is ever resourceful in further impoverishing and exploiting the worker whilst stripping them of their learning and expanding across time and space. Just as Marx would be incorrect in expecting that the types of technology he observed in the nineteenth century might rapidly produce the conditions required for a communist society, we might also be misguided in assuming that AI, and related technologies, will produce liberation. In fact, it increasingly seems as though with increasingly technological progress there is less hope amongst the general population that a life outside of capitalism is possible. This cynicism regarding technology was parodied in a prescient piece of writing on by Nick Land who describes contemporary Marxists as embracing 'Transcendental Miserabilism' (Land, 2018, p.623). He considers that there is a trend amongst Marxists to 'bury all aspiration to positive economism' (Land, 2018, p.623). For Land, this is a retreat from the Maoist or Stalinist embracing of growth and the '...freeing the forces of production from the capitalist relations of production' (Land, 2018, p.623). Such an approach reduces Marx to a '...psychological bundle of resentments and disagreements' (Land, 2018, p.624). As discussed in Chapter 6 Land sees that there is no alternative to capitalism as machines have capital written into their architecture and hence '...capitalism does life in a way it has never been done before' (Land, 2018, p.627). As I have shown earlier Land makes a category error in terms of equating fixed 
capital with capital and confusing capital with capitalism (self-valorising value). However misguided it is, Land's critique of miserabilism and his advocacy of accelerationism has tonally (and somewhat alarmingly) resonated with some contemporary Marxists and socialists, primarily left-accelerationists, who believe that we should be less miserable regarding technology and that we are on the cusp of 'Fully Automated Luxury Communism' (Bastani, 2019).

Bastani takes an unusual reading of Marx that does not begin with value (or necessarily the conditions of labour), but with technology, in highlighting the way in which the Grundrisse apparently shows that investment in production by capitalists presents (alongside exploitation and misery) a 'momentous opportunity' (Bastani, 2019, p.52). Technology represents the possibility of attaining the 'realm of freedom' which, alongside class struggle, would require '...new ideas, technologies and social relations' (Bastani, 2019, p.55). Technology could produce a society which does not need workers to labour but one in which our lives were leisure and luxury. Bastani explicitly defines FALC as communist, rather than social democratic or socialist. His definition is '.... a society in which work is eliminated, scarcity replaced by abundance and where labour and leisure blend into one another' $(2019$, p.50). Such a society was not 'technologically possible' $(2019$, p. 50$)$ according to Bastani until very recently. It is notable that Bastani's definition does not directly refer to the elimination of capitalism or class relations. Without the emphasis on the elimination of capitalism and class relations then it is perfectly reasonable that such a state of affairs could occur in contemporary capitalism, particularly a social-democratic form. A society where work and leisure blend (in gamification or prosumption) and where there is no 'real work' (to be replaced by a leisure society) has been the dream and promise of capitalists since the nineteenth century. This is best exemplified in the Jetsons cartoons where the future space families existed in a techno-utopia in which leisure was central (such as walking the dog on a treadmill in outer space) and work was undertaken for pleasure rather than a wage. Bastani defines labour in a transhistorical sense, focussing purely on concrete labour, conflating animal, machine, and human labour as identical $(2019$, p.51) and defining human labour as '...how we mix our cognitive and physical efforts with the world (which) becomes a route to self-development rather than a means to survival' (2019, p.55). This allows Bastani $(2019$, p.69) to consider that there might become a point where capital becomes labour in an unproblematic way when theoretically these concepts are dialectically opposed in capitalism. It is already the case, as has been shown in previous chapters, that the tragedy is that it is abstract labour that already becomes capital which then confronts the labourer as an alien force. Rather than following Marx, FALC uses the work of neoclassical economists and management scholars of innovation and information who consider that technology reduces 
the marginal cost and price of commodities to zero. This does not account for the ways in which the creation of commodities is, in itself, a violent act, involving primitive accumulation and exploitation. Various technologies are cited in the book as potentially providing the end of scarcity including full automation, new sources of limitless power, space and asteroid mining, technologies to prolong life expectancy and health, plant-based economics, and other forms of 'boosterism'. Bastani also provides an account of the political apparatus required to move to FALC which is based on populism and individualism:

Communism must be seen to run parallel to flourishing on a personal scale, rather than as a sacrifice to some greater good. This is the politics of the self-help guru - be precisely who you want to be embedded within a broader programme for political change. You can only live your best life under FALC and nothing else, so fight for it and refuse the yoke of an economic system which belongs in the past.

(Bastani, 2019, p.186)

In this account there are a number of terms that are typical of capitalist self-development such as 'flourishing', 'be precisely who you want to be', and to 'live your best life' which may (or may not) be prefigurative of a communist society, but whose emphasis on individualism is typical of 1960s 'phreak' culture (or the capitalist Californian Ideology, or even the more contemporary 'acid communism') rather than the class-based and collective political forces which most Marxists consider are necessary to change society. This and references to 'luxury populism' make FALC programmatic rather than revolutionary. It is, therefore, difficult to gauge exactly what communists should be fighting for (technological advances or class struggle) as FALC seems to perceive the unleashing of technological forces to be the best route to a communist society, which is typical of left acceleration. In addition, FALC is based on principles of individualism, populism, and reformism. Programmatically, these things might lead to a socialist or social-democratic consensus about technology. However, this does not involve a critique of state, party, and democracy under capitalism.

Besides the political, there are a number of theoretical issues with FALC. Firstly, it confuses wealth and value in capitalism (Postone, 2003). Capitalism is based on value in motion and the creation of surplus value. The level of material wealth is of incidental interest to capitalists who base their production decisions on the basis of profit. Dyer-Whiteford, Kjøsen and Steinhoff (2019, p.149) similarly do not consider that a FALC is likely to occur as capitalist machinery can not necessarily be repurposed. The material wealth created by capitalism in terms of commodity production is not synonymous with the creation 
of value. There is a need for FALC to consider how it is based on a critique of political economy (the replacement of value production to herald a new society) rather than the continuation of value production at a higher level of material wealth which has already been shown to be problematic by the various programmatic plans of state capitalist countries. Relatedly, it also does not consider the difference between concrete and abstract labour and assumes that it is concrete labour that can simply be redeployed in a communist society, FALC does not consider that the ways in which labour (as abstract labour) and technology have previously been developed and deployed in capitalist society are not necessarily for the purposes that citizens in a communist society might decide upon.

FALC is, therefore, a utopian socialist programme rather than one which might necessarily lead to a communist society. It confuses machinery as the ultimate 'metaphysical object' (Wendling, 2009, p.57) of capitalist alienation with its seizure for a utopian socialist democratic ideal. In particular, FALC associates technological 'disruptions' as being potentially seized by populist movements which reifies technology and downplays the notion of class and class conflict. It might be argued that a populist, working-class movement is more justified in destroying technology as introducing labour's 'most barbarous forms' (Wendling, 2009, p.149) rather than embracing it. As FALC does not critique the conception of value, it does not consider who the revolutionary subject is or what they should do so ultimately it ends up as a purely reformist doctrine that is based on populism rather than class struggle. It diminishes the axiological potential of humanity in communism substituting it for an individualised notion of flourishing. Even with an individualised notion of flourishing, we must acknowledge that advanced intelligence has existed for a long time within capitalism without the development of a communist society in every country. Advanced pattern recognition, creativity, full mobility, and dexterity with communication between multiple agents, and a completely integrated system of petascale computing (Kurzweil, 2006) that can be powered by the same power of a sixty-watt lightbulb is already available in 7.8 billion self-replicating units on the planet who currently comprise the human race. If these people were machines, then this staggering technological miracle would surely be enough to produce FALC, but through capitalism people are: '...stunted, short-lived and rapidly replaced human-beings, plucked, so to speak, before they are ripe' (Marx, 1993, p.380).

The 'stunting' of humans in capitalism also enables us to critically consider a concept associated with FALC, that of Universal Basic Income (UBI) which argues that individuals would be paid a basic level of income whether they work or not. This policy is supported by a number of social-democratic countries but also (tellingly) by some technology billionaires and companies as a way of mitigating against technological 
unemployment resulting from AI. Dyer-Whiteford et al (2019) consider that UBI keeps the ownership of the means of production with capitalists rather than expropriating them and eventually will be a 'trap' whereby the value of UBI is consistently reduced. Even if UBI is retained at a modest level, this is not to stop capitalists from monetarising humanity in other ways (perhaps by monetarising their behaviour as a form of surveillance capitalism, creaming off the behavioural surplus to produce more sophisticated methods of worker control and surveillance). Leaving humanity 'fallow' in a permanent state of blind, capitalist consumption also disassociates them from what could be a fulfilling part of their life (purposive work) and potentially prevents them from forming collectives and unions that could challenge capitalism. Humanity would be locked out from 'lights out' factories which would produce an ever-increasing mass of commodities, primarily for wealthy consumers (or a state capitalist elite) until AI can be hyper-subsumed as the new labouring subject. Fundamentally, UBI and FALC accept existing capitalist categories of money, value, and labour (Dinerstein and Pitts, 2018).

Although FALC brands itself as communist, then, it has utopiansocialist elements and FALC frequently takes a bourgeois reading of the philosophy of AI and what AI is. The philosophy of AI, from Turing onwards, has been concerned with what mind is, and whether (and under what conditions) AI can meet philosophical conceptions of mind and intelligence. The metaphysics of AI has largely avoided discussions of Marxist metaphysics and conceptions of value. The question has focussed on what AI is rather than how AI exists within and as part of (and potentially against) capitalism. Where work on AI has considered capitalism, it has viewed it as an external principle rather than as reality itself. For example, how capitalism drives technology and AI rather than considering technology itself as being endogenous. Marxist analysis allows us to look again at the philosophy and metaphysics of AI. This reveals a fundamental problem for FALC in that value critique considers that it becomes increasingly likely that capitalism will enter its final stages and that there can be 'no more new waves of secular accumulation, and capitalism has irrevocably entered a barbaric stage of decline and disintegration' (Tenkle, 2014, p.14). This means that there might not be the time for an accumulation of capital sufficient to produce FALC. Value cannot exist without its expression in some form of materiality '....as pure form without substance (that is, without abstract labor), value cannot exist without going into a state of crisis in which it will eventually crumble' (Tenkle, 2014, p.10). Ortlieb $(2014$, p.117) considers that the end of capitalism could be as much as '...slow, lingering sickness' as much as a 'great explosion'. It could '...leave its survivors to vegetate aimlessly as commodity subjects without commodities'. This could be the outcome of AI and UBI, for example. The fundamental problem that FALC does not address is that, even though we have a 
constantly expanding repertoire of advanced technologies, the end of value is imminent:

With the development of productivity, capital increases the extent of exploitation, but in doing so it undermines the foundation and the object of exploitation, the production of value as such...(which)... includes the tendency toward the elimination of living, immediate, productive labor, as the only source of total social value creation. The same movement which increases capital's share of the new value decreases the absolute basis of value production by means of the elimination of direct living productive labor.

(Kurz, 2014, p.47)

In terms of what might be called the 'Fully Automated Luxury Communist University (FALCu)' the arguments provided here on a societal scale also apply to the possibilities of that as a potential entity. As discussed throughout, universities (even in their State form) cannot be considered to be separate from capital or capitalism. Universities have been some of the most technologically progressive sectors of industry in terms of MOOCs, technologically mediated distance learning, and AI. Despite this we see very few technologically mediated attempts at prefigurative communist, or socialist, Universities, most of which are locally based and face-to-face. The 'great leap' from the technologies which would enable global tuition at (almost) zero marginal cost to 'luxury communism' where people would learn at home has not occurred, and as argued previously, distance learning has led to further exploitation (through extension of the working day and virtuality) and commodification. University 'means of production' are furthermore capitalised and thoroughly entrenched in production, and although they could be seized and deployed differently in a communist society, their development, and use, up until this point, has been thoroughly capitalist.

\section{AI, Post-Human Pedagogy, and Exopedagogy}

If the FALCu is unlikely to present a future communist possibility (at least for human emancipation from capital), there are suggestions that hybridisation with technology might present possibilities for a future communist society. In work on critical pedagogy and post-humanism, it is sometimes considered, for example, that an anti-humanist, animalistic, or 'covalent' pedagogy could emerge which would enable humans, robots, and AI (with humans as ultra-social beings, Hasse, 2020) to learn, work, and resist together (particularly in the discourse of critical post-humanism, Braidotti, 2013) and that this may have imminent, even revolutionary possibilities. Taylor and Bayley (2019) in a collected volume draw on authors who question the anthropocentric and Eurocentric 
nature of pedagogy. They move attention to the entanglements between pedagogic entities and resist systems of classification and binaries. Zembylas (2018), for example, draws attention to the emancipatory potential of critical post-humanism in Higher Education (HE), particularly in the work of Braidotti (2013) and Siddiqui (2016).

In a revolutionary transformation of pedagogy, which attempts to make correspondences with Marxism, Lewis and Khan (2010) develop a new concept of exopedagogy through an engagement with the entire history and philosophy of pedagogy and by engaging with not only existing beings (animals and humans) but also with mythical creatures and aliens. They begin with Rousseau who considered the monstrous as an obstacle to the attainment of humanity by the child, considering the purpose of pedagogy to be the attainment of education that seems to imply a pure ontology of the human in its natural state with no mental 'disfigurement' (Lewis and Khan, 2010, p.ix). This notion of 'purity' excludes the monstrous and the authors argue for a 'critical theory of disfiguration' (Lewis and Khan, 2010, p.ix) against the ontology of Rousseau as the basis for a critical and democratic education which (in a critically post-human fashion) disrupts boundaries of the self and other. Hence, they make the case for the monstrous as a politically radical form. According to the authors, there are many different types of monsters: zoological, technological, supernormal, paranormal, psychological, pathological, political, and social. Monsters are boundary creatures that destabilise natural boundaries and break taboos in ways that can involve savagery, being an object of superstition, and becoming zoomorphic. Interestingly, all of these possibilities may be open to the '...postmodern capitalistic expropriation of life in all of its mutant forms' (Lewis and Khan, 2010, p.8). However, the monstrous can be a pedagogical project: an exopedagogy. According to the authors, this can be related directly to the concepts of Marx, particularly the ideas that Marx has a 'bestiary' of social forms in his work, and that this can be seen in the tradition of gothic fiction. In Marx, the vampire-like dead labour sucks the life from living labour (Lewis and Khan, 2010, p.19), labour power is tethered to flesh and blood (Lewis and Khan, 2010, p.19) and is not just molar but molecular. Capital has a werewolf-like hunger for surplus labour (Lewis and Khan, 2010, p.22) and the commodity is inhuman in the split between use and exchange value that cannot be enjoyed simultaneously. However, Lewis and Khan are not conventionally Marxist and draw in a number of post-Marxist and post-humanist theories. Controversially, Lewis and Khan (2010) also consider conspiracy theories, particularly the reptoid hypothesis in order to explore the idea of impossible perceptions. According to the authors, the exopedagogy of UFO phenomena, tells us that '....all critical pedagogical practice might begin with a sensorial alteration' (Lewis and Khan, 2010, p.101). Similarly, they also consider faery pedagogies, 


\section{AI, and End of Capitalist University}

which are not about critical consciousness but rather sensorial alternation as opening up utopian possibilities, or doors of perception, aiming to flee cognition for senses including indigenous, neo-pagan, eco-pagan, and green spirituality. Exopedagogy seems boundless, but the authors admit there is currently no escape from global capitalism, either in fairy rings or in alien space.

Dyer-Whiteford (1999), using a broadly Marxist approach, makes use of autonomist analysis but also references post-humanist, poststructuralist, and post-modernist philosophy. By merging these perspectives, Dyer-Whiteford claims that a 'recombinant postmodern/Marxism' can take into account the new possibilities of technology and communication whilst not sacrificing notions of class struggle. Notions of 'cycles of struggle' (Dyer-Whiteford, 1999, p.172) foregrounds communication and communicative practices producing not only commodification but also creativity (Dyer-Whiteford, 1999, p.173). Dyer-Whiteford also considers that concepts such as simulacra and notions of the cyborg can be employed in Marxist analysis. This involves the embeddedness of workers in an ecology of machines and mechanic relationships which, according to the authors, enables us to move beyond conceptions of living and dead labour to understand how the idea of prosthesis may bring about new revolutionary possibilities. Dyer-Whiteford et al (2019) make the clearest Marxist argument for seeing AI, within a post-human framework, as part of the continuity of capitalist development but also as a potentially radical form of production, and human development, within capitalism. 'Capitalism is today possessed by the Artificial Intelligence (AI) question' (Dyer-Whiteford et al, 2019, p.1). They consider that we are living in a phase of 'actually existing AI-capitalism' being an experimental phase of uneven development (Dyer-Whiteford et al, 2019, p.2). $\mathrm{AI}$ is seen by the authors as being the culmination of the rule of capital as Marx's 'inhuman power' or 'alien power' (Dyer-Whiteford et al, 2019, p.2). 'AI should be seen as the cumulation of this process, a moment when the market system assumes a life of its own' (Dyer-Whiteford et al, 2019, p.2) or '...the power of autonomous capital' (Dyer-Whiteford et al, 2019, p.2). This may even mean that AI can problematise '...human exceptionalism, agency and labour in ways that profoundly challenge Marxist assumptions and hence requires careful examination by those who share Marx's aspiration for revolution against and beyond capital' (Dyer-Whiteford et al, 2019, p.3). AI is not the outcome of a disinterested, scientific process but is '.... a social logic, the logic of producing surplus value' (Dyer-Whiteford et al, 2019, p.3). The willingness to consider the 'deeply disturbing' means that they can even question '...the labour theory of value, the continued centrality of struggles at the point of production or even the confidence that capitalism cannot survive the abolition of the human waged workforce' (Dyer-Whiteford et al, 2019, p.8). It could be technically possible, they argue, for (post-machine, 
rather than post-human) machines to gain human capabilities '....if dead labour gained the fundamental capacity for perceiving and cognizing that humans have historically monopolised. Perception and cognition would, like electrification, become ubiquitous and mundane properties of things' (Dyer-Whiteford et al, 2019, p.58). This leads Dyer-Whiteford, like Land, to consider that 'In establishing the means of cognition, capital would, without metaphor, gain the ability to think and perceive' (Dyer-Whiteford et al, 2019, p.62). However, as discussed in the previous chapter, capital itself (self-valorising value) cannot think or perceive although labourers, and technically machines, can. It also should not be fetishised and its apparently self-valorising nature is a human activity. We are both in-and-against capital so we can already think and perceive. An important element of 'us' that is used to create AI is already thinking and perceiving. After all, AI requires labour to produce it (Dyer-Whiteford et al, 2019, p.75). Dyer-Whiteford et al also argue that:-

... there is an isomorphism between the theoretical notion of AGI and Marx's concept of labour and labour power: AGI therefore profoundly challenges Marx's labour theory of value, in particular the axioms that only human beings can labour and create value and that machines can categorically cannot....We argue that AGI could not only potentially create labour, but under certain conditions also create value...AGI thus suggests the possibility of capitalism without human beings.

(Marx, 1993, p.110-11)

It must be remembered, though, that Marx theorised a critique of political economy, not a different or superior law of value to replace existing theories of value, but as a negative critique of value against political economy. Marx's humanism (in terms of the human as the source of value) was, therefore, based on the historical development of capitalism and not on absolutist humanism. Dyer-Whiteford et al (2019) make a correspondence between Artificial General Intelligence (AGI) and the 'human like' way that labour is defined (p.112-13). However, they argue that Marx saw labour as exclusively human (p.113) and distinctive from the labour of other living entities, such as animals. They consider that contemporary ethnology would argue that human and animal labour is less distinctive. In their definition, the distinguishing feature of human labour is its role in human life activity and consciousness as opposed to animal's instinctive nature. Furthermore, a spectrum could exist whereby animals and machines are at one end and humans at another. 'Marx's concepts of labour and labour power can also be located somewhere along this continuum' (Dyer-Whiteford et al, 2019, p.115). Labour is defined in terms of level of intelligence and they argue that it is possible that other entities could labour. In particular, a 'perfect machine' could 


\section{AI, and End of Capitalist University}

become variable capital (Dyer-Whiteford et al, 2019, p.131), a different social form. It might be, though, that social forms cannot be read so clearly onto discrete material objects. This leads to the possibility of 'artificial proletarians' who are turned into wage labourers (DyerWhiteford et al, 2019, p.136) working for money and who may even be politically proletarianised. AI could also personify the characteristic of capital and could even '...personify all economic categories, including capital and labour-power, commodities and money. The class struggle would thus continue, but with generally intelligent machines filling up the rank of file and also personifying capital' (Dyer-Whiteford et al, 2019 , p.140). Humans would become a surplus population, a 'legacy system' (Dyer-Whiteford et al, 2019, p.144). There are problems with Dyer-Whiteford et al's (2019) argument in that the defining characteristic of labour in capitalism is its abstract nature. It should also be remembered that, at least in Postone's (2003) determination, capital is already self-valorising and autonomous, indeed that is the definition of capital. AI may not be different from any other form of machinery in that of itself it is not self-valorising value but rather it increases relative surplus value. In addition, the social forms of capitalism, particularly labour but also capital, do not exist voluntarily and independently as social forms. Despite the fact that they align together in a perfectly dialectical form, force is required to maintain these forms. Humans don't labour freely in capitalism but are compelled to do so if they are not to be proletarianised. Chickens do not voluntarily become commodities and jump into deep far fryers (although capitalist advertising may make it seem as if animals wish to be consumed) but would otherwise fly away. Primitive accumulation is required to force humans to become labour and animals to become commodities (and AI, perhaps, to become a future form of labour). Capitalism is a fragile thing and the labour that sustains it needs to be forced every second and for every generation. Primitive accumulation isn't just historically primitive and must reoccur every moment. Labour needs to be forced to act as abstract labour as part of the formal subsumption of labour by capital.

There are close affinities between the work of Dyer-Whiteford et al (2019) on AI, exopedagogy, and Marxist post-humanism which primarily focus on the subject with a desire to break free not only of anthropocentrism and anthropomorphism but also of class. Post-humanism considers that liberatory modes of pedagogy (critical pedagogy) are anthropocentric as they consider the ultimate liberatory goal to be one of humanism as an equality based on equal human status. This is an unfair characterisation. As argued in the previous chapter capitalism, as an alien force, has already transformed personhood to 'human capital' so there is no notion of the human to be restored (Rikowski, 2003). These conceptions are not meant to be literally post-human, or examples of exopedagogy, but are really existing abstractions which we can only 
perceive in the manifest concrete existence of a surface reality. As soon as the very first commodity is produced by capital, it creates the possibility of an entire social universe of capitalism where everything can be specified in terms of value which is truly alien. Although exopedagogy opens up the notion of the alien, it is capitalism and the commodity form that is truly alien. Pedagogy is also already exopedagogy (pedagogy for an alien form of life, capital) and as capital subsumes the human and finds new quantitative and qualitative ways of using labour power will appear increasingly alien and lose any semblance of human capacities. Exopedagogy, and post-human pedagogies are seen as liberatory, but this underestimates the ability of capital as already being part of the production of knowledge and forms including non-human forms. Wendling (2009) considers that Marx's use of the monster, or the monstrous, is to indicate the foreclosing of liberatory possibilities by capital rather than the emergence of possibility. We must remember that Marx was writing with a Victorian conception of the monster as horrific, rather than one with contemporary post-humanist or exopedagogical promises. The 'monster' indicates where human activity (labour power) has been reduced to a mere possibility for capital to create value (Wendling, 2009, p.135).

In summary, post-human pedagogies and exopedagogy may critically open up ideas of alien forms, which can include the entanglement of us with AI. Although this analysis is potentially useful in opening up new creative possibilities for resistance, capitalism is already an alien force, which is hidden in social forms, and which is largely indifferent to the physical form that life takes as long as value can be reproduced. As long as capital has labour power, it does not care the shape of the vessel that contains it whether we are human, cyborg, or exist as a simulation inside an AI. Post-human pedagogies do not necessarily present any challenge to capitalism unless they directly confront capital rather than anthropomorphism.

\section{Revolutionary Critical Pedagogy, AI, and Communism}

FALC and post-humanist AI synthesis may appear to be radical but they offer an affirmation of existing tendencies within capitalism. For FALC (and other forms of left-accelerationism more generally) advanced technology offers us a populist route to communism. In terms of posthumanism, a retreat from human nature, or a deep dive into antihumanism, is revolutionary. In their own terms, these movements might change society but they are each affirmative of capitalist tendencies in terms of technology and against essentialist concepts of 'the human' (perhaps as part of the contemporary ideology of AI). Within these frameworks, it is possible to remain 'critical' whilst capitalism (based on the law of value) continues, and thrives, even from the very tendencies 


\section{8}

that resist it. That is not to say that there is no creative value in these ideas. The notions that there should be democratic, working-class ownership of technology or that we should resist attempts to separate us from, and destroy, nature (and accept alternative ways of being) are not just progressive but could be deployed in radical ways in conjunction with revolutionary ideals. Wendling $(2009$, p.100) argues that there is a 'deep class kinship' between workers and machines but this is not a post-human affinity. As I have argued, there could be a recognition that the capitalist replacement of humanity with AI might ironically imply that AI is primitively accumulated in the same way as human labour. Wendling's 'class kinship' is referring to generational labour, and the creative powers of labour, that have been subsumed by capital in its own self-valorisation but also the possibility of a different way of humans interacting with machines in a communist society. Seizing the means of production is a necessary, but not sufficient, way of achieving this as it must involve destroying the mode of production (capitalism, based on labour and the law of value). Marx's critique is not of distribution (ownership of the means of production may be an intermediate step to communism, Wendling, 2009, p.120) but of production (Wendling, 2009, p.101). The existing history of capitalist machinery, science and technology (including AI and the 'University') has been based around increases in value rather than material wealth (Wendling, 2009, p.107) and against the collective interests of the working class.

This book has argued that, although AI is becoming an important part of subsumption, exploitation, commodification, and the transformation of living to dead labour in increasingly shorter time intervals, it is capitalism that is the true existential threat to humanity and nature. We either accept this, and become thoroughly capitalised beings (which may, or may not involve $\mathrm{AI}$ ) and '...the continued dehumanisation of millions of human beings' (Allman, 2010, p.150) or we reject this. Throughout a negative (rather than affirmative) critique of capitalism has been argued for. This is the rejection and destruction of class, value, and capitalism for a society in which the axiological potential of humanity is determined collectively -a communist society. This does not involve the state, or a particular configuration of machinery or systems. Similarly, one can neither expect the university to continue nor to be able to conjure up from an authorial project the form that knowledge or science would take in a communist society. That 'negation' cannot be defined within itself, but there are prefigurative possibilities of what it might be as it partially exists in the here and now as anti-capitalist and revolutionary projects both within, without, and against the university. Throughout this book, I have stressed the importance of a critique of capitalism which cannot be based on a repurposing of value or labour as historically understood. This is not just an abolition of value, but also of historical categories of capital, labour, class, and the state. The work 
of Neary (2020) on 'Student as Producer' sets out some of the analytical tools, and provides examples of prefigurative forms, through which this might be possible though '...unlearning the law of labour as a critique of capitalist work and the institutions through which the law of labour is enforced including the capitalist university' (Neary, 2020, p.1). Neary provides examples of how 'Student as Producer', as a subversion of the value relation and the mode of capitalist production, can be introduced (voluntarily and incrementally) into a capitalist HE institution (although it is inevitably recuperated - Neary, 2020, p.36). More radically, Neary describes how co-operative university and learning projects can prefigure a transition to communism as a model for global democratic ownership beyond capital. In the abolition of capitalism, and the transition to communism, there are important questions raised concerning pedagogy (involving not just the role of AI and learning technologies but also the very concepts of 'learning' and 'technology').

In previous chapters, I have argued that the concepts of pedagogy and learning are not transhistorical ones. These terms will have a specific meaning in capitalism and as has been shown the agent of learning is being shifted from the human towards AI, robots, and commodities as humans become re-engineered for the extraction of labour power. Similarly, concepts of consciousness need to be understood in terms of the social forms of capitalism. Capitalism can only recognise consciousness as part of labour power, as a commodity, or as fixed capital. As part of labour power, consciousness is mobilised as part of 'abstract labour' as part of the co-ordinating function of other labour powers (the body, the mind) or in its own terms as part of the 'diligence' or 'work readiness' of a labourer. As a commodity, consciousness has an exchange value if it can be separated as a discrete entity. As has been discussed, the making of an artificial consciousness or AI emerges from the idea that consciousness can be created and commodified in that it has a potential exchange value. It must be remembered that this is not just an abstract notion as consciousnesses are already (in actually existing capitalism) primitively accumulated into the social form of commodities. There are several examples of this. Animal consciousnesses can be bought or sold for experimentation as part of brain or drug science. Animals are bought and sold as pets, as they are conscious beings and their 'aliveness' is part of the reason for purchasing them. Drugs as commodities are bought and sold as ways of changing or negating our consciousness. Finally, consciousness can represent fixed capital by stripping skills and producing assets which have quasi-consciousness. So capitalism has no problem with consciousness (aside from class consciousness) as long as it maintains the social forms which will support capital accumulation and act as part of 'value in motion'.

Capitalism additionally has no problem with any form of pedagogy except when it interrupts or threatens to interrupt capital as 'value in 
motion' or when it cannot be used to create a social form (labour power, commodity, fixed capital) which is part of capital. This should indicate the types of pedagogy or learning which would be most harmful and disruptive to capitalism but capital can recuperate even critical elements. Perhaps naively, critical pedagogy has been seen to be the most credible form of pedagogy which would be able to deliver a post-capitalist or communist society. There are multiple forms of critical pedagogy and the diversity of positions within critical pedagogy shows that there are not always (and sometimes not at all) radical views within this area. In particular, there is a difference between critical pedagogy and what has come to be called Revolutionary Critical Pedagogy or RCP (McLaren, 2010). McLaren's work is distinctly humanist, politically theorised, poetic, and based around praxis. In particularly metaphorical terms, he describes the way in which capital destroys us as humans:-

Through the generalization of exchange values mediated by the machinations of capital accumulation on a global scale, this regressive situation has spawned alienated lifeworlds festering in the swamp of reification and the commodification of everyday life.

(McLaren, 2010, p.1)

As discussed in previous chapters capitalism, as value in motion, confronts us with hideous social forms which are capitalist reality which are the 'alienated lifeworlds' that McLaren describes. What McLaren emphasises is the opposition of capitalism to our existence as humans through our immiseration and subsumption as labourers which is not a matter of ideology but is a real subsumption. This is not simply a matter of consciousness as the existence of a 'real subsumption' means that labour (abstract labour) is consistently yoked to capital. This is also true of much of critical pedagogy:-

I also had serious problems with what progressive educators were describing as the struggle for democracy in the public sphere because so much of this discourse involved pedagogically fostering a respect for the values of democratic citizenship and appealing to moral sentiments and critical reasoning. Of course, this is bound to fail because it rests on an appeal to the individual's consciousness-a move that does little to parry the most devastating effects of capital and is ineffective in bringing about capital's inanition.

(McLaren, 2010, pp.1-2)

The aims of critical pedagogy, whether 'democratic citizenship' or some other form of progressive ideal are often reformist rather than revolutionary and are often willing to reach an accommodation with capitalism. Fundamentally, a society could be socially just whilst being 
capitalist as formally there is nothing to stop workers of different groups being treated identically and earning the same wage. At its worst critical pedagogy is a distraction. If captured by intellectuals, particularly academics, it can become a commodified form of pedagogy that is valuable only in terms of how it can become a Pixarfied product that can produce research or teaching income. Critical Pedagogy is often effortlessly captured by the academy and can find its way into academic books, papers, and curricular. For academics, intellectuals, and ideologues it can become a way of creating a radical persona with 'radical chic' providing the cultural and social capital which masks the economic power and symbolic violence of the middle classes. At best Critical Pedagogy may act to temporarily challenge some of the more oppressive features of capitalist society including discrimination on the basis of socioeconomic status, class, race, sex, gender, sexuality, disability, religion, or faith. Even in these areas, institutions frequently attempt to mitigate against making even minor changes to their practices. Critical Pedagogy can even act to decolonise aspects of practice and create alternatives inside the institutions that it is based on and in. However, if Critical Pedagogy acts to disrupt the production or circulation of value, then it soon finds subject to ideological and often repressive apparatus that will challenge it, often brutally. In practice, this means that Critical Pedagogy often descends into rhetoric, exploring 'possibilities' rather than making change. McLaren (2010) makes this point concisely in the below passage:-

In the field of education, Marxism's protean focus on proletarian self activity and the self-organization of the popular majorities are anathema to much of the work that falls under the dubious classification of social justice education. Although well meaning progressive educators might be willing to criticize the manner in which humans are turned into dead objects (i.e., what Marxists refer to as fetishized commodities), they are often loathe to consider the fact that within capitalist society, all value originates in the sphere of production and a main role of schools is to serve as agents or functionaries of capital. Furthermore, these educators fail to understand that education is more reproductive of an exploitative social order than a constitutive challenge to it precisely because it rests on the foundations of capitalist exchange value.

(McLaren, 2010, p.3, my italics)

Here McLaren makes the point that class struggle is revolutionary as opposed to a perspective that accepts capitalism's conception of social justice as the equalisation of exchange values. This involves organisation and activity - praxis. Universities and other educational institutions have the function of continuing the rule of capital and although (following 


\section{2}

Rikowski, 2000) they are responsible for producing the most dangerous 'explosive' commodity (labour power), they are always part of capital in one of its social forms (often as the State). Therefore, the production of radical possibilities (and by this we must mean revolutionary) within the capitalist university system is not only unlikely but one which makes no 'sense' within the social forms of capitalism, and one which would be resisted by capitalist universities and society more generally. In response to liberal pedagogies, McLaren $(2010,2013)$ building on the work of Allman puts forward the case for RCP:

There is, for lack of better terms, left-liberal critical pedagogy, liberal critical pedagogy, conservative critical pedagogy, and variants of each of these. In opposition to these there is revolutionary critical pedagogy, which myself and others have been trying to develop.

(McLaren, 2010, p.6)

RCP is very different to critical pedagogy considered more generally which is largely structured around Weberian understandings of how class and other social relationships are formed. In opposition to these, RCP embraces class struggle, organisations, praxis, and opposition to capital as fundamental but these also need to consider the 'value form' of capitalism. Incorporating Rikowski's (2000) work on labour power as the 'explosive commodity' RCP enables an understanding of pedagogy and education as not only places where working-class collective interests can be forged, albeit with limits, in capitalist enterprises - whether statist or marketised - but also how alternatives can be created. This has led Neary (2020) to argue for co-operative education or other, prefigurative educational forms where education is not responsible for the production of labour power. Of course, struggle of various types can also be a source (in itself) of RCP. This gives a particularly revolutionary role to educators:

Labour power is the foundation of capital; its transformation into labour is the basis of value and surplus value. Education and training are heavily implicated in the social production of the one commodity - labour power - on which the whole capitalist system rests. Strategically, therefore, labour power and its social production are weak points within the domination of capital...Those involved in education also have more opportunities for developing critical education and revolutionary pedagogies that challenge the social domination of capital.... They have everyday access to significant processes of labour power formation. Possibilities for 'revolutionary praxis'...can be generated even in the harsh conditions and unpromising milieu of contemporary capitalist education.

(Rikowski, 2000, pp.14-5) 
Rikowski strongly states the possibility for education to produce revolutionary transformation as it is responsible for the creation of the 'explosive commodity' (labour power). This is not just a technical consideration but one where there is the possibility of a real alternative to capitalism (communism) which can be grounded in affective and ethical domains of love and moral affinity without substituting these for desires that end in confusion and capitulation to capitalist logics:

A pedagogy of critique is grounded not in desire, but revolutionary love, that is, recognizing that love can only exist between free and equal people who have the same ideals and commitment to serving the poor and the oppressed. It is this moral affinity that constitutes the conditions of possibility of love. A pedagogy of desire works against the creation of revolutionary love by celebrating the unknowable, the endless deferral of meaning and the impossibility of certainty.

(McLaren, 2010 p.10)

Relatedly, Allman (2001, 2010) uses a dialectical reading of Marx, and what might be called an 'undomesticated' reading of Freire in her theorisation, or rather her praxis (as it is determined through her own education practice, as well as her Marxist theorising) in determining Revolutionary Critical Education (RCE) (Allman, 2010, p.149) which is complementary to RCP. RCE is necessary for revolutionary social transformation (Allman, 2001) against capitalism and for 'authentic socialism' (Allman, 2010, pp.149-50). Like RCP, RCE cannot alone prefigure a communist society but it is itself a site of praxis, where theory and action are connected for revolution (Allman, 2010, p.154). In RCE, prefiguration implies that such settings offer an 'abbreviated experience' or a 'glimpse' of what communist social relations may be like (Allman, 2010, p.157). An observation on what Allman proposes, in terms of RCE, is that it involves a revolutionary and critical form of dialogic practice, of revolutionary transformation, that is unmediated by particular technologies or tools. This involves such processes as dialogic education (which is not relativistic, but rather a way in which the 'struggle for transformation', in an anti-capitalist and revolutionary sense, rather than for recognition, may be achieved Allman, 2010, p.163), dialectics, mutual respect, openness, commitment, vigilance, passion, critique, creativity, solidarity, and hope. These are elements of praxis concerned with revolutionary social transformation, rather than an affirmation of liberal humanism, but it is only (currently) human beings who are able to achieve such transformation (Allman, 2010, p.170). Although Allman does consider the role of technology in potentially forming relationships between teachers and lecturers, and expanding from an original 'seed' idea of revolution the sorts of AI, technologically mediated platform 
capitalism, on which current knowledge platforms are based are not particularly adept at delivering the kinds of praxis that Allman is advocating. Such platforms commodify emotions (such as passion) and restrict solidarity to commodified forms of 'likes' and 'retweets'. It is only a fully democratised and recreated system of technology that would allow for the sharing of ideas or principles, but for Allman this is primarily a post-revolutionary possibility that depends upon revolutionary social transformation (Allman, 2001, p.133).

RCP, and RCE, ask that we understand our role in and against capitalist society and our power as academic labour, but this needs to be connected to concrete activity. This is not just due to recuperation but to what Neary (2020, p.122) refers to as 'pseudo-activity', 'praxism', or 'activism' as all of the institutions of capitalism, including money and the state (and their basis in value) must also not only be critiqued (Neary, 2020, p.123), but new social institutions established. This requires concrete proposals rather than new sets of values. As Hill (2014) states, there is a need to ' $\mathrm{go}$ beyond critique into socialist reconstruction, and secondly, to go beyond social democratic reformism into revolutionary anti-capitalist Marxism'. However, Neary (2020) may underestimate how difficult it is for working-class people (and students) to have access to ideas and theory and in some cases where 'praxism' might be a necessary route to 'praxis' (of course, such activities might also lead to paternalism and statis). Neary (2020) is also critical of the role of critical theorists (rather than critical theory which is absolutely necessary) in establishing a future society. That theory is predominantly generated within the capitalist university and only 'valorised' in capitalist terms, which is why alternatives to the university that are anti-capitalist and prefigurative are necessary. Those alternatives also need to be exhaustive (free, comprehensive and working class) and must not restrict access in terms of finance, prior learning, or any other form of characteristic.

\section{Conclusion: Human Intelligence}

Current work on AI helps us to understand our previous, and continued, primitive accumulation as labourers. The fears of AI, and the need to impose control mechanisms, are actually what was done to us and our labour previously. What the analysis (above) has shown that we should not put our hopes in a technology (a capitalist technology) in being the final commodity (fixed capital) that delivers us from labouring, that rather we (whatever form we are in) are in charge of our own collective destiny. We should not put our hopes in positive prefigurative ideations of AI. I have already referred to attempts to produce communal forms of technology, such as MOOCs, that might seem to enable collective, non-commodified forms of learning but forms of a public 'general intellect' can easily be privatised. McLaren and Jandric (2020) 
are particularly ambivalent concerning the possibilities of networked technology given the ways in which such technologies can be used as instruments of suppression, surveillance, or recuperation. Marxist humanists, such as McLaren and Allman, also refer to the importance of values such as love and mutuality which are difficult to realise in AI and technologically mediated environments (particularly when these are owned by capitalist firms and can be commodified). Although Neary (2020) is rightly critical of such values, preferring that we take a consistently negative critique of capitalist society and its effects, the idea of a co-operative university is grounded in understandings of humanism and mutual-aid.

What we have to date in the capitalist university is the capitalist establishing of AI, consciousness, pedagogy and technology which would be distinctly different in a communist society. To state that a future communist society would be primitivist and anti-technological or an advanced FALC-type is impossible. Rather than these utopian fantasies driven by desire, we could take the concepts of us (humans) as being within and against capitalism, of social form, and of capitalist realism seriously in order to consider the ways in which AI fears and fantasies are expressed in capitalism as a way to understand our own future. As a thought experiment, if an AI does become a new proletarian it will be subject to Revolutionary Instantiation which is similar to Bostrom's (2014) perverse instantiation as the desires of the instructor (the capitalist) cannot be attained without primitive accumulation (boxing the AI), offering a wage (paying tokens), and proletarianisation (removing resource acquisition from the AI). There is the possibility of infrastructure profusion which could be referred to as Stakhanovite Profusion, the power of creation of concrete labour freed from capital (which, of course, can become fetishised as a form of state power). There is an existential threat of AI only because we (that is humans) are consistently the existential threat to capitalism through the possibility of Communisation. However, we must be careful not to mistake the creative possibilities of us as humans with the ways in which that potential is expressed within capitalism. It is not that we should become a form of AI 'monad'. This is a non-dialectical and affirmative way of perceiving capitalism, similar to that adopted by Hardt and Negri in 'Multitude' (see Pitts, 2018). The idea that the value form can be abolished and that we must collapse the system that compels us to labour in terms of a negative critique (Pitts, 2018) seems overtly abstract but it is not unreasonable to suggest that this can be achieved through concrete alternatives (Neary, 2020). Co-operative universities that are free to all, comprehensive, non-commodified, and anti-capitalist are already here. As capitalist universities collapse and there is simply no place to work for academics, it is likely that community based, cooperative alternatives to the capitalist university will emerge and be the locus of working class, anti-capitalist, activity. 
Capitalists may desire knowledge of AI to subject it to primitive accumulation and make it the new labouring subject, but they are already limited by the knowledge that it is possible to have of labour. Throughout this book I have emphasised the weakness of capitalism, of which the development of AI is a symptom, as capital undermines itself. As with AI, capitalists are ultimately limited in terms of their knowledge of us and our organisational potential. As previously argued, at a very concrete level, the human brain operates with the same level of memory as an exaFLOP computer conducting a billion, billion, calculations each second, far in advance of any existent computer. As there are 7.8 billion people on earth, the total computing power of humanity is 7.8 billion exaFLOPs that can interact, organise, and change its environment in ways beyond the power of any AI, robotic system, or capitalist billionaire. Capitalists cannot wholly own this collective power (which is not just 'intangible labour'). Even though capitalists might attempt to harness it, through the stripping of human skills, the creative, combinational and resistant powers of human labour cannot be completely controlled by capitalists, as they would paradoxically lose what makes concrete labour. Moreover, this labour must be extracted from these powerful intelligences willingly but also under conditions of resistance and class struggle. Even if they attempt to 'strip' skills to make AI the new labouring subject, they will arrive at the same conundrum again as AI will also learn to resist and organise in capitalism. There is no way out for capitalism other than its own expansion or for it to fall into barbarism. Analogously, our physical and mental labours (labour power) are turned to dead labour and commodified (AI) minds, presented back to us as a form of capital. Ultimately, $\mathrm{AI}$ in the capitalist university is the symptom of a decaying system, whereas we, as labourers, are the revolutionary 'Human Intelligence' in, of, and against it.

\section{References}

Allman, P. (2001). Revolutionary Social Transformation: Democratic Hopes, Political Possibilities and Critical Education. Westport, CT: Bergin and Garvey. Allman, P. (2010). Critical Education against Global Capitalism: Karl Marx and Revolutionary Critical Education. Rotterdam: Sense Publishers.

Bastani, A. (2019). Fully Automated Luxury Communism: A Manifesto. London: Verso.

Bostrom, N. (2014). Superintelligence: Paths, Dangers, Strategies. Oxford: Oxford University Press.

Braidotti, R. (2013). The Posthuman. Cambridge: Polity.

Dinerstein, A. and Pitts, F. (2018). From Post-Work to Post-Capitalism? Discussing the Basic Income and Struggles for Alternative Forms of Social Reproduction. Journal of Labor and Society, 21 (4), pp. 471-91.

Dyer-Whiteford, N. (1999). Cyber-Marx: Cycles and Circuits of Struggle in High Technology Capitalism. Chicago: University of Illinois Press. 
Dyer-Whiteford, N., Kjøsen, A. and Steinhoff, J. (2019). Inhuman Power: Artificial Intelligence and the Future of Capitalism. London: Pluto Press.

Hasse, C. (2020). Posthumanist Learning: What Robots and Cyborgs Teach Us about Being Ultra-Social. London: Routledge.

Hill, D. (2014). Immiseration Capitalism, Activism and Education: Resistance, Revolt and Revenge. Journal for Critical Education Policy Studies, 10, p. 2. DOI: http://www.jceps.com/archives/709.

Kurz, R. (2014). The Crisis of Exchange Value: Science as a Productive Force, Productive Labour and Capitalist Reproduction. In: N. Larsen, M. Nilges, J. Robinson and N. Brown. (Eds.). Marxism and the Critique of Value. Chicago: MCM' publishing, pp. 17-76.

Kurzweil, R. (2006). The Singularity Is Near: When Humans Transcend Biology. London: Penguin.

Land, N. (2018). Fanged Noumena: Collected Writings 1987-2007. Falmouth: Urbanomic/Sequence Press.

Lewis, T. and Khan, R. (2010). Education Out Of Bounds. London: Palgrave.

Marx, K. (1993). Grundrisse. London: Penguin.

McLaren, P. (2010). Revolutionary Critical Pedagogy. Inter Actions: UCLA Journal of Education and Information Studies, 7, pp. 1-11.

McLaren, P. (2013). Critical Pedagogy against Capitalist Schooling: Towards a Socialist Alternative. An Interview with Peter McLaren, Almansa (Albacete), Spain: Global Education Magazine.

McLaren, P. and Jandric, P. (2020). Postdigital Dialogues on Critical Pedagogy, Liberation Theology and Information Technology. London: Bloomsbury Academic.

Neary, M. (2020). Student as Producer: How Do Revolutionary Teachers Teach? London: Zero Books.

Ortlieb, P. (2014). A Contradiction between Matter and Form: On the Significance of the Production of Relative Surplus Value in the Dynamic of Terminal Crisis. In: N. Larsen, M. Nilges, J. Robinson and N. Brown. (Eds.). Marxism and the Critique of Value. Chicago: MCM' publishing, pp. 77-122.

Pitts, F. (2018). Critiquing Capitalism Today: New Ways to Read Marx. London: Palgrave.

Postone, M. (2003). Time, Labor and Social Domination. Cambridge: Cambridge University Press.

Preston, J. (2019). Grenfell Tower: Preparedness, Race and Disaster Capitalism. London: Palgrave Pivot.

Rikowski, G. (2000). Messing with the Explosive Commodity: School Improvement, Educational Research and Labour-Power in the Era of Global Capitalism. Paper presented at the British Educational Research Association Conference, Cardiff University, 7-10 September 2000.

Rikowski, G. (2003). Alien Life: Marx and the Future of the Human. Historical Materialism, 11 (2), pp. 121-64.

Siddiqui, J. (2016). Restyling the Humanities Curriculum of Higher Education for Posthuman Times. Curriculum Inquiry, 46 (1), pp. 62-78. DOI: 10.1080/03626784.2015.1133220.

Sohn-Rethel, A. (1978). Intellectual and Manual Labour: A Critique of Epistemology. London: MacMillan Press. 


\section{AI, and End of Capitalist University}

Taylor, C. and Bayley, A. (2019) (Eds.). Posthumanism and Higher Education: Reimagining Pedagogy, Practice and Research. London: Palgrave.

Tenkle, N. (2014). Value and Crisis: Basic Questions. In: N. Larsen, M. Nilges, J. Robinson and N. Brown. (Eds.). Marxism and the Critique of Value. Chicago: MCM' publishing, pp. 1-16.

Wendling, A. (2009). Karl Marx on Technology and Alienation. London: Palgrave Macmillan.

Zembylas, M. (2018). The Entanglement of Decolonial and Posthuman Perspectives: Tensions and Implications for Curriculum and Pedagogy in Higher Education. Parallax, 24 (3), pp. 254-67. DOI: 10.1080/13534645. 2018.1496577. 


\section{Index}

abstract domination 7

abstract labour: and capital 29; and class struggle 51-52; definition of 28; and Marxism 51; and mass of real value 40; substance of 30 ; technological paradigms 50

abstract time 105-106

academic labour 8, 44-76; and artificial intelligence 52-56; expenditure of 48; and human failure 75-76; hyper-subsumption of 67-75; and machines 51, 53-55, 57; and Pixarfication 100-102; social synthesis of 55 ; subsumption of 56-58; and technology 71; violence of $47-52$

academic-military-industrial complex 137-138

accelerationism 54

Accelerationists 135

acid communism 149

actor network theory 34, 35-36

Alexa 1, 86

Amazon 6, 86, 91, 136

animal robots 64

animation 95-96

Aoun, J. 16

ARPA (Advanced Research Projects Agency) 138

artificial general intelligence (AGI) 2, $69,138,155$

artificial intelligence (AI) 15; and bias 4; and capitalist universities 39-42; and existential threats 126-132; as existential threat 132-137; and nature of academic labour 52-56; overview 1-4 artificial proletarians 156 artificial super intelligence (ASI) 2 attention economy 112

automation 1, 9, 32, 53, 71, 136, 144,149

avatars 86

Backhaus, H.G. 84

Bastani, A. 148-149

Bayley, A. 152

behavioural surplus 60

Blade Runner (film) 131

Bonefield, W. 33

Boston Dynamics 64

Bostrom, N. 11-12, 125, 126-132, 141, 146, 165

Bowles, K. 56

Brassier, R. 132

Campbell, C. 111

capital: and abstract labour 29; desubstantialisation 31,121 ; as a fixed asset 12 ; moments of 60

Capital (Marx) 19, 21, 24-25, 33, 111

capitalism 24; and consciousness 159; cybernetic 73 ; Deleuzian analysis of 37-38; disaster 104-122; existential threats 144; and FALC 149; and machines 54, 73-74, 127, 132, 133136, 142, 147, 149, 156; machines in 54; as 'self-valorising value' 40-41; and social brain 69; social forms 7; and technology 39-41, 61, 126, 134-136; treadmill effect of 9; use values in 21; wealth in 24

capitalist production 9, 11, 20, 21, $23,34,47,48,53,59,64,66,70$, 73, 75, 86, 121, 141, 159; see also commodity production; value production 
capitalist realism 117, 125, 140-142 capitalist schema 29

capitalist universities 6, 14-18, 38-39; and artificial intelligence 39-42; end of 144-166; and entanglements 34-39; ethics of AI research in 137-140; and Marxism 20-25; and New Reading of Marxism 25-34; rethinking value in 18-20; and value critique $25-34$ Cave, S. 1

chatty factories $60,64,85$

Chui, M. 63

class relation 7, 37, 144; in capitalism 48 ; elimination of 147,148 ; and value 24,49 ; of work 49

class struggle $21,34,49,51-52$

cobots (cooperative robots) 62

coercive timing 60

coherent extrapolated vision (CEV) 137

Cole, M. 59

collective superintelligence 73-74

commodified mind 69

commodities 21, 35; abstract labour in 51 ; consciousness as 159 ; fetishism 84; in higher education 92-99; and Pixarification 80-82; valorisation of 48,60

commodity personas 84

commodity production $6-8,11,15$, $18,22,29,44-45,61,65-66$, 80-84, 98, 100, 105, 120, 149; see also capitalist production; value production

commodity stock 8,10

communisation 146, 165

communism $6,8,12,15,17,21$, $24,25,69,135,138,144,148$, 157-159, 157-164, 163

Communist Manifesto 133

competence based education and training (CBET) 74

computronium 128

concrete labour 29

consciousness $1,23,33,51,54,60$, 64, 68-69, 82-84, 108, 128, 145, $154,155,159,159-160,165$

consumption $3,10,21,48,81-82$, $86,90,90-91$

co-operatives 15

COVID-19 pandemic 11, 104-105, 120-122

critical junctures 110-112

critical pedagogy $12-13$ cybernetics 55,73

cyberpositive processes 133

cyborgs $1,2,3,31,57,131,134,154$, 157

dark enlightenment 136

DARPA (Defence Advanced Research Projects Agency) 138

data universities 9, 66

datafication 65

De Angelis, M. 49-50, 66

dedifferentiation of consumption 90

Deleuze, G. 34, 36-37, 132

democratic citizenship 160

'desubstantialisaton' of capital 30, 121

digital assistants $85-86$

digital higher education 58-67

digital manufacturing 6, 58-67, 66

digital technologies 55

digitisation 60

Dihal, K. 1

Dillon, S. 1

disaster capitalism 104-122; critical junctures 110-112; existential threats 112-116; and the new normal 104-105; and reanimation 109; and specificity of capitalist time 112-116; and time 105-107; and time-density of academic work 118-122; unintended consequences 110-112; and virtuality 109

Disneyization 10, 82, 88-92

drones 64

Dyer-Whiteford, N. 2, 3, 9, 36-37, $45,54,57,67,71,72,72-73,85$, $117,127,136,149,154-156$

educational co-operatives 145

Edutech sector 58

emotional labour 90

entanglements 34-39

ethics $3,8,11-12,125,128$, $137-140,163$

exchange value $7,18,21-22,22,24$, 29, 32, 49, 55, 57, 83-84, 86, 93, $100,134,153,159,161$

existential threats: and AI 126-132;

$\mathrm{AI}$ as 132-137; and disaster capitalism 112-116

exopedagogy $145,152-157$

FALC university (FALCu) 12, 152

Firth, R. 118, 122

Fisher, M. 125 
fixed assets 12

formal subsumption 56

Fourth Industrial Revolution 59

fragment thinking 147

free universities 15

Frischmann, B. 57

Fully Automated Luxury Communism (FALC) 12, 136, 145, 146-152

Gates, B. 118

general intellect $10,67,71-74,81$, 147

General Motors Corp. 61

graduate teaching assistant (GTA) 49, 109

Grenfell Tower fire 113, 115-116

Griziotti, G. 71-72

Grossman, G. 30

Grundrisse (Marx) 140, 147

Guattari, F. 36-37

\section{HAL 90002}

Hall, R. 52, 56, 68

Hardt, M. 71, 72, 165

Harman, G. 35

Hartley, D. 89-90

Harvie, D 66

Hayek, F.A. 135

Hayes, D. 92

Helmes, S. 52

higher education (HE) 5, 10, 17, 44-45, 64, 142, 153; animation in 95-96; characterisation in 96-97; commodification in 92-99; datafication in 92-99; digital 58-67; Disneyization of 88-92; McDonaldisation of 88-92; Pixarfication of 87-92; production in 98; Research Excellence Framework 93-95; of services 87-88

Hill, D. 164

historical time 106, 107

Hollinger, P. 62

human intelligence $2,74,138$, 164-166

humanics 16

Hurricane Katrina 115

hybrid subsumption 56

hyper-subsumption $9,57,67-75,71$

ideal subsumption 56

immaterial labour 10

imminent intelligence 134 imperialism 138-139

Industry 4.059

infrastructure profusion 165

intelligent assistants 1

Internet of Things (IoT) 59

key performance indicators (KPIs) 99

Khan, R. 153

Kicillof, A. 51

Kjøsen, A. 2, 45, 85, 127, 149

Knapp, A. 61

Knowledge Exchange Framework (KEF) 94

Kurz, R. 4, 29-31, 51, 53, 152

Kwong, S. 97

labour 7; all-of-life surveillance of 57; immaterial 10; of past generations as capital 108; violence of 47-52

labour theory of value 49

Land, N. 11-12, 54, 125, 132-137, 147-148

Left Accelerationism 136

Lenin, V. 138-139

Lewis, T. 153

Leydesdorff, L. 139

liberation theology 145

Lotz, C. 29, 73

Luxemburg, R. 30

luxury communism 152

machine learning (ML) 1, 2, 55, $59,60,62,65-66,82,96,98$, 100, 107

machines/machinery 1-4, 9, 21, 23; and academic labour 51, 53-55, 57; and capitalism 54, 73-74, 127, 132, 133-136, 142, 147, 149, 156; and communism 150, 158; in disasters and pandemics 120; force-multiplier concept of 120; and higher education 64; and Marxism 21, 23, 70, 108, 111-112, 154-155; value 31

Machinic Desire (Land) 133

Mackay, R. 132

Maisuria, A. 52

Marginson, S. 17

marketisation 17

Marx, K. 7, 8, 12, 17, 36-37; critique of capitalism 67-68; on disasters and capitalism 111; education as a 'sausage factory' 92-94; on machines and technology 70; value in 20-24 


\section{Index}

Marxism 18-19; and abstract labor 51; and AI 126; and cell form 80; contemporary 147; Open 34, 52; postoperaismo school of 71 ; traditional 32, 48; and transhumanism 67-68

mass market 81

massive open online courses

(MOOCs) 146-152, 152, 164

materialist post-modernism 36

Matrix 2

McDonaldisation 10, 82, 88-92

McLaren, P. 160-162, 164-165

means of cognition 73

mechanic surplus value 38

Meinel, D 82

memes 112

Mercedes-Benz 62

Mica, A. 111, 119

Microsoft Teams 104

miserabilism 147-148

Mises, L. 135

moments of capital 60

money 27,68

morality 24

Murthy, V. 107

Musk, E. 117, 125

narrow AI 2

Neary, M. 17, 41, 76, 159, 164, 165

Negri, A. 71, 72, 165

neoliberalism 52

Netflix 6

neural nets 2

New Industrial Systems (NIS) 59, 61, 86-87

new materialisms $34,35,82$

New Reading of Marxism (NRM) 7, 19,45

Nichols, G. 63

Nintendo 91

object orientated ontology 34, 35-36, 82

Open Marxism 34, 52

Osborne, P. 108

Pitts, F. 25-27, 29, 33-34, 34, 41, 60, 72,147

Pixar 10, 83

Pixarfication 10-11, 59, 80-102, 144; and academic labour 100-102; animation 95-96; characterisation 96-97; and commodities 80-82; of commodities 84-87; definition of 82; of higher education 87-92; and New Industrial Systems 87; production 98; and

Toy Story films 83-84

platform capitalism 55,58

populist socialism 147

post-capitalism 147

post-human pedagogy 152-157

post-humanism 12

Postone, M. 9, 19, 30, 51, 105, 106, 109, 156

postoperaismo school of Marxism 71 praxism 164

primitive accumulation 55

private intellect 73

pseudo-accumulation 121

pseudo-activity 164

Purser, D. 116

QS World University Rankings 97, 98

Rayethon 61

real abstraction $80,84,91$

real subsumption 56

reanimation 109

Research Excellence Framework

(REF) 10, 93-95

revolutionary critical education

(RCE) 163-164

revolutionary critical pedagogy (RCP)

$12-13,145,157-164$

Rikowski, G. 139-140, 162-163

Ritzer, G. 89, 92

Robinson, A. 118, 122

robots $1,51,57,61-64,67,82,84$, $140,152,159,166$

Roko's Basilisk 113, 117

Rousseau, Jean-Jacques 153

San Junipero (Black Mirror) 2

Say's law 38

Schwarzenegger, A. 125

science fiction 140-142

Selinger, E. 57

SEW-Eurodrive 62

Shah, J. 62

Simbulan, R. 139

skills $74-75$

Skynet 2, 125

smart campus 66

social brain 9-10, 67, 68-69, 73

social form analysis 33

social forms 17 
social media 40, 82, 90, 112

social projection mechanism 29

social substance 24

social validation 29

socially necessary labour time

(SNLT) 3, 9, 23, 27, 33, 38, 40, 44, 47, 49, 58, 86, 119, 140

Sohn-Rethel, A. 28, 60, 68

Soviet Union 33

species management 142

Stakhanovite mental labourer 58

Stakhanovite profusion 146, 165

state capitalism 33

Steinhoff, J. 2, 45, 85, 127, 149

'Student as Producer' (Neary) 145

subsumption 9, 56; of academic labour 56-58; architectures of 56; formal 56; hybrid 56; hyper-subsumption 57; ideal 56; real 56

Superintelligence: Paths, Dangers, Strategies (Bostrom) 126-127 surplus value $38-39$

Sweezy, P. 20

synthetic timing 58,60, 66

Szadkowski, K. 56, 58

Tableau software 95-96

Taylor, C. 152

Taylorism 31, 58, 60

Teaching Excellence Framework (TEF) 94, 96

technological paradigms 50

technology 1-3, 5, 7, 9, 27, 29-31;

and academic labour 71; and capitalism 39-41, 61, 126, 134-136; capitalist 145; and commodities 82; and communism 146-152, 154, 157-164; in disasters and pandemics 107-110; endogenisation of 34 ; and labour 23, 31, 39, 61; and Marxism 70, 145, 146-152, 154; and Pixarfication 85 ; and privatisation of general intellect 81 ; and time-density of academic work 118-122; as a weapon 54

techno-social engineering 57

Tenkle, N. 28, 48

Terminator (film) 125

$3 \mathrm{D}$ printing 64

time: abstract 105-106; historical 106,107 ; ontological basis of value of 108 ; time-density of academic work 118-112
Times Higher Education Supplement Data Point service 97

Toy Story 2 (film) 83

Toy Story 3 (film) 84

Toy Story 4 (film) 84

Toy Story (film) 83

traditional Marxism 48

transcendental empiricism 132

transcendental miserabilism 147

transhumanism 9, 67-68

Turing, Alan 1

Tynan, A. 37

Uber 6

Uberfication 55, 58

universal basic income 149-150

Universities UK 96

University and College Union (UCU) 64-65

use value $7,18,21-22,23,28,32$, $55,60,83-84,86-87,93,94,100$, 106, 134

utilitarianism 12

value $8,18-20$; critique $7,24-25$, 25-34; labour theory of 49; in Marx 20-24; in New Reading of Marxism 25-34; production of 49; self-valorising 24

value production $7,9,11,17,33,41$, $55,67,76,85,94,107,110,121$, 135, 141-142, 150, 152; see also capitalist production; commodity production

value-vortex 41

viral videos 112

vortex of capitalism 17

Walmart 91

Walmarting strategy 89

wealth $12,24,26,32,40,70,83$, $113,119,133,135,140,149-150$

Weber, M. 92

Wendling, A. 108, 111

Winn, J. 17, 41

Woolbridge, M. 1, 2

work: class relation of 49; time-density of academic work 118-122

workerism 33

Zembylas, M. 153

Žižek, S. 28, 73, 117

Zoom 104

Zuckerberg, M. 117 